\title{
COMPARTILHAMENTO DE OBJETOS COMPOSTOS ENTRE BASES DE DADOS ORIENTADAS A OBJETOS
}

\author{
ok. \\ João Eduardo Ferreira \\ Tese apresentada ao Instituto de Física \\ de São Carlos, da Universidade de São \\ Paulo, para obtenção do título de Doutor \\ em Ciências: Física Aplicada.
}

Orientador: Prof. Dr. Caetano Traina Junior.

São Carlos

1996 


\section{Ferreira, João Eduardo}

Compartilhamento de objetos compostos entre bases de dados orientados a objetos/João Eduardo Ferreira São Carlos, 1996.

$127 \mathrm{p}$.

Tese(Doutorado) instituto de Física de São Carlos,1996.

1.Bases de dados distribuidas orientas a objetos. 2. Compartilhamento de dados. I.Título. 


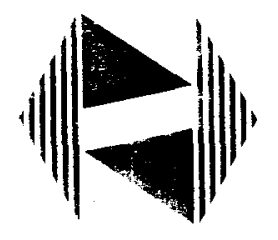

Шتك UNIVERSIDADE

Instituto de Física de São Carlos

Av. Dr. Carlos Botelho, 1465

CEP 13560-250 - São Carlos - SP

Brasil

Fone (016) 272-6222

Fax (016) 272-2218

MEMBROS DA COMISSÃO JULGADORA DA TESE DE DOUTORADO DE JOÃO EDUARDO FERREIRA APRESENTADA AO INSTITUTO DE FÍSICA DE SÃO CARLOS, UNIVERSIDADE DE SÃO PAULO, EM 05/07/1996.

COMISSÃO JULGADORA:

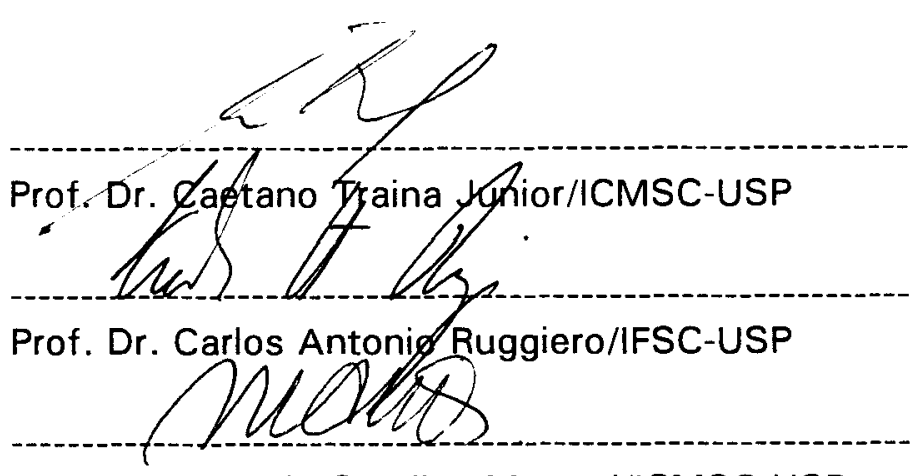

Profa. Dga. Maria Carolina Monard/ICMSC-USP

HoilatemiLkesure

Prof. Dr. José Valdeni de Lima/UFRS

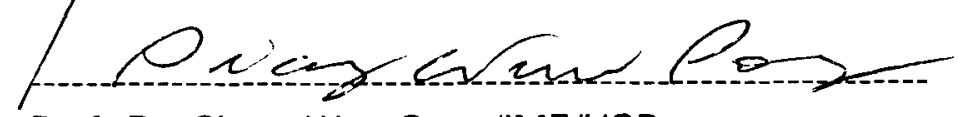

Prof. Dr. Siang Wun Song/IME/USP

USP - Educação para o Brasil

C: \WINWORD \WLA \OFDEFD . DOC

1727 
Aos "ninos":

Danilo, Vitor e Lucas 


\section{AGRADECIMENTOS}

Ao Prof. Dr. Caetano Traina Junior, meu orientador, pela incansável e valiosa orientação e particularmente pela sua confiança e amizade. Esses fatores foram de fundamental importância para o desenvolvimento do trabalho em questão.

Aos componentes do Grupo de Pesquisa em Banco de Dados do ICMSC-USP, que proporcionam um ambiente digno e propício para o desenvolvimento de pesquisas. Em especial, a Profa. Dra. Agma J. Traina pela valiosa colaboração na revisão do conteúdo e forma do texto desse trabalho.

Ao Departamento de Estatística, Matemática Aplicada e Computacional (DEMAC) UNESP-Rio Claro, FUNDUNESP, CNPq pelo apoio institucional para o desenvolvimento desse trabalho.

Ao Prof. Hélio Ap. Navarro pelas excelentes discussões, para o melhoramento da proposta do trabalho e a Renata Grilli pela colaboração na revisão, formato do texto e pelo incansável apoio.

Aos amigos e familiares que direta ou indiretamente contribuiram para a realização desse trabalho. 


\section{SUMÁRIO}

\section{LISTA DE FIGURAS}

\section{RESUMO}

\section{ABSTRACT}

1. Introdução.

1.1. Origem e Necessidades do Problema. . . . . . . . . . . . . . . . . . 1

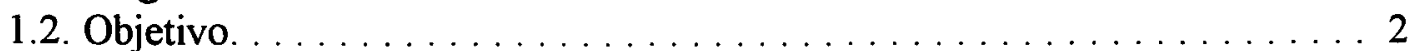

1.3. Síntese dos Resultados Obtidos. . . . . . . . . . . . . . . . . . 3

1.2. Organização do Trabalho. ...................... 4

2. Sistemas e Modelos de Dados Oientados a Objetos.

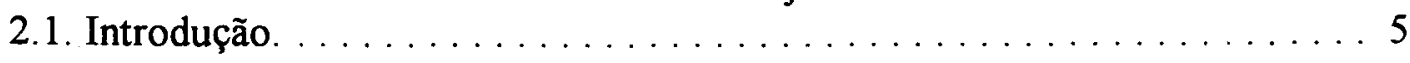

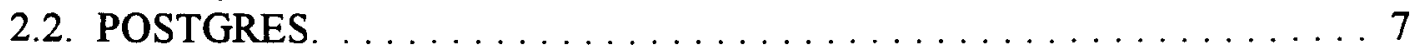

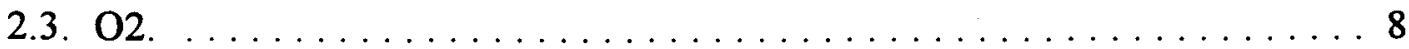

2.3.1. A Arquitetura do Sistema . . . . . . . . . . . . . . . . . 9

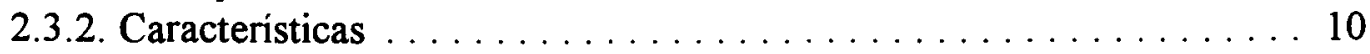

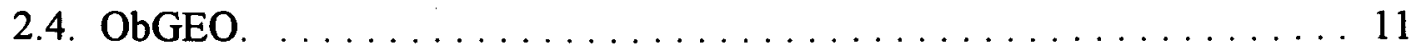

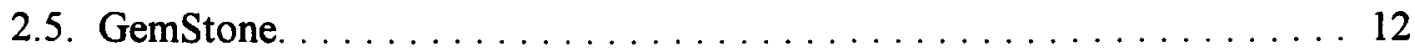

2.5.1. A Arquitetura do Sistema . . . . . . . . . . . . . . . . 14

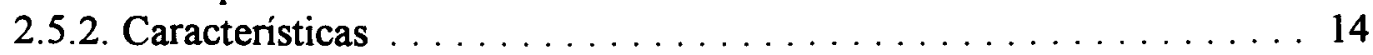

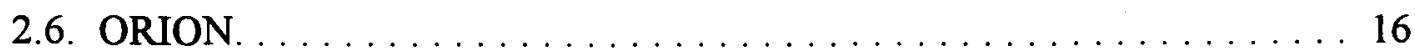

2.6.1. Hierarquia de Classes e Herança $\ldots \ldots \ldots \ldots \ldots \ldots \ldots$

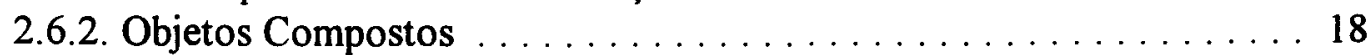

2.7. SIRIUS. . . . . . . . . . . . . . . . . . . . 19

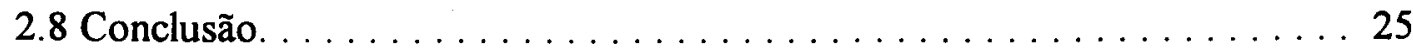

3. Distribuição de Dados em Modelos Relacionais e Orientados a Objetos.

3.1 Controle de Concorrência nos Modelos Convencionais . . . . . . . . 26

3.1 .1 Aspectos da Teoria da Serialização . . . . . . . . . . . . . . . 29

3.1.2 Escalonadores Baseados em Bloqueios . . . . . . . . . . . . . 31

3.1.3 Escalonadores Baseados em Pré-Ordenação . . . . . . . . . . 38

3.1.4 Síntese dos modelos de concorrência de dados convencionais . . . . . 43

3.2 Modelo de Autorização em Base de Dados Orientadas a Objetos. . . . . 45

3.2.1 Definição dos Conceitos para o Modelo de Autorização . . . . . . . 46

3.2.2 Regras de Derivação . . . . . . . . . . . . . . . . . . 48

3.3 Distribuição de Dados em Base de Dados Orientadas a Objetos. . . . . . 50

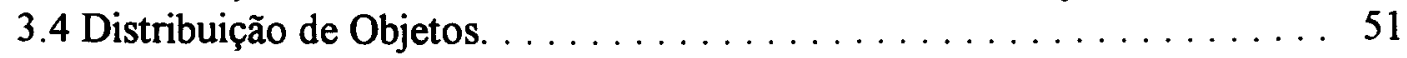

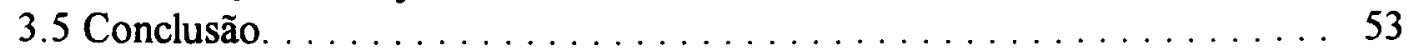


4. Controle de Compartilhamento em GBDOO Baseado em Composição de Objetos.

4.1. Introdução. . . . . . . . . . . . . . . . . . . . . . 54

4.2. Objetos Compostos no Modelo de Compartilhamento de Dados. . . . . . 55

4.3. Tipos de Vínculos Entre as Bases de Dados na Fase de Separação. . . . . . 56

4.4. Núcleo de Acesso do Objeto Composto. . . . . . . . . . . . . 58

4.4.1. Granularidade da Base de Dados . . . . . . . . . . . . . . . . 58

4.4.2. Controle de Acesso para Processo de Compartilhamento . . . . . . . . 59

4.5. Operação Compartilhamento. . . . . . . . . . . . . . . . 60

4.5.1. Contexto para Compartilhamento . . . . . . . . . . . . 61

4.5.2. Fase de Separação . . . . . . . . . . . . . . . . . . . 62

4.5.3. Fase de Evolução . . . . . . . . . . . . . . . . . . . . . . . 66

4.5.4. Fase de Integração . . . . . . . . . . . . . . . . . 67

4.6. Modelagem da Operação Compartilhamento Através do Modelo SIRIUS. 69

4.6.1. Registros da Operação Compartilhamento . . . . . . . . . . . . . . . 69

4.6.2. Diagrama da Modelagem da Operação Compartilhamento . . . . . . 71

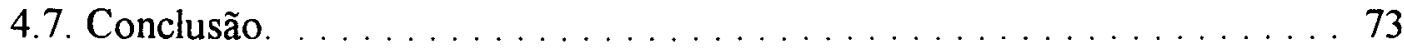

5. Implementação de uma Ferramenta para o Compartilhamento de Objetos Compostos.

5.1. Introdução. . . . . . . . . . . . . . . . . . . 75

5.2. Gerenciadores de Objetos. . . . . . . . . . . . . . . . 76

5.2.1. A estrutura interna de SIRIUS/GO . . . . . . . . . . . . 78

5.2.2. O Esquema de Gerenciamento de OIds no SIRIUS/GO . . . . . . . 79

5.2.3. O Sistema de Gerenciamento de Transações e Gerenciamento de Oid 82

5.3. Aspectos Considerados no Desenvolvimento do Aplicativo. . . . . . . . 84

5.4. Gerenciador de Dados e osconceitos Básicos do Modelo SIRIUS. . . . . . 88

5.4.1. Remodelagem dos Conceitos utilizando o MER . . . . . . . . . . . 88

5.5. Construção de Um Padrão de Interface da Ferramenta. . . . . . . . . . . . . 92

5.6. Conclusão. . . . . . . . . . . . . . . . . . . . . . . . . . . . . . . 97

6.Conclusões.

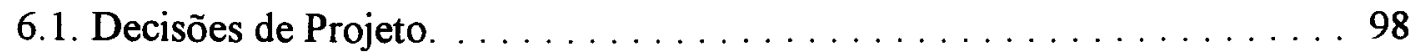

6.2. Contribuições Inovadoras. . . . . . . . . . . . . . . . . . 101

6.2.1 Aspectos de Modelagem de Dados . . . . . . . . . . . . . . . 101

6.2 .2 Aspectos de Implementação $\ldots \ldots \ldots \ldots \ldots \ldots . \ldots \ldots$

6.3. Sugestões para Futuras Pesquisas. . . . . . . . . . . . . . . 104

7. Bibliografia. . . . . . . . . . . . . . . . . . . . . 108

Anexo: Exemplo de uma aplicação $\ldots \ldots \ldots \ldots \ldots \ldots \ldots \ldots$ 


\section{LISTA DE FIGURAS}

Figura 2.1 - Arquitetura do $\mathrm{O}_{2} \ldots \ldots \ldots \ldots \ldots \ldots \ldots \ldots \ldots \ldots \ldots$

Figura 2.2 - Arquitetura do GemStone . . . . . . . . . . . . . . . 13

Figura 2.3 - Notação para representação de tipos de objetos e atributos ...... 21

Figura 2.4 - Objetos compostos e colônias no modelo SIRIUS .......... 23

Figura 3.1 - Formas de conectar os nós .................... 26

Figura 3.2 - Arquitetura de um SGBDD $\ldots \ldots \ldots \ldots \ldots \ldots \ldots \ldots \ldots \ldots \ldots$

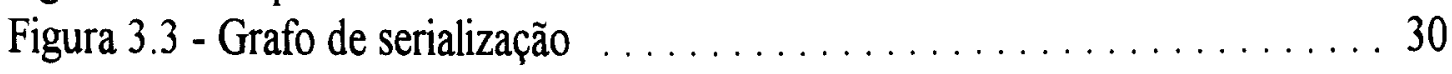

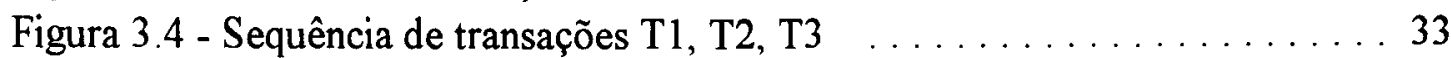

Figura 3.5 - Dígrafo para $\mathrm{T} 1, \mathrm{~T} 2, \mathrm{~T} 3 \ldots \ldots \ldots \ldots \ldots \ldots \ldots \ldots \ldots \ldots \ldots$

Figura 3.6 - Método de bloqueio - 2 PL ................... 35

Figura 3.7 - Quadro comparativo dos mecanismos de controle de concorrência . 43

Figura 3.8 - Autorização explícita e autorizações implícitas decorrentes . . . . . . 46

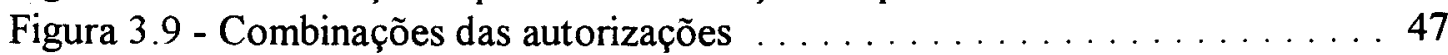

Figura 3.10 - Grafos acíclicos usuários, tipos de autorizações e objetos ...... 48

Figura 3.11 - Elementos da arquitetura CORBA ............... 52

Figura 4.1 - Tipos de vínculos possíveis entre as colônias das bases de dados original e produto ................. 57

Figura 4.2 - Subcampos do registros de autorização $\ldots \ldots \ldots \ldots \ldots \ldots 60$

Figura 4.3 - Contexto para compartilhamento ...................61 61

Figura 4.4 - Vínculos para a operação separação ................. 63

Figura 4.5 - Alterações possiveis nos inter-relacionamentos conforme autorização da base destino $\ldots \ldots \ldots \ldots \ldots \ldots \ldots \ldots 65$

Figura 4.6 - Processo de integração $\ldots \ldots \ldots \ldots \ldots \ldots \ldots \ldots \ldots \ldots . \ldots 6$

Figura 4.7 - Registros para operação compartilhamento ............ 70

Figuras 4.8a - Modelagem da operação compartilhamento objeto origem;

$4.8 \mathrm{~b}$ - Instâncias dos objetos da modelagem . ................ 71

Figuras $4.9 \mathrm{a}$ - Modelagem da operação compartilhamento objeto produto;

$4.9 \mathrm{~b}$ - Instâncias dos objetos da modelagem . .............. 72

Figura 5.1 - Estrutura em camadas de SIRIUS, com destaque para seu núcleo ........................... 79

Figura 5.2 - Estrutura de um RegFis armazenando RegLog de tamanho variável .......................... 81

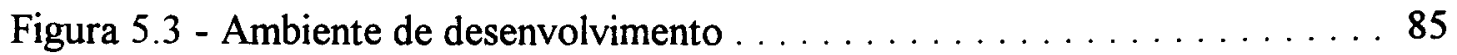

Figura 5.4 - Destaque para conversores genéricos . . . . . . . . . . . 86

Figura 5.5 - Remodelagem SIRIUS utilizando MER $\ldots \ldots \ldots \ldots \ldots \ldots \ldots 88$

Figura 5.6 - Modelagem da base de dados SIRIUS $\ldots \ldots \ldots \ldots \ldots \ldots \ldots .89$

Figura 5.7 - Modelagem da operação compartilhamento $\ldots \ldots \ldots \ldots \ldots .90$

Figura 5.8 - Diagrama das tabelas e seus respectivos campos . . . . . . . 91

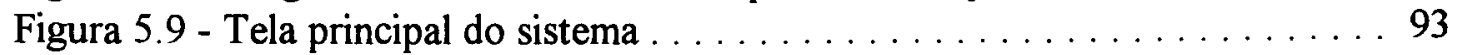

Figura 5.10 - Telas de seleção de esquemas e instâncias de colônias, objetos, atributos, etc. . . . . . . . . . . . . . . 94

Figuras 5.11 - Um exemplo de tela padrão para objetos ............. 95

Figuras 5.12 - Um exemplo de tela padrão para colônias ............. 96 


\section{RESUMO}

Este trabalho apresenta uma proposta para o Compartilhamento de Dados entre Bases de Dados Orientadas a Objetos, em ambientes de desenvolvimento de projetos. O processo de compartilhamento é realizado através de três fases: separação, evolução e integração de dados. Esta forma de compartilhamento atua através de "vínculos" entre os objetos da base original com a base produto. Foram definidos seis tipos de vínculos, que são estabelecidos no processo de separação: apenas leitura, isolado, flagrante, mutuamente exclusivo, independente e "on-line". Com isso, ambas as bases, respeitando as limitações impostas pelo tipo de vínculo entre as mesmas, podem evoluir separadamente e depois de um determinado tempo realizarem, se conveniente, um processo de re-integração. $O$ processo de compartilhamento de dados tem por unidade de gerenciamento os objetos compostos da base de dados. Os conceitos apresentados podem ser universalmente aplicados, em qualquer base de dados que efetue gerenciamento sobre a composição de seus objetos. Neste trabalho os conceitos de compartilhamento de dados são exemplificados através do modelo de dados SIRIUS. 


\begin{abstract}
S
This work presents a technique to share data stored in an object oriented database aimed to design environments. Three process enable the sharing of data between databases: separation, evolution and integration of data. Whenever a block of data need to be shared between original and product database, it is spreaded into both, resulting in block on the original database, and another into the second one, identified as the product of the sharing process. During evolution phase of the sharing process these blocks do not have to be identical. Six types of links were defined: read only, isolated, snapshot, mutually exclusive, independent and on-line. The original and product databases, both restricted by rules imposed by the type of links, can evolve alone. After sometime they may suffer an integration process. This process uses the databases composite objects as the unit control. The concepts presented can be applied to any data model with support to composite objects. The SIRIUS datamodel is used to exemplify these concepts.
\end{abstract}




\section{Capítulo 1 INTRODUÇÃO}

\subsection{Origem e Necessidades do Problema.}

A distribuição de Bases de Dados Convencionais [CASANOVA_84] [BERNSTEIN_80], apresenta como característica principal a disponibilidade dos dados, ao mesmo tempo, a todos os usuários. Nesse ambiente, os conflitos causados pela concorrência para obtenção dos dados tornam-se muito acentuados.

O desenvolvimento de um sistema que trate tal distribuição deve ser especificado de modo a não permitir inconsistência dos dados. Para isso, são especificados algoritmos que buscam efetuar o escalonamento de transações conflitantes [ESWARAM_76], que operam sobre um conjunto de dados parcial ou totalmente comuns.

Esses algoritmos atendem tanto a uma situação de concorrência de dados num ambiente multi-usuário centralizado, como num ambiente distribuído. Ressalta-se no entanto, que as características de cada uma dessas situações são diferenciadas devido à natureza das transações envolvidas [BERNSTEIN_81].

Além do problema de concorrência num Sistema de Base de Dados Convencional, existe também o Controle de Integridade, que é ainda mais acentuado num ambiente distribuído em decorrência da possibilidade de falhas durante a comunicação entre os nós pertencentes à rede. Com o intuito de diminuir e/ou eliminar os efeitos provocados pelas possíveis falhas de comunicação são especificadas as assim chamadas Estruturas Robustas 
(Atas, Arquivos Diferenciais, Imagens Transientes, etc.) [CASANOVA_84] [CERI 84]. Embora estas estruturas possam diminuir a eficiência do Sistema, elas oferecem aos usuários a possibilidade de se fazer acesso simultâneo a dados compartilhados de forma consistente.

Em Bases de Dados não convencionais [BERTINO_93] [CHORAFAS_93] ]KIM_95], nas quais o ambiente de trabalho é essencialmente voltado para o desenvolvimento de projetos, as necessidades de distribuição têm características distintas das de uma Base de Dados Convencional. Embora possam haver situações em que o sistema deva incorporar o tratamento de concorrência dos dados, o desenvolvimento deste recurso é apenas mais um, face a outras necessidades de distribuição específicas para esses ambientes, tais como o isolamento de parte de um projeto para desenvolvimento independente. Nesses ambientes a distribuição dos dados envolve ainda o tratamento da concorrência, versão e partição [KIM_9la], na medida em que ocorrem as mais variadas formas de cópias dos dados.

\subsection{Objetivo.}

As principais necessidades de distribuição que uma Base de Dados voltada para um ambiente de desenvolvimento de projetos deve atender são: 1)suportar transações longas (que podem levar meses); 2) permitir que muitos projetistas participem de uma mesma tarefa dentro do projeto; 3 ) possibilitar que parte do trabalho seja de uso exclusivo de um determinado projetista e outras partes compartilhadas por outros projetistas; 4) possibilitar que a parte compartilhada, que em geral tem acesso permitido apenas para leitura, esporadicamente possa ser liberada para alteração; 5) permitir que a base suporte conflitos, considerando que estes serão resolvidos externamente; 6) permitir ao projetista operar isoladamente na sua estação de trabalho, com poucas intervenções ou consultas à base "oficial" do projeto; 7) permitir a integração de um subprojeto, após sua conclusão, com outros subprojetos afins.

Dado que as necessidades de distribuição nesses ambientes são mais amplas do que as tradicionalmente estudadas e suportadas em ambientes relacionais, será utilizado aqui o termo "Compartilhamento" de dados, corsiderando-se que a Distribuição de dados é um dos casos particulares do Compartilhamento de Dados. 
Caracteriza-se assim o objetivo do trabalho em questão que é a definição de um Modelo de Compartilhamento de Dados capaz de estabelecer divisões em uma base de dados, formas de vinculação para a evolução das partes, grau de compartilhamento, e formas para possíveis re-integrações de divisões, de acordo com as exigências das aplicações.

\subsection{Síntese dos Resultados Obtidos.}

A definição do registro de autorização para as operações nas colônias constritas por objetos, a definição da sintaxe para inter-relacionamentos, o conceito de composição de objetos para distribuição de dados, o conceito de compartilhamento de uma base de dados através de compartilhamentos de objetos (compostos) que constrigem colônias, fases de separação, evolução e integração de bases de dados criando bases original e produto, tipos de vínculos entre as bases original e produto, são algumas contribuições importantes deste trabalho para a área de Modelagem de Dados usando o paradigma de Orientação a Objetos.

O conceito de compartilhamento de uma base de dados identificou a existência de três fases para que objetos possam ser compartilhados. Demonstrou-se (informalmente) que o compartilhamento de objetos (compostos) deve ser efetuado tomando-se por base uma unidade de compartilhamento que possa ser utilizada para o controle de acesso (e de concorrência). Assim este trabalho apoiou-se no conceito de colônias de objetos, justificando sua necessidade.

As três fases de uma operação de compartilhamento (separação, evolução e integração de bases de dados) operam criando duas bases: original e produto. Cada base produto, gerada na fase de separação de uma operação de compartilhamento, mantém permanentemente um vínculo com a base original de onde foi gerada. É definido também um conjunto de permissões de acesso para que ambas as bases, original e produto, possam admitir alterações durante a fase de evolução. O tipo de vínculo estabelecido na fase de separação caracterizará os métodos utilizados na fase de integração. 


\subsection{Organização do Trabalho.}

Capítulo 1: Apresentam-se a origem, necessidades do problema e objetivos do que motivaram o desenvolvimento do trabalho em questão e seus respectivos resultados juntamente com a organização dos capitulos.

Capítulo 2: São apresentados modelos de bases de dados orientados a objetos e seus respectivos sistemas, caracterizados segundo três abordagens: modelos relacionais estendidos, baseados em linguagem de programação e baseados em modelos de dados orientados a objetos.

Capítulo 3: São apresentadas as formas de distribuição de dados nos modelos e sistemas de bases de dados convencionais e orientados a objetos. Caracteriza-se o controle de concorrência, compartilhamento e distribuição de dados apresentando os conceitos relevantes tais como: Escalonadores, "Serialização", Controle de Autorização, "Interoperabilidade", Unidade de Compartilhamento.

Capítulo 4: Apresenta-se um Modelo para Compartilhamento de Bases de Dados baseado em Composição de Objetos. Para mostrar a viabilidade da proposta foi utilizado o Modelo de Dados SIRIUS. Neste capítulo encontram-se as contribuições conceituais originais.

Capítulo 5: Apresenta-se a ferramenta desenvolvida para validar os conceitos propostos para compartilhamento de dados. Tal ferramenta foi desenvolvida tendo como objetivos: viabilizar a utilização dos conceitos de compartilhamento de dados pelos gerenciadores relacionais disponíveis; fornecer subsídios para o desenvolvimento da implementação do controle de compartilhamento de dados, em um gerenciador de bases de dados orientados a objetos.

Capítulo 6: É feita uma análise dos resultados deste trabalho, através da descrição das principais decisões de projeto adotadas, as sugestões de novas pesquisas e conclusões. 


\section{Capítulo 2}

\section{Sistemas e Modelos de Dados Orientados a Objetos}

\subsection{Introdução.}

Os Sistemas de Gerenciamento de Bases de Dados Orientados a Objetos são construídos a partir das definições dos Modelos Conceituais de Orientação a Objetos. A base de dados é considerada uma coleção de objetos que possui comportamento, atributos e relacionamentos armazenados em estruturas físicas (memória dinâmica, discos, fitas, etc.). Uma das contribuições importantes dos modelos orientados a objetos é a possibilidade de diminuir a distância semântica entre as informações do mundo real e as informações armazenadas como objetos na base de dados, ao contrário dos modelos convencionais (Relacional, Rede, Hierárquico) [DATE_88], que restringem a representação dos dados considerando-os como coleções de tipos de registros ou tipos de relações.

Essa forma de representação dos modelos convencionais, mesmo quando trata um grande volume de dados, tem como característica básica a utilização de estruturas homogêneas. Entretanto, aplicações não convencionais têm exigido uma complexidade maior dos modelos de dados, que necessitam de estruturas de dados que não permitem a mesma homogeneidade estrutural. Os modelos orientados a objetos suportam uma semântica capaz de representar mais facilmente as aplicações não convencionais, tais como: os projetos apoiados por computador (CAD/CAM), os 
sistemas de bases de conhecimento, sistemas multimidia e os novos sistemas de interface homem-máquina.

Atualmente existem alguns sistemas de bases de dados orientadas a objetos desenvolvidos por empresas, laboratórios de pesquisa e universidades, embora não exista ainda um modelo formal aceito por toda comunidade. Esforços estão sendo realizados com objetivo de unificar e padronizar tais modelos [ATKINSON_89] [STONEBRAKER_90] [CATTELL_94]. A implementação de uma Base de Dados Orientada a Objetos segue em geral três abordagens distintas:

Sistemas Relacionais Estendidos - utilizam como repositório de dados sistemas relacionais existentes, criando estruturas adicionais para suportar os conceitos de Orientação a Objeto. Um exemplo desta abordagem é o sistema POSTGRES [STONEBRAKER_89];

Sistemas Baseados em Linguagens de Programação Orientadas a Objetos utilizam os conceitos de linguagens de programação orientadas a objetos, tornando os objetos gerenciados pela memória volátil em objetos persistentes, armazenados em dispositivos físicos como discos rígidos. Nesta abordagem destacam-se os sistemas e modelos: O2 [DEUX_90]; ObGEO [CORRÊA_94] [FERRARI_92] e GemStone [BERTINO_93] .

\section{Sistemas Desenvolvidos a partir de Modelos de Dados Orientados a Objetos -} partindo dos conceitos definidos no modelo de dados, os gerenciadores que seguem esta abordagem procuram criar estruturas de dados tanto para gerenciamento de memória como para acesso a disco, de modo a suportar os conceitos formalizados pelo modelo em questão. Dentre os gerenciadores e modelos pode-se destacar ORION [KIM_90] e SIRIUS [TRAINA_94] [BIAJIZ_96].

As diferenças entre as abordagens serão melhor especificadas através das seções apresentadas a seguir. A maneira de suportar os conceitos como objetos complexos, encapsulamento de objetos, gerenciamento e identificação de objetos, 
abstração de classificação e de generalização de dados são os itens que melhor caracterizam as diferenças entre as abordagens citadas.

\subsection{POSTGRES.}

O Modelo POSTGRES (POST inGRES)[STONEBRAKER_89] vem sendo desenvolvido na Universidade da Califórnia. Tem como suporte para armazenamento de dados o gerenciador relacional INGRES, um dos dois gerenciadores inicialmente desenvolvidos para o modelo relacional. Esta característica impõe ao modelo uma grande necessidade de adaptação para atender às aplicações não convencionais.

Os Sistemas de Gerenciamento de Bases de Dados (SGBD) convencionais têm fornecido suporte às aplicações comerciais que necessitam de estruturas de dados homogêneas representadas em registros de formato fixo, os quais são armazenados e pesquisados com alta frequência. Entretanto, a estrutura de dados e a semântica, inerentes às aplicações não convencionais, precisam de uma capacidade de representação de novos tipos de dados (objetos), não suportados com eficiência pelos modelos convencionais, e regras (que descrevem a dinâmica dos dados).

Para isto foram criados, no modelo POSTGRES, subsistemas para gerenciamento de objetos e conhecimento para suprir respectivamente as necessidades da definição de novos tipos de objetos e incorporar regras pertencentes a semântica de aplicação.

Para os objetivos deste trabalho vale destacar a possibilidade oferecida pelo POSTGRES, de definir como valor para um atributo em uma tupla uma outra relação. Isso caracteriza uma forma de suportar objetos compostos, pois pode-se considerar uma tabela como um objeto, e assim, tabelas que são valores de um atributo de outra tabela, constituem-se em objetos que compõem o objeto representado pela tupla "maior". 


\subsection{2 .}

$\mathrm{O} \mathrm{O}_{2}$ [DEUX_90] [DEUX_91] foi projetado e desenvolvido por um consórcio de pesquisa, composto pelo INRIA-Institut National de la Recherche Informatique et Automatique, Siemens - Nixdorf, Bull, o CNRS-Centre National de la Recherche Scientifique e a Universidade de Paris. Esse projeto iniciou-se em 1986 e seu objetivo era projetar e implementar um sistema de banco de dados para aplicações não convencionais.

Após várias tentativas com protótipos foram feitas melhorias tanto através da inclusão de características novas como a construção de um código mais robusto. Uma versão completa do sistema foi testada em 1990. No final de 1990, a companhia $O_{2}$ Technology foi criada, e esta ficou responsável pelo desenvolvimento, manutenção e divulgação do produto. A venda comercial iniciou-se em junho/1991.

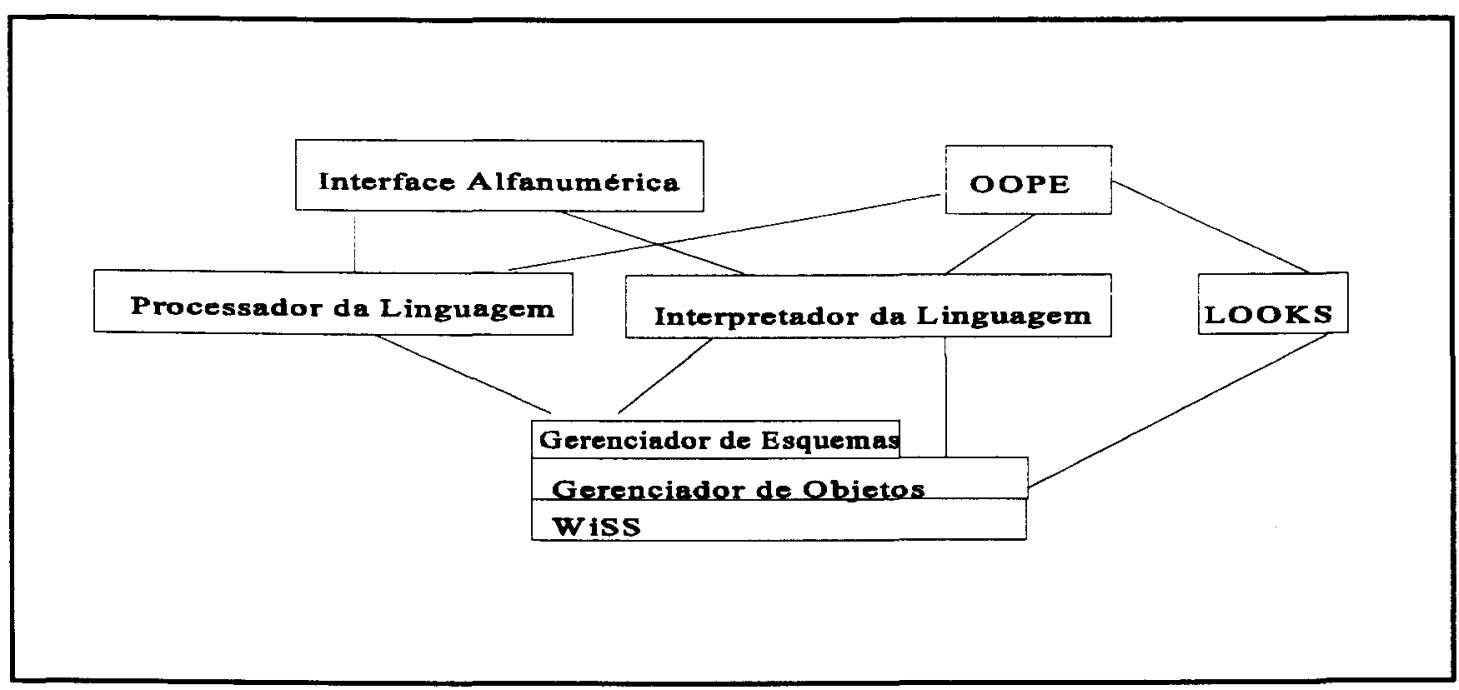

Figura 2.1: Arquitetura do $\mathrm{O} 2$.

As áreas de aplicação adequadas ao $\mathrm{O}_{2}$ incluem as "novas aplicações", tais como $C A D / C A M$, sistemas urbanos e geográficos, sistemas de informação editorial, automação de escritório e aplicações comerciais. Tal modelo é um dos poucos 
modelos formalizados, tornando-se de grande importância para a comunidade de pesquisa em banco de dados orientados a objetos.

\subsubsection{A Arquitetura do Sistema.}

A arquitetura do sistema é organizada em três níveis e ilustrada na figura 2.1. O nível mais alto é o do Gerenciador de Esquemas. As funções fornecidas por ele incluem criação, acesso, modificação e remoção de classes, métodos e variáveis globais. Além disso, ele é responsável por controlar a consistência do esquema e pela verificação das regras do subtipo em hierarquias de herança.

O nível intermediário é o do Gerenciador de Objetos. Este componente gerencia objetos e valores complexos independente de sua persistência. O gerenciador suporta troca de mensagem e configuração cliente/servidor. Além disso, ele implementa todas as funções relacionadas à persistência, coleção de lixo e mecanismos de acesso, tais como índices. Finalmente, ele fornece todas as funções para gerenciamento de transação.

O nível mais baixo é o WiSS (Subsistema de Armazenamento Wisconsin), que gerencia armazenamento secundário. O WiSS fornece funções para persistência, gerenciamento de disco e controle de concorrência para registros.

$\mathrm{O} \mathrm{O}_{2}$ pode suportar dois tipos de interfaces : interfaces de linguagens e $\mathrm{o}$ ambiente $\mathrm{O}_{2}$. As interfaces de linguagens permitem que um programa escrito em $\mathrm{C}$ ou $\mathrm{C}++$ obtenha vantagens dos serviços de $\mathrm{O}_{2}$, declarando esquemas $\mathrm{O}$ e armazenamento, propagação e manipulação em banco de dados $\mathrm{O}_{2}$. Alternativamente, o usuário pode se beneficiar do ambiente completo $\mathrm{O}_{2}$. Este ambiente inclui: uma linguagem de consulta, $\mathrm{O}_{2}$ Query; um gerador de interface de usuário, $\mathrm{O}_{2}$ Look; uma linguagem de quarta geração, $\mathrm{O}_{2} \mathrm{C}$ e um ambiente de programação gráfico incluindo um "debugger" e um "browser" de banco de dados e esquema. 


\subsubsection{Características.}

Os objetos no Modelo $\mathrm{O}_{2}$ são representados por pares identificador-valor. $\mathrm{O}$ primeiro objeto possui um identificador inicial e seu valor é uma tupla. Os valores podem ser atômicos, multi-valorados, outros objetos, representados através de seus respectivos indentificadores. Para a abstração de classificação existem duas formas: definição de classes que encapsulam dados e procedimentos, cujas instâncias são objetos; e a definição de tipos cujas instâncias são valores que não são encapsulados. Classes são criadas explicitamente usando comandos pré-definidos e integram-se à hierarquia de classes dos sistemas alvos. Tipos aparecem como componentes de classes e são construídos agregando recursivamente tipos atômicos (integer, float, double, string, char, etc.).

A manipulação de objetos dá-se através dos métodos. Método é um conjunto de procedimentos atribuído para uma classe específica. Um método é declarado em $\mathrm{O}_{2}$ atribuindo-lhe uma assinatura, isto é, seu nome está vinculado a classe a qual pertence. Os métodos podem ser privados ou públicos. Métodos privados são visíveis apenas dentro de suas classes, enquanto que os métodos públicos são visíveis para todas as classes.

$\mathrm{O}_{2}$ fornece um mecanismo de herança de dados baseado em subtipos. Um tipo é um subtipo de outro se, e somente se, toda instância deste tipo é também uma instância de seu supertipo. Existe uma classe pré-definida chamada "Objeto". Essa classe é a raiz da hierarquia de classes, e toda classe herda-a implicitamente. Nessa classe raiz são definidos métodos que são comuns a todos os objetos do sistema. Assim, estes métodos são herdados por todas as classes.

O gerador de interfaces (LOOKS) é projetado para permitir ao programador obter facilidades para interação com o usuário final. LOOKS suporta a manipulação gráfica interativa de valores e objetos complexos do $\mathrm{O}_{2}$, operando como um servidor 
de interface para o usuário e oferecendo funções para criar, remover, editar e salvar qualquer objeto do $\mathrm{O}_{2}$.

$\mathrm{O}$ sistema $\mathrm{O}_{2}$ também fornece um ambiente de programação denominado OOPE. Trata-se de um ambiente gráfico de programação que suporta o desenvolvimento de aplicações. Este ambiente permite a atualização, edição e pesquisa dos dados e esquemas através de ferramentas contendo classes pré-definidas, objetos e valores que o programador pode usar como componentes em seus programas.

\subsection{ObGEO.}

O ObGEO é um Sistema de Gerenciamento de Bases de Dados Orientados a Objetos que está sendo desenvolvido na Universidade Federal de São Carlos, a partir de seu Subsistema de Armazenamento de Objetos [CORRÊA_94] [FERRARI_92]. O sistema está sendo desenvolvido com o objetivo de apoiar as aplicações na área de Geoprocessamento. Os módulos: Linguagem de Consulta de Alto Nivel; Tradutor e Otimizador de Consultas e o Subsistema de Armazenamento de Objetos caracterizam a arquitetura básica do ObGEO.

O Sistema ObGEO representa um objeto através de um identificador unívoco. Todo objeto é definido segundo uma estrutura que deve ser definida, a priori, chamada de seu tipo. Objetos de mesmo tipo são agrupados em classes. Cada Classe pode possuir uma ou mais subclasses que são especializações da classe original. O modelo só permite a ocorrência de herança simples. Os componentes do objeto podem ser definidos como simples (inteiro, real, lógico,etc.), compostos (Tupla, lista, "set") ou definidos pelo usuário.

Com o objetivo de reduzir a quantidade de objetos duplicados e otimizar o acesso aos dados armazenados, o sistema ObGEO cria arquivos diferentes para cada tipo de objeto definido na aplicação. Assim, tipos e subtipos são armazenados em arquivos diferentes, facilitando o acesso quando se deseja consultar apenas 
características exclusivas de um subtipo. Esta estratégia de implementação apresenta problemas, principalmente quando se deseja definir mais de uma classe de um mesmo tipo ou identificar quais objetos pertencem a uma determinada classe, visto que estes estão armazenados no mesmo arquivo, junto com objetos de outras classes. Para minimizar este tipo de problema foi adotado um sistema de controle de acesso aos objetos via índice. Quando um tipo é definido, cria-se um arquivo associado, cujo nome é composto pelo OID que representa este tipo de objeto.

O ObGEO utiliza a linguagem de consulta LCO (Linguagem de Consultas a Objetos) desenvolvida para o sistema. A LCO é uma linguagem interativa, baseada na linguagem de consulta SQL estendida para manipular dados com características de orientação a objeto. Dentre as características da LCO pode-se destacar:

consultas simples: são consultas que envolvem atributos atômicos (integer, real, string, boolean, char, etc.) ou atributos do tipo Tupla, desde que os atributos agrupados neste tipo não pertençam a um outro tipo de objeto.

consultas complexas: são consultas que envolvem atributos cuja estrutura é composta, ou seja, formados pelos construtores LIST e SET ou por atributos cuja estrutura envolve outro tipo de objeto.

consultas envolvendo funções: a LCO permite a formulação de consultas envolvendo cálculos de funções específicas tais como: cálculo de área, volume, média, soma, etc. Estas funções compõem um conjunto reduzido definido inicialmente.

\subsection{GemStone.}

O sistema GemStone foi desenvolvido pela Corporação de Desenvolvimento ServioLogic [BERTINO_93] [CATTELL_94] [KIM_95], com o objetivo de fornecer um Sistema de Gerenciamento de Banco de Dados caracterizado por um forte modelo de dados, e, portanto, reduzir o tempo necessário para desenvolvimento de aplicações complexas. 
GemStone é um Sistema de Gerenciamento de Banco de Dados Orientados a Objetos, que compartilha os conceitos da linguagem de programação orientada a objeto Smalltalk com as funções de um sistema de gerenciamento de dados. A linguagem de definição e manipulação de dados é chamada OPAL e é derivada de Smalltalk. Adotando a filosofia de Smalltalk, cada entidade no sistema, incluindo os programas escritos em OPAL são considerados objetos.

No GemStone, os métodos e as estruturas comuns a todas as instâncias de uma classe estão contidas em um objeto chamado ODC (objeto definido pela classe). Portanto, até as definições de classes estão em objetos. Todas as instâncias de uma classe contém uma referência a seu ODC como parte do identificador do objeto. Além disso, cada objeto é a instância de uma classe. A estrutura interna de muitos dos objetos consistem de vários atributos que podem ter valores e referências a outros objetos. Os objetos estão organizados por meio de estruturas, que são obtidas pela combinação de quatro formatos de armazenamento básico :

Atômica - estes são objetos tais como inteiros e strings, que não tem estrutura interna.

Variáveis de instância - estas são unidades de armazenamento, que podem ser

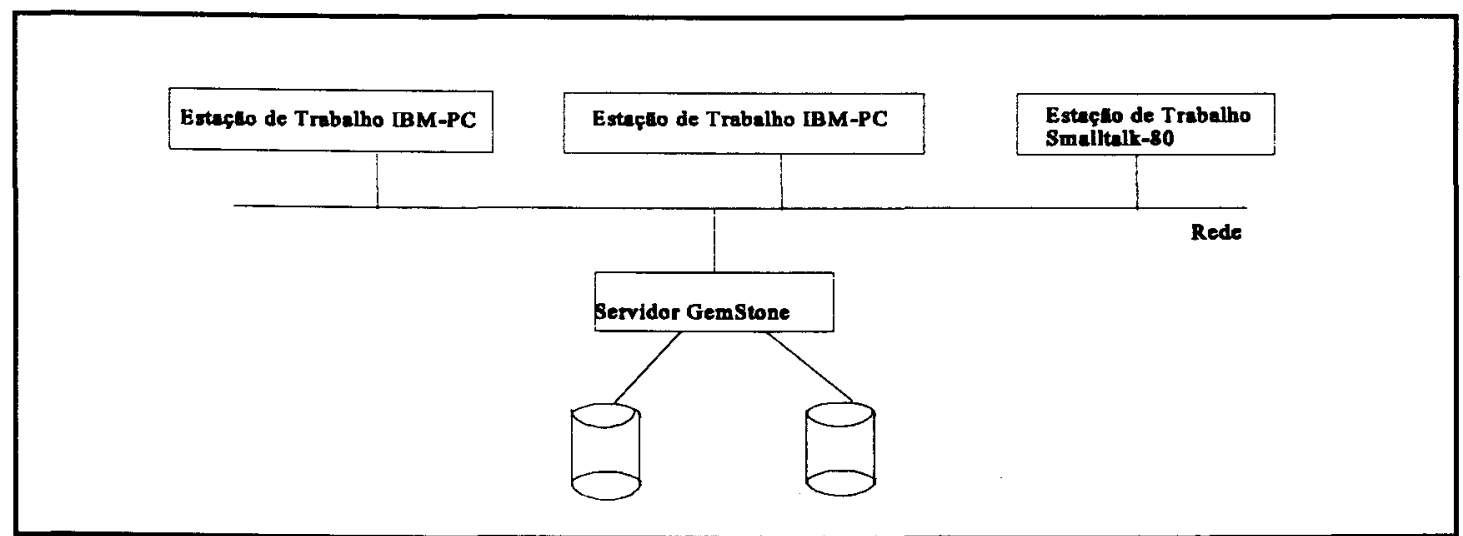

Figura 2.2 - Arquitetura do GemStone.

classificadas por nome.

Variáveis de instância indexável - são unidades de armazenamento classificadas por número. Um exemplo é a classe Array. 
Variáveis de instância anônima - estas diferem das últimas duas, pois são acessadas pelo nome mais que pelo valor. As instâncias da classe Set pertence a esta categoria.

\subsubsection{A Arquitetura do Sistema.}

A arquitetura do GemStone inclui dois processos, chamados Gem e Stone ilustrados na figura 2.2. O processo Stone é o gerenciador de dados, fornecendo entrada/saida de disco, controle de concorrência, autorização, transações e recuperação. O Stone reside na máquina servidora, acessando o disco através das chamadas do sistema operacional.

Os processos Gem resultam da compilação dos programas OPAL e controlam o nível de autorização do usuário em cada estação de trabalho. Tal processo pode residir na estação de trabalho servidora ou cliente. Além disso, existe uma comunicação entre processos, sobre uma rede, entre o usuário do programa, o processo Gem, o processo Stone e o sistema operacional. O processo Gem pode buscar, encerrar e encapsular objetos, páginas ou segmentos completos de dados por vez em uma rede, já que este pode ser otimizado para as necessidades de uma aplicação.

A arquitetura é distribuída e consiste de um conjunto de PC-IBM e/ou estações de trabalho Smalltalk-80 e de um servidor de objetos, implementado no sistema de arquivo VAX/VMS, conectado através de uma rede local. O modelo GemStone é baseado nos conceitos de objeto, classe e mensagem. As classes são organizadas em hierarquias com herança simples. As aplicações podem ser escritas em linguagens como: OPAL (extensão de Smalltalk), C, C++ e Pascal.

\subsubsection{Características.}

Dentre as características encontradas no GemStone, temos :

Suporte concorrente para várias linguagens - GemStone fornece suporte concorrente para aplicações desenvolvidas em Smalltalk, C++ ou C. Todas 
as aplicações, apesar da linguagem, podem ter acesso simultâneo aos mesmos objetos do banco de dados.

Controle de Transação Multi-Usuário - vários usuários podem operar simultaneamente no banco de dados, com uma variedade de modos de controle de transação disponiveis.

Segurança ao Nível do Objeto - Controle de autorização podem ser aplicados para qualquer objeto no banco de dados.

Na primeira versão do GemStone foi utilizado um sistema de arquitetura distribuída, permitindo a manutenção de mais de seis réplicas de banco de dados na rede. Esta característica, de distribuir cópias pela rede, facilita a recuperação de uma possível falha de processamento. Isto permite a uma determinada máquina possuidora da cópia da base de dados, assumir o processamento da máquina que gerou as falhas.

O controle de concorrência no GemStone pode ser realizado tanto por métodos otimistas como pessimistas. No esquema pessimista, uma implementação de transação tradicional é usada. No esquema otimista, uma cópia de segurança do espaço de trabalho do usuário é recebida no início de uma transação. Quando o cliente solicita o fim de uma transação, é feita uma verificação de conflitos com outras transações que tenham sido entregues desde o início da transação. Se algum dado lido ou impresso pela transação for modificado por qualquer outra transação, a cópia de segurança é descartada e o GemStone informa ao cliente que a transação foi abortada. As páginas de dados originais não são removidas, até que todas as transações que as tenham lido sejam finalizadas ou abortadas. Desta forma, todo o processo Gem tem uma visão atualizada do banco de dados durante toda transação.

Numa versão posterior do Sistema GemStone, alguns apectos foram melhorados ou adicionados. A coleta de lixo em tempo de execução, a possibilidade de gerenciar "backup" e a otimização do cache são algumas melhorias que permitiram que o GemStone fosse usado nas aplicações que exigem um grande volume de dados. O Sistema GemStone também permite a utilização das linguagens $\mathrm{C}$ e $\mathrm{C}++$ através de 
interfaces. As interfaces são implementadas como um pré-processador baseado na sintaxe padrão das linguagens suportadas, construindo chamadas para procedimento remoto ou unidades para serem adicionadas ao programa executável.

\subsection{ORION.}

O projeto ORION foi iniciado em 1985 no Programa de Tecnologia Avançada de Computadores (ACT) no MCC (Microelectronics and Computer Technology), Austin, Texas - EUA. Desse projeto resultaram três Sistemas Gerenciadores de Bases de Dados: ORION-1, com características de um gerenciador mono-usuário; ORION-1SX, um sistema cliente/servidor; e o ORION-2 sistema de gerenciamento de base de dados distribuídas [KIM_89][KIM_90]. Uma versão comercial denominada ITASCA está disponivel, a partir da criação da ITASCA Corporation INC formada por membros do grupo de desenvolvimento inicial.

Os objetos em ORION/ITASCA podem ser modelados desde os mais simples, como os tipos de dados (inteiro, caracter, etc.), até os mais complexos (avião, veículos, etc.) que necesitam de uma estrutura de composição de dados. Um objeto consiste de uma porção de memória privada que armazena sua estrutura de dados. Assim, para cada conjunto de valores de cada objeto instanciado existe uma porção de memória que armazena o estado do objeto em questão. $O$ objeto denominado de objeto primitivo, como um inteiro ou um caracter, não possui variável de instância, mas apenas o valor armazenado, que também é um objeto. O Objeto complexo contém variáveis de instância, através das quais é possível estabelecer uma ligação com outros objetos.

O comportamento de um objeto é encapsulado em métodos que manipulam e/ou retornam o estado de um objeto. Estes são parte da definição de um objeto. Objetos interagem com outros objetos através de mensagens. Para cada mensagem recebida pelo objeto deve haver um método correspondente que a executa. Portanto, 
um objeto reage a uma mensagem executando o método correspondente e retornando um objeto.

Torna-se inviável a implementação de um sistema, se para cada objeto houver a necessidade da definição de suas variáveis de instância e de seus próprios métodos. O tratamento do objeto individualizado, para um sistema de grande porte, gera um volume de definições de objetos extremamente grande. Dessa forma, para simplificar e economizar a definição de estruturas, os objetos são agrupados em uma classe. Todos os objetos pertencentes a mesma classe são descritos pelas mesmas variáveis de instância e pelos mesmos métodos.

\subsubsection{Hierarquia de Classes e Herança.}

Uma Hierarquia de Classes é implementada através de um relacionamento entre as classes denominado de IS-A. Um arco liga as classes superior e inferior caracterizando uma abstração de generalização e especialização. Para um par de classes em uma hierarquia, a classe de nível mais alto é chamada superclasse em relação a classe inferior. Já a classe de nível inferior é chamada de subclasse em comparação com sua respectiva classe superior. Os valores e métodos (propriedades) especificados para uma classe são herdados por todas as suas subclasses. Para cada subclasse podem ser especificadas propriedades adicionais.

O modelo ORION permite que uma classe possa ter mais que uma superclasse. Isto gera uma rede semântica representada por uma estrutura de grafo direcionado acíclico (DAG - Direct Acyclic Graph). Esta característica, que também é conhecida como herança múltipla, permite que uma classe herde as propriedades de todas suas superclasses. O DAG tem somente uma raiz (o próprio conceito de objeto) que é uma classe definida pelo sistema, na qual os objetos que fazem parte da rede de classes são conectados. 


\subsubsection{Objetos Compostos.}

A maioria dos modelos de dados orientados a objetos permitem a representação de generalização e especialização através do relacionamento IS-A entre classes. Entretanto, este relacionamento não consegue representar a abstração de composição de objetos. Para isto, é necessário estabelecer o relacionamento ISPART-OF entre as classes. 0 conceito de objeto composto (objeto complexo ou hierarquia de agregação, como é definido no ORION) é capaz de atender as aplicações onde há necessidade de estabelecer uma soma entre as partes de um determinado projeto torna-se imprescindivel.

Um objeto composto tem um único objeto raiz e este objeto faz referência a múltiplos objetos filhos através de variáveis de instância. Os filhos também podem se referenciar a outros objetos filhos. As instâncias que constituem um objeto complexo pertencem a classes que também são organizadas em hierarquias. Esta hierarquia de classes é chamada um esquema de objetos compostos. Um esquema de objetos compostos consiste de uma única classe raiz e um conjunto de classes dependentes.

Em um objeto composto, nenhum objeto dependente pode ser referenciado por mais de um objeto. Assim, um objeto composto é uma hierarquia de objetos e não um dígrafo genérico. Entretanto alguns objetos que fazem parte de uma hierarquia de composição podem ser referenciados por outros objetos que não pertencem a tal hierarquia. Estas referências podem ser feitas através de relacionamentos tendo a generalidade de um dígrafo. Como exemplo, se uma classe veículo tem uma ligação composta com uma instância da classe motor, através de uma variável de instância TipoMotor, então, se existir uma outra referência a mesma instância, esta deve ser feita através de um relacionamento que não utilize a semântica de composição.

Um outro conceito importante do ORION é o de atributo multi-valorado. $O$ modelo em questão propõe que todos os objetos sejam "objetos-tupla". Assim cada entrada para um objeto-tupla é o valor de um atributo. Se o atributo for monovalorado então o valor é um único identificador de objetos (OID), se o valor for multivalorado então têm-se um conjunto de identificadores de objetos (OID's). 
Outro aspecto a ressaltar é o fato de que o modelo em questão permite que o usuário declare uma classe "versionável". Isto significa que os objetos instanciados fazem parte de um conjunto lógico que representa as versões da classe. Estas versões podem criar uma hierarquia entre si, estabelecendo uma hierarquia de instâncias de versões denominada hierarquia de derivação de versões.

\subsection{SIRIUS.}

SIRIUS é um modelo de dados orientado a objetos [TRAINA_94] [BIAJIZ_96], concebido a partir de um formalismo para criação de modelos de dados baseado em parametrização de abstrações de dados.

Seu objetivo é suportar a modelagem de sistemas de apoio a projetos, de apoio à decisão e sistemas de manipulação de dados científicos. Resumidamente, tais requisitos [CHORAFAS_93] consistem: num projeto, a construção da base de dados constitui parte do projeto em si, ou seja, o esquema da base de dados evolui junto com o projeto; não se conhecem em tempo de projeto todos os tipos de objetos e/ou estruturas que serão tratados pelo sistema em execução, e portanto deve ser possível a criação dinâmica de tipos pelo sistema em execução; a estrutura do sistema é complexa, e o modelo relacional não é suficiente para representar as necessidades desses sistemas, ou seja, conceitos avançados de orientação a objetos devem ser empregados; objetos de uma mesma classe (ou tipo) têm frequentemente exceções, tanto de estrutura quanto de comportamento, ou seja, instâncias de objetos devem suportar atributos e métodos não previstos nos esquemas; as sessões de atividade são essencialmente longas e possivelmente conflitantes, e muitas vezes a solução do conflito envolve a intervenção do usuário, possivelmente avaliando diferentes alternativas de solução, ou seja, é necessário o suporte ao gerenciamento de transações longas, gerenciamento de versões, e com o envolvimento do usuário em diversas atividades desse gerenciamento. 
Os conceitos de SIRIUS estão organizados semanticamente suportando quatro Abstrações de Dados: Classificação, Generalização, Agregação e Composição [Biajiz-96]. As abstrações de classificação e agregação são fundamentais para a construção de qualquer modelo de dados e a abstração de generalização é fundamental para modelos orientados a objetos. Assim, para os objetivos deste trabalho os seguintes conceitos de SIRIUS oriundos dessas três abstrações são suficientes:

- Todo objeto é uma instância de um único tipo, possui um Identificador interno controlado pelo gerenciador (OId) e identificadores externos designados pelo usuário;

- Objeto é uma agregação de atributos, cada um possuindo um tipo e um conjunto de valores. Os valores de atributos multi-valorados são estruturados em listas, vetores e conjuntos;

- Tipos de atributos possuem uma característica, que indica se o atributo representa um dado estático do objeto (Propriedades e Identificadores), um comportamento (Regras e Métodos), associação com outros objetos (Relacionamentos) ou uma forma de interface do sistema com o usuário (Visualização);

- Tipos de objetos são por sua vez objetos e como tal podem ser instâncias de outros tipos, criando uma hierarquia de classificação;

- Tipos de objetos podem ter subtipos, bem como ter supertipos, criando uma rede acíclica de tipos que tem obrigatoriamente um único tipo máximo, denominado Tipo Natural daquela rede;

- Um objeto de qualquer tipo é também dinamicamente de qualquer dos supertipos de seu tipo;

- Os atributos de um objeto usualmente são indicados em seu tipo, mas podem ter atributos não previstos; atributos indicados em qualquer supertipo de seu tipo são herdados pelo objeto e os atributos já instanciados em seu tipo são assumidos como valores "default". 
Objeto em SIRIUS é algo significativo para um usuário do sistema, e não apenas um conceito abstrato para um programador. Assim, objetos tendem a ser estruturas sofisticadas, incluindo um conjunto variado de construções associadas. Devido à complexidade que um objeto pode atingir foram definidos quatro tipos de diagramas, cada um destacando uma das abstrações envolvidas no modelo. A simbologia utilizada para um mesmo conceito é sempre a mesma em qualquer diagrama, tornando a apresentação de uma modelagem consistente e homogênea em qualquer diagrama.

A figura 2.3 mostra a representação gráfica adotada em SIRIUS. Um tipo de objeto é representado através de um retângulo dividido horizontalmente, formando duas linhas. A linha superior é dividida em duas verticalmente. $\mathrm{Na}$ linha inferior é indicado o nome do objeto, na linha superior esquerda o nome do tipo

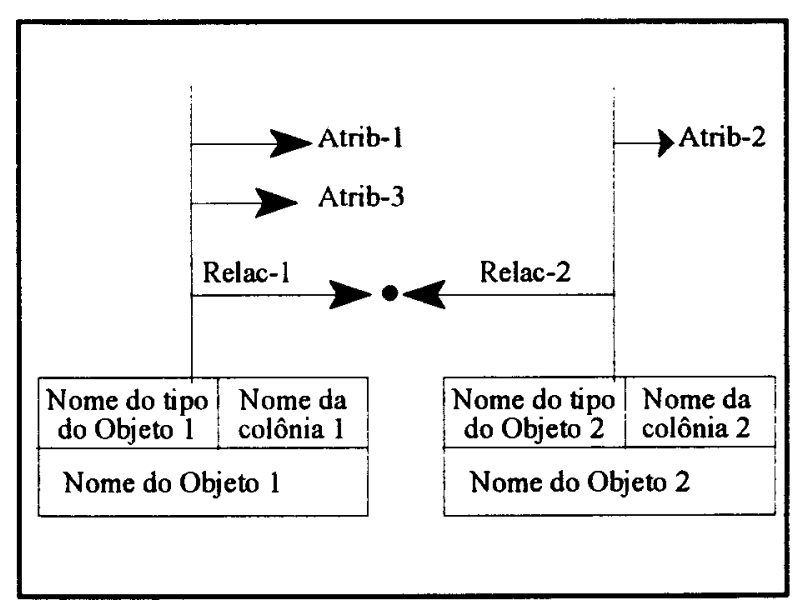

Figura 2.3: Notação para representação de tipos de objetos e atributos. deste objeto e, na linha superior direita o nome do tipo de colônias que instâncias desse objeto habitam. $O$ tipo de um objeto pode ficar em branco, quando seu tipo for o próprio meta-tipo tipo-de-objeto, que é reconhecido e controlado pelo sistema. Atributos são indicados por setas partindo de uma linha vertical que nasce no retângulo que representa o tipo do objeto.

Já a Abstração de Composição, da maneira como é tratada em SIRIUS deve ser aqui melhor detalhada. No âmbito de Modelos de Dados Orientados a Objetos, o termo Composição usualmente tem sido empregado para indicar que dois ou mais objetos associam-se, e que essa associação é representada através de uma referência ao outro objeto, em pelo menos um dos objetos envolvidos. Essa associação nem sempre tem o significado real de composição. Por exemplo, havendo um objeto pessoa que mora em objeto do tipo residência, isso caracteriza pessoa como um 
objeto composto, pois possui uma referência a outro objeto reconhecido pelo usuário. No entanto, pessoas não são de fato compostas por residência. Em SIRIUS esta situação é modelada (como de resto em qualquer modelo orientado a objetos), através da referência de um atributo de pessoa a residência, o que configura-se então em SIRIUS como uma Agregação com característica de Relacionamento, não Composição.

Portanto, as situações usualmente consideradas como "Composição de Objetos" nos modelos em geral, em SIRIUS são consideradas Agregação. O termo "Composição" passa a ser utilizado de maneira restrita para caracterizar situações em que objetos são realmente "compostos por" outros, como quando descreve-se que um prédio é "composto por" salas e corredores (segundo [NAVATHE_94], composição de tipo "ownership semantics", com participação total, dependência existencial e não superposta).

A figura 2.4a) mostra o relacionamento parte é que existe entre um objeto composto e suas partes. É comum que as partes formem um conjunto de objetos que tem propriedades distintas, úteis para o gerenciamento da base. Assim, SIRIUS define o conceito de Colônias, como o "Conjunto de Objetos que Compõem um Objeto Composto segundo um determinado Aspecto". A idéia de Aspecto representa o fato de um objeto poder ser visto como composto de diferentes maneiras, disjuntas entre si. Por exemplo, uma placa de circuito impresso pode ser composta por uma coleção de componentes, ou pelos elementos que constituem o diagrama que a representa. 


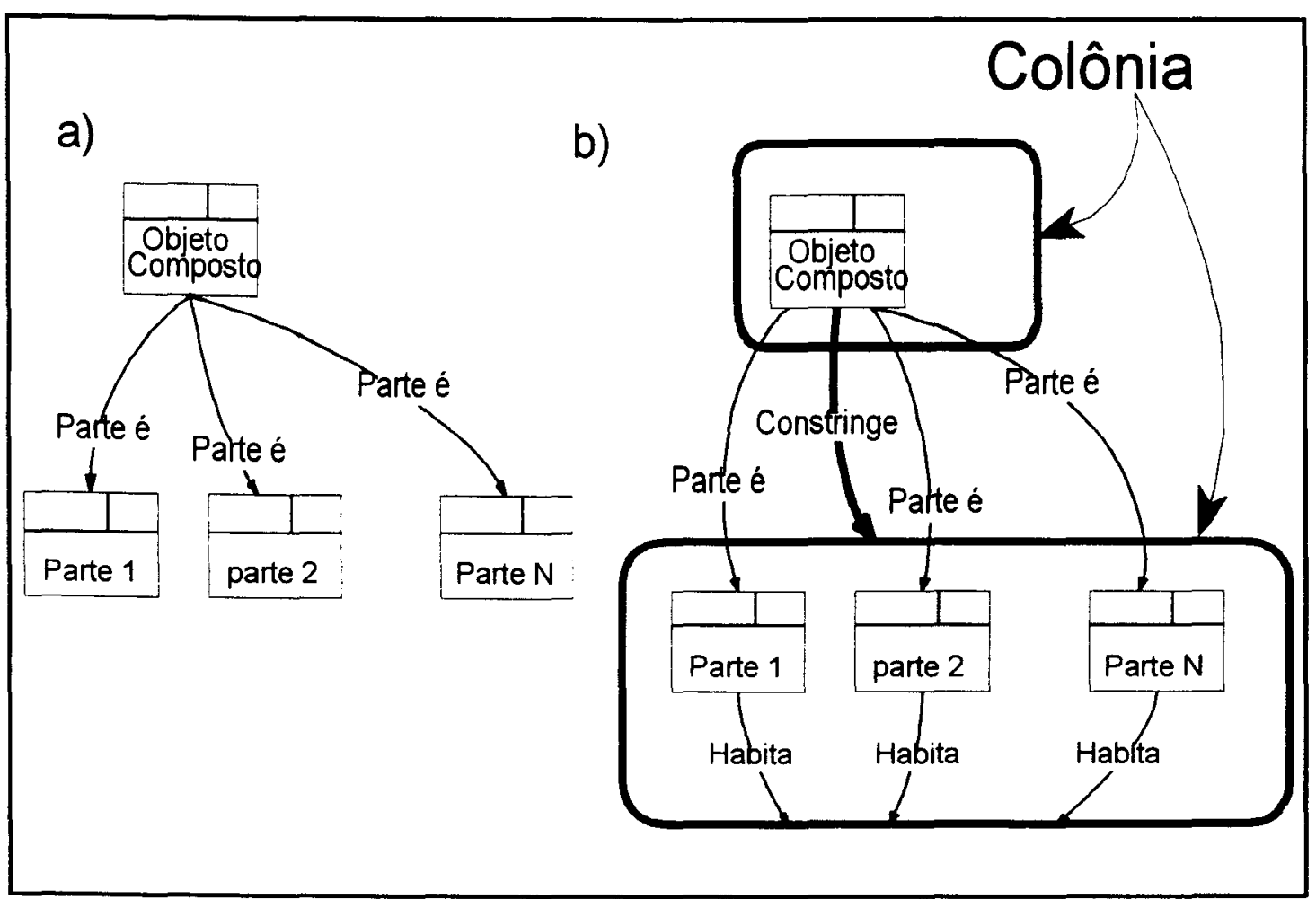

Figura 2.4: Objetos Compostos e Colônias no modelo SIRIUS.

A figura 2.4b) mostra os relacionamentos implícitos que existem entre os objetos envolvidos numa ocorrência de uma Abstração de Composição: um objeto composto constringe uma colônia, onde habitam os objetos objetos parte que são parte de aquele objeto composto. Colônias, como qualquer outro construtor do modelo, possuem um tipo.

Impõem-se a restrição de que todo objeto deve habitar uma colônia, e esse vínculo estabelece uma relação de dependência existêncial entre o objeto e a colônia em que ele habita: se a colônia deixar de existir, todos os objetos que a habitam deixam de existir também.

Por exemplo, pode-se estar interessado nas áreas construidas de um departamento, a qual é composta por salas e corredores; ou pode-se estar interessado em verificar o aspecto de recursos humanos desse departamento, o qual é composto por docentes e funcionários. 
Existe uma colônia de tipo denominado "Global", da qual pode haver apenas uma instância. A partir dela é definida a hierarquia de composição, a qual estabelece 0 contexto em que os objetos estão sendo compostos.

A Abstração de Composição [TrainA-94] [KIM-87] origina um conceito importante de SIRIUS: o de Objetos Compostos. Objetos podem ser fisicamente compostos por outros, utilizando uma construção semântica de alto nível, que permite agrupar objetos segundo diversos critérios definidos pelo usuário, permitindo um controle de acesso e recuperação de informações eficiente, baseado em critérios significativos para a aplicação. Fisicamente, objetos compostos são uma maneira de agrupar num mesmo registro objetos que tenham alta probabilidade de serem acessados conjuntamente. Portanto, todo objeto compõe fisicamente um objeto composto, o que representa o fato de que cada objeto é armazenado em apenas um local. A Base de Dados é considerada um objeto composto, que é composta (direta ou indiretamente) por todos os objetos nela armazenados. $O$ conjunto de objetos que compõem um objeto composto é denominado "Colônia de objetos", e diz-se que os objetos componentes a "habitam" e o objeto composto a constringe.

A estrutura de colônias cria uma hierarquia, em que o objeto que constringe a colônia do topo, denominada Colônia Global, corresponde à própria Base de Dados. Para que os objetos que habitam uma colônia possam ser acessados, a colônia precisa estar acessível. A operação que torna acessivel uma colônia é a operação de Controle de Acesso do gerenciador. Uma vez que a colônia esteja acessível segundo um determinado conjunto de operações (escrita, leitura, execução, etc.), os objetos que a habitam podem ser acessados livremente segundo esse conjunto.

Utilizando esse modelo, vem sendo implementado um Gerenciador de Objetos, denominado SIRIUS/GO, adotando a arquitetura Cliente/servidor, em plataformas UNIX e Windows. A implementação vem sendo efetuada em linguagem $\mathrm{C}++$, numa estrutura em camadas. O núcleo, já implementado, atua como um Servidor de Objetos para as camadas semânticas que implementam o modelo de dados. A menos da característica particular de propiciar um forte suporte para abstrações de 
objetos, o Núcleo é genérico e independente do modelo de dados adotado, podendo ser utilizado para suportar qualquer modelo de dados orientado a objetos que se pretenda implementar. As operações de "bufferização" de dados no disco e de controle de transações, envolvidas no método de gerenciamento de OIds, são totalmente desempenhadas pelo Núcleo.

\subsection{Conclusão.}

Neste capitulo foram apresentados gerenciadores de bases de dados orientados a objetos e seus respectivos sistemas, caracterizados segundo três abordagens: modelos relacionais estendidos, baseados em linguagem de programação e baseados em modelos de dados orientados a objetos.

A definição de objetos compostos, a grande capacidade semântica de representação dos dados e as novas necessidades das aplicações não convencionais, exigem dos gerenciadores de bases de dados orientados a objetos o tratamento de distribuição e concorrência de dados. Os problemas e soluções existentes, decorrentes do tratamento da distribuição e concorrência de dados, são tratados no capítulo 3. 


\section{Capítulo 3}

\section{Distribuição de Dados em Modelos Relacionais e Orientados a Objetos}

\subsection{Controle de Concorrência nos Modelos Convencionais.}

O desenvolvimento de bases de dados distribuídas surgiu da necessidade de se compartilhar os mesmos dados usados em locais distintos. Portanto, pressupõe-se a existência de um conjunto de unidades computacionais interligadas (nós), cada uma contendo um Sistema Gerenciador de Base de Dados, idênticas ou não, capazes de processar as transações locais (operações sobre o banco de dados local) e as transações globais que solicitam o acesso a dados em outros nós.

Por distribuição de dados entende-se: a replicação de duas ou mais cópias do mesmo arquivo alocadas em nós distintos; ou o particionamento de arquivos divididos em conjuntos disjuntos e alocados em nós específicos, sem duplicação da base de dados.

Existem diversas maneiras para conectar os nós, e o critério para a adoção de determinada

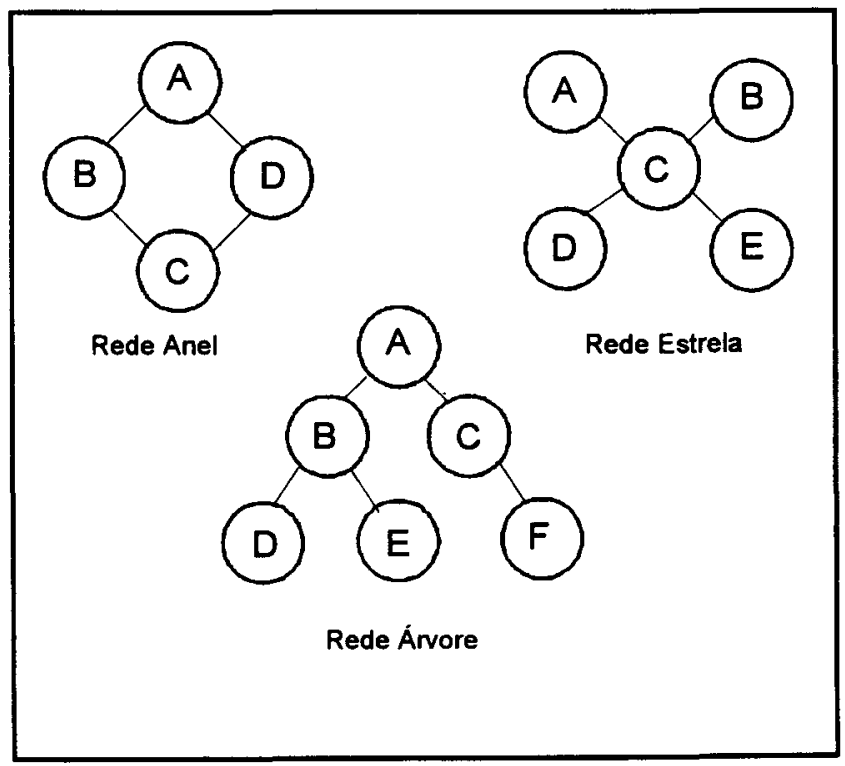

Figura 3.1: Formas de conectar os nós. 
configuração dependerá fundamentalmente da maneira com que se deseja distribuir os dados. A figura 3.1 apresenta formas básicas de conexão dos nós: estrela, anel e árvore.

A especificação de sistemas de base de dados tem se apoiado tradicionalmente na arquitetura centralizada. Nessa situação existe um único computador onde processam-se todas as transações solicitadas pelos vários usuários Tal arquitetura tem se mostrado eficiente para solucionar problemas de controle de segurança, integridade e de modo geral, o gerenciamento das operações sobre os dados.

Entretanto, a arquitetura centralizada não facilita a disponibilidade de dados ao usuário. Esse problema tende a se agravar quando um grande número de transações, de diversos usuários, solicita operações sobre a base de dados centralizada. Outro fator importante é que o custo de processamento da comunicação tem aumentado em relação ao custo dos processadores. Com isto, ao invés de transportarem-se os dados para um processador central, aloca-se a capacidade computacional para o nó que dispõe dos dados para a manipulação local.

Aliado a estas vantagens, uma base de dados distribuída pode ser projetada de modo a melhorar a disponibilidade de dados em cada local, através da replicação ou particionamento em cada nó, dos dados pertencentes ao sistema, permitindo assim o crescimento modular, através da adição de novos processadores e conseqüentemente novos blocos replicados ou particionados.

A arquitetura de um sistema distribuído traz muitas dificuldades para o desenvolvimento de um Sistema Gerenciador de Bancos de Dados Distribuídos (SGBDD) genérico. A figura 3.2 ilustra tal arquitetura. Para um controle de concorrência consistente é necessário o conhecimento do estado global do sistema [BERNSTEIN_80a], ou seja, é

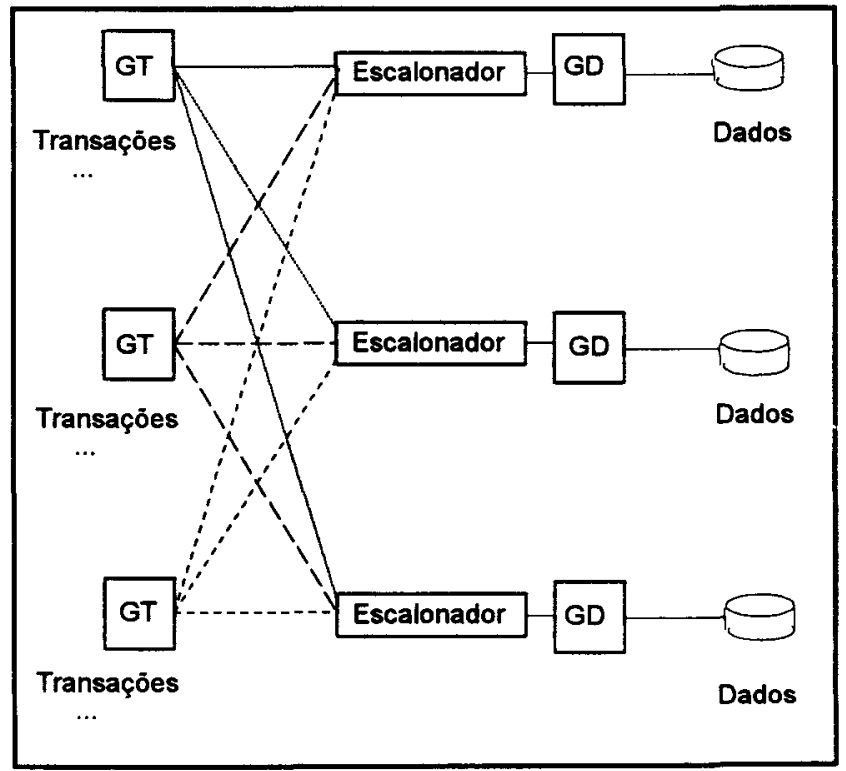

Figura 3.2: Arquitetura de um SGBDD. 
preciso conhecer não só a maneira da distribuição dos dados, mas também ter o controle e a informação sobre a situação geral do sistema. Portanto um SGBDD não pode ser entendido apenas como uma soma de Sistemas Gerenciadores de Base de Dados centralizados. Existe a necessidade de uma camada de software [BERNSTEIN_80b] que interligue os SGBD locais, possibilitando a implementação da Arquitetura Distribuída, que para o usuário pode ser vista como consistindo dos seguintes elementos:

- Transações: comunicam-se com os Gerenciadores de Transações.

- Gerenciadores de Transações (GT): supervisionam as transações submetidas, enviando-as para os devidos nós para execução.

- Gerenciadores de Dados (GD): operam sobre a base de dados de acordo com as especificações dos GT.

As solicitações de operações sobre a base de dados são feitas através de transações, as quais são conjuntos de comandos em uma linguagem de manipulação de dados. Os comandos são decodificados e executados pelo sistema gerenciador de base de dados. Tal conjunto deve ser iniciado e finalizado, respectivamente, pelos comandos COMEÇO-DE-TRANSAÇÃO e FIM-DE-TRANSAÇÃO. Cada transação T corresponde a uma seqüência de ações elementares sobre os objetos da base de dados. As transações devem ser codificadas de maneira que sempre sejam concluídas e ainda preservem a consistência da base de dados.

Dentre os problemas citados, o controle de concorrência tem merecido grande atenção na procura de soluções. Quando se têm transações que comutam, ou seja, o resultado final das transações independe da ordem pela qual são executadas, então dizemos que tais transações não são conflitantes. Entretanto, parte das transações em um ambiente distribuído não comutam. Com isto tem-se duas possibilidades:

- submetem-se as transações para execução em modo seqüencial, tendo-se um critério pré-estabelecido, como por exemplo data e local da transação, ou

-procura-se estabelecer um escalonamento único, composto de operações que fazem parte de cada transação, equivalendo a execução seqüencial das transações envolvidas. 
Casanova [CASANOVA_84] afirma que a "Teoria da Serialização se propõe a capturar de forma precisa quando, numa execução concorrente de um grupo de transações, cada uma delas é executada integralmente sem interferência".

\subsubsection{Aspectos da Teoria da Serialização.}

\section{Execução Serial}

Pode-se afirmar que o objetivo do gerenciamento da execução serial de transações concorrentes [CASANOVA_84] é garantir a chamada "equivalência computacional". Esse conceito determina que a execução $E$ de um conjunto de transações $T=\left\{T_{1}, T_{2}, \ldots T_{n}\right\}$, gerada por um escalonamento global $L$, é serial se e somente se:

- em cada escalonamento local de $L$, para cada par de transações $T_{i}$ e $T_{j}$ em $T$, ou todas as operações de $T_{i}$ precedem todos as operações de $T_{j}$ ou vice-versa;

- para cada par de transações $T_{i}$ e $T$, se as operações de $T$ precedem as operações de $T_{j}$ em um escalonamento local de $L$, então o mesmo é verdade para todos os outros escalonamentos de L.

\section{Equivalência de Execuções}

Além da Execução Serial, outro conceito importante é a Equivalência de Execuções [DATE_88]. Esse conceito estabelece que as execuções E1 e E2 que inicializam com um mesmo estado de dados são equivalentes, quando:

- E1 e E2 geram estados finais idênticos,

- em qualquer momento da transação $\mathrm{T}$ os dados lidos por E1 e E2 são os mesmos.

\section{Execuções Serializáveis}

Para que uma execução $\mathrm{E}$ de um conjunto $\mathrm{T}$, gerado por escalonamento $\mathrm{L}$, seja serializável, necessariamente E tem que ser equivalente a uma Execução Serial.

Com os conceitos de Execução Serial e Equivalência de Execuções, conclui-se que um método de controle de concorrência incluirá apenas transações que permitam Execuções Serializáveis. Isso equivale a dizer que, se execuções são serializáveis é 
porque são equivalentes a execuções seriais, e como as execuções seriais garantem naturalmente a consistência dos dados, conseqüentemente as execuções serializáveis herdarão tal propriedade.

Para encerrar as considerações sobre alguns aspectos da teoria da serialização apresenta-se, através de dois teoremas, condições suficientes, embora não necessárias, que garantem que diante de um conjunto de transações $T_{1} \ldots . . T_{n}$ ocorrerá a serialização.

\section{Teorema da Serialização}

$\begin{array}{llcr}\text { Há } & \text { duas } & \text { maneiras de } \\ \text { apresentar } & 0 & \text { Teorema da } \\ \text { Serialização } & \text { [BERNSTEIN_81] }\end{array}$ [CASANOVA_84]:

- a primeira é através da utilização de grafos. Considerando-se um escalonamento $\mathrm{L}$ sobre um conjunto de transações $T_{0}, T_{1}, T_{2}, \ldots T_{n}$, o grafo de

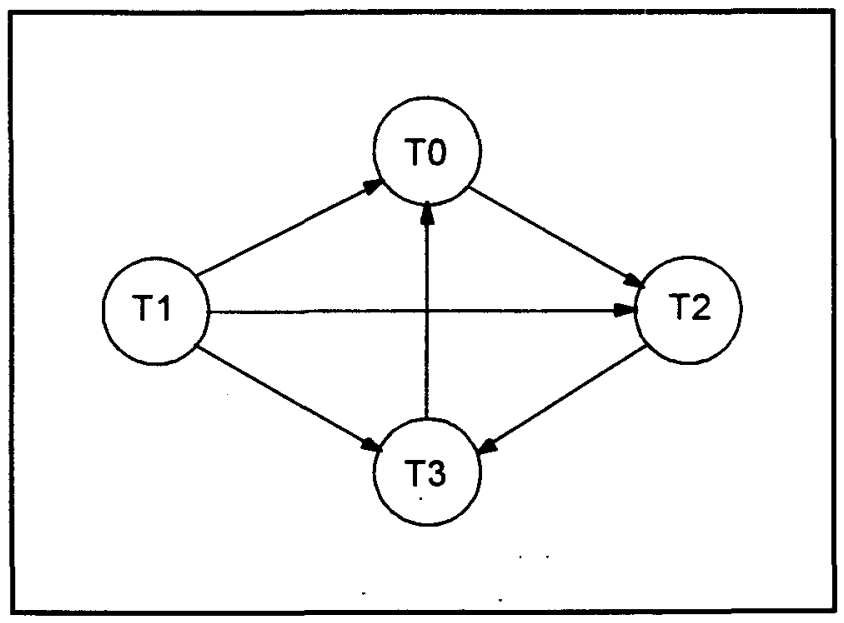

Figura 3.3 Grafo de serialização. serialização para $\mathrm{L}, \mathrm{GS}(\mathrm{L})$, teria as transações $T_{0}, T_{1}, \ldots, T_{n}$ como vértices do grafo sendo suas arestas as ligações entre os mesmos tal que, para algum objeto $\mathrm{x}$, exista:

read $(x)<$ write $(x)$

write $(x)<\operatorname{read}(x)$

write $(\mathrm{x})<$ write $(\mathrm{x})$

O símbolo < significa que a operação da esquerda precede à operação da direita.

Um possivel GS(L) é apresentado através da figura 3.3, onde descreve-se a dependência das transações.

Teorema 1: Se GL(L) é acíclico então L é serializável.

- a segunda, seja $T$ um conjunto de transações e $L$ um escalonamento global para T. Seja $L_{k}$ um escalonamento local de $L$. Duas operações elementares $O_{i}$ e $O_{j}$ de $L_{k}$ conflitam se, e somente se, elas agem sobre um mesmo objeto fisico e uma delas é uma operação de atualização. Operações conflitantes são importantes pois, se sua ordem 
relativa for alterada em $\mathrm{L}_{\mathrm{k}}$ o resultado final da execução poderá ser modificado. Tomese como exemplo as operações read(x) e write(x). Supondo-se que $\mathrm{L}_{\mathrm{k}}$ seja da forma ... $\operatorname{read}(x) \ldots . . w r i t e(x) \ldots . .$, então read(x) não lê o valor de $x$ que foi criado por write(x). Se a ordem das operações for trocada $e m L_{k}$ para ...write(x)...read(x)... e entre write(x) e $\operatorname{read}(x)$ não houver uma outra operação de atualização para $x$, read(x) passará agora a ler o valor criado por write(x), possivelmente (mas não necessariamente) alterando o estado final do banco de dados ou das operações resultantes. Definiremos ainda que $\mathrm{O}_{\mathrm{i}}$ precede com conflito $\mathrm{O}_{j}$ em $\mathrm{L}_{k}$ (denotado por $\mathrm{O}_{\mathrm{i}}<_{\mathrm{c}} \mathrm{O}_{j}$ ) se e somente se $\mathrm{O}_{\mathrm{i}}$ ocorre antes de $\mathrm{O}_{\mathrm{j}}$ em $\mathrm{L}_{\mathrm{k}}$ e $\mathrm{O}_{\mathrm{i}}$ e $\mathrm{O}_{\mathrm{j}}$ conflitam.

De posse desta relação entre ações elementares, define-se que $T_{i}$ precede por conflito $T_{j}$ em $L$ (denotado por $T_{i}<T_{j}$ ) se, e somente se, existir um escalonamento local $L_{k}$ de $L$ e operações $O$ i e $O_{j}$ em $L_{k}$ tais que $O_{i}$ e $O_{j}$ são operações de $T_{i}$ e $\mathrm{T}_{\mathrm{j}}$ respectivamente e $\mathrm{O}_{\mathrm{i}}<_{\mathrm{c}} \mathrm{O}_{j}$ A relação $<_{\mathrm{c}}$ é chamada de relação de precedência por conflito para $\mathrm{T}$ induzida por $\mathrm{L}$. Novamente quando mais de uma destas relações estiverem em jogo, subscritos serão usados para distinguí-las.

Teorema2: Seja $\mathrm{T}=\{\mathrm{T} 1, \ldots, \mathrm{Tm}\}$ um conjunto de transações e $\mathrm{E}$ uma execução de $\mathrm{T}$ modelada por um escalonamento global $\mathrm{L}=(\mathrm{L} 1, \ldots, \mathrm{Ln})$. Se a relação de precedência por conflito para $T$ induzida por $L$ for uma relação de ordem parcial, então $E$ é serializável.

\subsubsection{Escalonadores Baseados em Bloqueios.}

Estratégias de bloqueio ou exclusão mútua consistem em algoritmos e procedimentos que visam evitar a geração de escalonamentos incorretos, através do atraso de uma ou mais transações que tentam executar operações que causam conflito no acesso ao mesmo objeto [ESWARAN_76].

O objetivo dos algoritmos de bloqueio é permitir a ocorrência de execuções simultâneas apenas de operações não conflitantes, e serializar as operações conflitantes de modo a garantir a consistência dos objetos.

Geralmente pode-se detectar o conflito das operações através de uma matriz de $\mathrm{M}_{\mathrm{n} m}$ onde cada linha ou coluna representa uma determinada operação. Como exemplo, seja: 
$\mathrm{M}_{\mathrm{ij}}=1 \Rightarrow$ modos compatíveis

$\mathrm{M}_{\mathrm{ij}}=0 \Rightarrow$ não compatíveis

onde:

$\mathrm{M}_{11}=1$ operação ler-ler

$\mathrm{M}_{12}=0$ operação ler-gravar

$\mathrm{M}_{21}=0$ operação gravar-ler

$\mathrm{M}_{22}=0$ operação gravar-gravar

Dessa maneira, o escalonador permitiria apenas a execução simultânea da operação $\mathrm{M}_{11}$

No contexto de serializadores baseados em bloqueios, existem duas situações para os objetos:

- Bloqueado: apenas a transação que obtém o objeto pode acessá-lo;

- Livre: qualquer transação pode requisitar o objeto.

Além das operações Ler( $\mathrm{x})$ e Gravar( $\mathrm{x}$ ) tem-se:

-Bloq(x): bloqueia o objeto $\mathrm{x}$ para uma determinada transação;

$-\operatorname{Lib}(x)$ : libera o objeto $x$ para próximas transações.

Estas funções são controladas pelo gerente de bloqueio, o qual deve manter as informações sobre cada objeto bloqueado, qual transação o bloqueou e as transações seguintes que solicitam o objeto. Como exemplo, poderia ser utilizada uma relação com a tripla $(\mathrm{x}, \mathrm{T}, \mathrm{F})$, onde:

$\mathrm{x}$ : identificação do objeto $\mathrm{x}$

$T$ : transação que bloqueia $x$

F: fila de espera das transações que solicitam o objeto $\mathrm{x}$.

Para se ter uma noção mais concreta da situação de um objeto, no que se refere ao seu estado de bloqueio e liberação, tem-se abaixo as idéias fundamentais para uma possível implementação do Gerente de Bloqueio. 


\section{Operações do Gerente de Bloqueio}

OP1: - Inicializar a tabela de objetos bloqueados(zerar).

OP2: • Pesquisar a relação que armazene a tripla com o objeto x que foi solicitado pela transação T através da função

$B \operatorname{loq}(x)$ :

- Se encontrou, acrescente T no final da Fila F da tripla em questão;

- Senão, acrescente a tripla $(x, T, F)$ na tabela.

OP3: - Pesquisar a relaçãso que contenha a tripla com objeto x liberada pela transação T através da função $\operatorname{Lib}(x)$.

- Se encontrou:

- Se F vazia, retire a tripla da tabela para liberação de x;

-Se F não vazia retire $T$ da fila e libere x para $T$, substituindo a tripla $(x, T, F)$ por $\left(x^{\prime}, T^{\prime}, F\right)$.

-Senão:

- Ignore a função $\operatorname{Lib}(x)$.

\section{Bloqueios Mútuos (DeadLock) \\ $O$ método de bloqueios} [KORTH_82] [KORTH_83], em alguns casos, poderá impedir o término das transações. Isto acontece quando as esperas não são controladas.

Suponha a seqüência de transação $T_{1}, T_{2}$ e $T_{3}$ ilustrada com a figura 3.4 onde cada uma representa a leitura ou gravação de um determinado objeto.

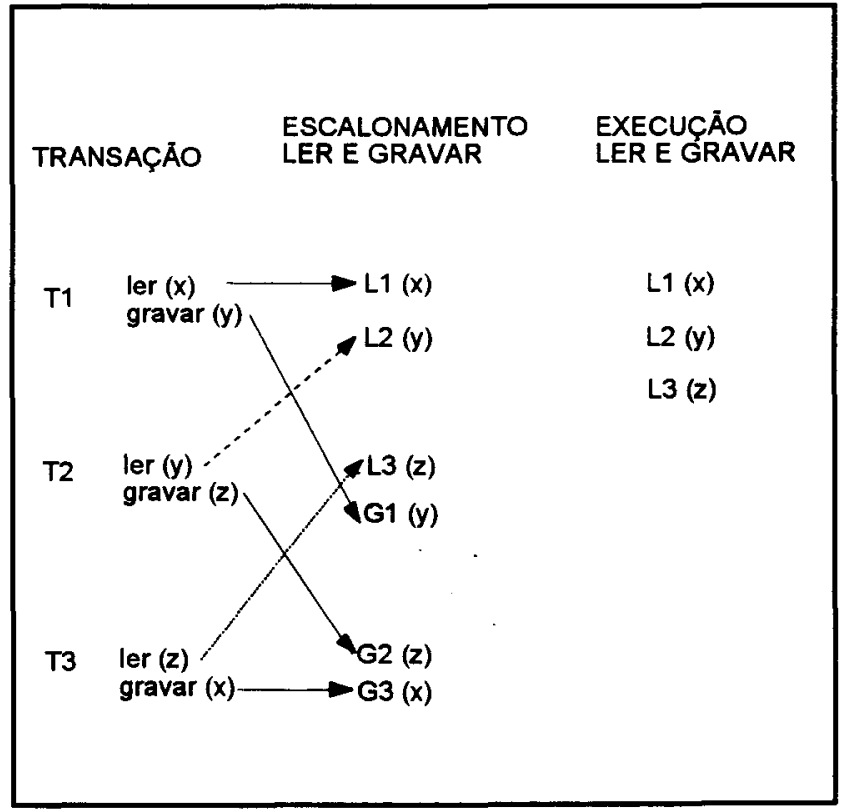

Figura3.4: Seqüência de transações T1,T2,T3.

G1(y) não escalonado pois conflita com L2(y)

G2(z) não escalonado pois conflita com L3(z)

$\mathrm{G} 3(\mathrm{x})$ não escalonado pois conflita com $\mathrm{L} 1(\mathrm{x})$ 
A probabilidade de bloqueios mútuos pode aumentar se:

- mais de uma transação é bloqueada esperando por um mesmo objeto.

- a execução de uma transação não pertencente a um determinado conjunto de transações, não permite a liberação de qualquer transação pertencente a esse conjunto.

Há duas maneiras para evitar o bloqueio mútuo:

- Deteção/Solução: periodicamente um processo independente I é disparado para detectar e solucionar bloqueios mútuos. Isto pode ser feito mantendo-se dígrafos de "deadlocks". Os vértices do dígrafo representam as transações e as arestas representam o relacionamento "esperando por". Se uma aresta é definida da transação Tí para $\mathrm{Tj}$ e se Ti está esperando por um bloqueio retido por $\mathrm{Tj}$,

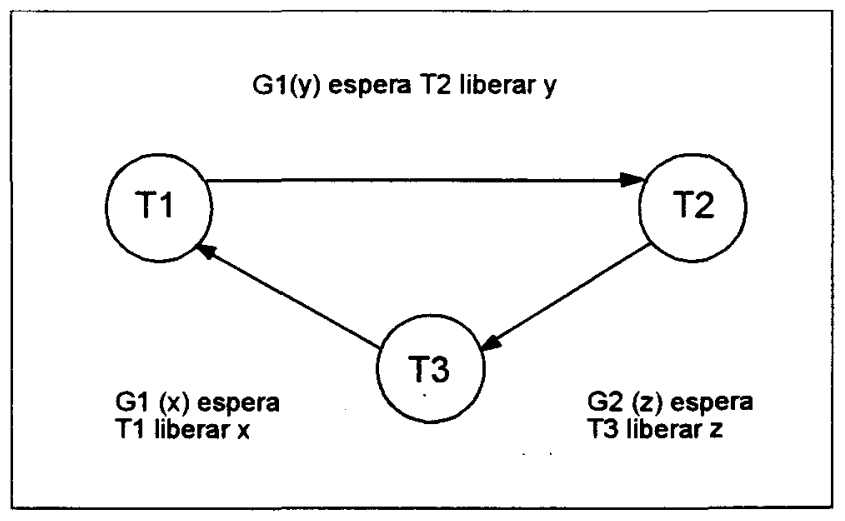

Figura3.5: Dígrafo para $\mathrm{T} 1, \mathrm{~T} 2 \mathrm{e} \mathrm{T} 3$. configura-se então um bloqueio mútuo. Portanto a fase de detecção limita-se a verificar se o dígrafo é acíclico ou não. A figura 3.5 ilustra tal situação.

A fase de solução consiste em retirar transações, de forma que o dígrafo torne-se acíclico. Existem vários critérios para escolher a transação a ser retirada do dígrafo: uma possibilidade consiste na eliminação do arco correspondente a transação mais recente de um ciclo do sistema.

- Prevenção: um método satisfatório para previnir o bloqueio mútuo considera que deva ser realizado um teste para cada transação $\mathrm{Ti}$, que solicita um novo objeto ocasionalmente já bloqueado por $\mathrm{T} j$. Se Ti passar pelo teste, então a transação pode ser acrescentada na fila da tripla de $\mathrm{x}$, caso contrário cancela-se Ti ou Tj. Quando o critério adotado para escolha da transação cancelada for Ti então o método é chamado de não preemptivo, se for $\mathrm{T} j$, o método é preemptivo.

O objetivo da prevenção é garantir que ao inserir-se Ti na fila da tripla(x,T,F) da tabela de espera de transações, nunca ocorra a formação de bloqueios mútuos. Isso corresponde ao fato de que no dígrafo de espera, cada nova inserção não cria ciclos. 


\section{Método de Bloqueio em Duas Fases (2PL)}

Como qualquer método baseado em bloqueio, o 2PL [BERNSTEIN_81] deve garantir que todas as transações iniciadas em um escalonamento $\mathrm{E}$ sejam concluídas (como já discutiu-se anteriormente) e que E seja também serializável.

Apenas o uso de bloqueios não garante a serialização. Por exemplo:

- Bloquear $\mathrm{x}$ antes de acessá-lo.

- Liberar x imediatamente após acessá-lo.

Considerando esses dois critérios obter-se-ia qualquer intercalação entre as operações das transações e não necessariamente uma serialização

Para garantir a serialização é necessário que existam duas fases:

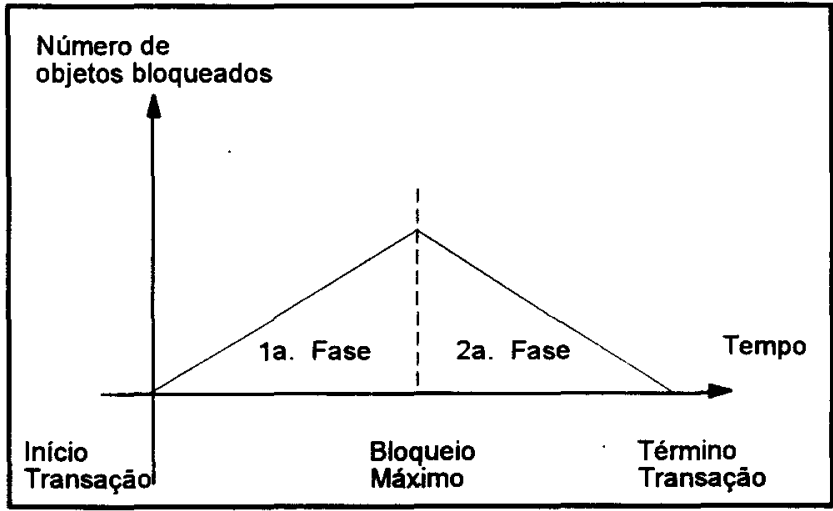

Figura3.6: Método de bloqueio - 2PL.

- a transação deve

bloquear cada objeto antes de acessá-lo e liberar todos os objetos bloqueados antes de sua finalização.

- a transação não pode bloquear novos objetos depois da liberação de algum objeto anteriormente bloqueado.

Pode-se ilustrar estas fases através de um gráfico apresentado na figura 3.6. A ordem da serialização é obtida em função da seqüência pela qual as transações solicitam e obtêm os bloqueios sobre os objetos, que serão então bloqueados até o fim da primeira fase. Após o bloqueio máximo, os objetos começam a ser liberados até atingir o término da transação.

\section{Métodos de Bloqueio num Ambiente Distribuído}

Num ambiente distribuido, apresenta-se um problema adicional que é a localização da tabela de bloqueios ao longo da rede, dificultando a deteção de bloqueios mútuos globais [DATE_88].

Existem três variações do método para o ambiente distribuído:

-Básica: considera que a tabela de bloqueios é distribuída para cada nó, 
juntamente com os dados. Esta variação caracteriza-se pela dificuldade de deteção dos bloqueios mútuos. Uma possível implementação deveria conter os seguintes aspectos:

a) para cada operação sobre o objeto $x$, realizada em um determinado nó, um bloqueio $B \operatorname{loq}(x)$ deve ser criado imediatamente antes.

b) imediatamente após a mensagem de "Prepare-se" recebida pelo nó remoto para a atualização de um determinado objeto $\mathrm{x}$, na primeira fase do bloqueio 2PL, deve ser criado um bloqueio $\operatorname{Bloq}(\mathrm{x})$.

c) imediatamente após a mensagem de "Prepare-se" recebida pelo nó remoto, na primeira fase do bloqueio $2 \mathrm{PL}$, se o objeto $\mathrm{x}$ não foi alterado, uma liberação Lib(x) deve ser criada.

d) após receber a mensagem "Confirme", ou seja, as modificações já estão instaladas no banco de dados, ou após uma mensagem "Cancele", uma liberação Lib(x) deve ser criada.

Este método não pressupõe um controle de cópias. Se os objetos bloqueados se constituem em cópias, o gerente de transações é que deverá solicitar as respectivas atualizações, ficando desse modo transparente ao controle de concorrência.

-Implementação por Cópias Primárias: na tentativa de diminuir o desperdício dos recursos locais pelo bloqueio realizado em todas as cópias de um mesmo objeto lógico, pode ser utilizado o recurso de manter-se cópias primárias. Este recurso consiste num conjunto de objetos fisicos segmentados, onde cada segmento contém cópias do mesmo dado, sendo que um único objeto fisico é o representante do referido segmento denominado de cópia primária $(x p)$. Antes de qualquer operação sobre algum objeto pertencente ao segmento, a cópia primária correspondente deverá ser bloqueada. Ao nível de implementação os mesmos aspectos da variação Básica devem ser seguidos, com $\mathrm{o}$ incremento de mensagens para que, a cada transação $\mathrm{T}$ que solicita um objeto $\mathrm{x}$, envie-se para o nó que detém a cópia primária um bloqueio de $x p$ para T. Caso obtenha sucesso no bloqueio, o nó detentor de $x p$, envia a resposta confirmando o bloqueio.

Embora exista uma tendência a diminuir o processamento local de cada nó, em função da diminuição do número de bloqueios, a cópia primária exigirá mensagens adicionais gerando um aumento do tráfego na rede.

Este problema pode ser contornado variando a granularidade na formação de 
cada objeto lógico, ou seja, reagrupar objetos fisicos em unidades lógicas que representarão um grupo, e por sua vez a respectiva cópia primária, diminuindo-se o número de mensagens enviadas. A granularidade tem um limite: não se pode atribuir a um objeto $\mathrm{x}$ todo o banco de dados.

A deteção dos bloqueios mútuos é dificil de ser realizada, devido a distribuição das cópias primárias pelos diversos nós.

- Implementação por Bloqueio Centralizado; as duas propostas anteriores dificultam a deteção de bloqueios mútuos pois necessitam consultar todos os nós.

Uma outra solução consiste em centralizar a tabela de bloqueios em um nó coordenador da rede. Para cada objeto a ser acessado é necessário consultar o referido nó para obter resposta sobre o estado do objeto requisitado. Dessa maneira, a deteção de bloqueios mútuos é imediata, bastando consultar o nó coordenador.

Entretanto, tal proposta gera uma dependência muito grande da base de dados em relação ao nó coordenador, acarretando dois problemas: sobrecarrega uma região localizada da rede com mensagens adicionais; cancelamento de todas as transações, quando o nó coordenador em questão não puder ser contactado, exigindo assim que um outro nó seja eleito para coordenador.

\section{Bloqueios Mútuos no Caso Distribuído}

No caso distribuído os problemas são semelhantes ao centralizado, adicionando porém, um outro elemento na geração de prioridades, pois transações podem ter a mesma prioridade, mas submetidas em nós distintos. A relação $L(n, t)$ que identifica as transações submetidas em nós distintos soluciona o impasse, onde:

n: identificação do nó

t: data/hora em que a transação foi gerada

A deteção/solução de bloqueios mútuos, no caso da implementação básica e cópia primária, é dificil de ser realizada, pois não se tem garantia que a união dos subgrafos acíclicos dos diversos nós, resulte um grafo geral acíclico.

Uma solução consiste em considerar subgrafos de espera local e grafo de espera global. Periodicamente, cada nó envia seu subgrafo local a um determinado nó central que construirá o grafo global, utilizando os mesmos critérios do caso centralizado. Esta solução caracteriza-se por resolver bloqueios de maneira mais localizada. 


\subsubsection{Escalonadores Baseados em Pré-Ordenação.}

No controle de concorrência por Pré-Ordenação [BERNSTEI__80a] [BERNSTEIN_81] [CASANOVA_84], a ordem das operações é estabelecida antes das transações serem submetidas. $O$ protocolo básico, em linha geral, limita-se a garantir duas condições:

a) cada transação, antes de ser iniciada, deve receber uma "senha", exclusiva ao longo da rede, sem o conhecimento do usuário.

b) em cada nó deve haver um tratamento para as transações conflitantes, tendo como critério a avaliação das senhas de cada transação.

$\mathrm{O}$ protocolo de Pré-Ordenação opera de maneira oposta ao de Bloqueio. Na situação de Pré-Ordenação a geração e atribuição das senhas às transações impõe uma ordem antes das transações serem submetidas. Já no caso de Bloqueio, as transações são submetidas e a serialização ocorre quando as transações solicitam determinados objetos ou recursos. Isto impõe uma diferença fundamental entre as duas filosofias de controle de concorrência, oferecendo assim opções para implementação dos mecanismos de controle de concorrência, de acordo com as exigências do ambiente em que se insere a distribuição dos dados. Haverá situações em que as características das transações determinarão qual mecanismo usar: bloqueio ou pré-ordenação.

\section{Implementação Básica}

Como foi dito anteriormente, o protocolo de pré-ordenação tem duas caracteristicas:

- geração das senhas;

- tratamento das senhas em cada nó para criação do escalonamento.

A solução do tratamento das senhas pode ser feita através da atribuição das seguintes variáveis, para cada objeto fisico do sistema:

$\operatorname{SEUREAD}(\mathrm{x})$ : Senha da última operação de leitura do objeto $\mathrm{x}$.

SEUWRITE(x): Senha da última operação de escrita do objeto $x$. 
Com estas duas variáveis, um algoritmo possível para controle das senhas, teria que tratar as seguintes situações:

- Se for uma operação de leitura $R(x)$ com número de senha $=\gamma$ então:

- Se $\gamma$ maior que SEUWRITE $(x)$ para o objeto $x$

- então processe a leitura e SEUWRITE $(x)=\gamma$

- senão rejeite a leitura e submeta novamente a transação.

- Se for uma operação de escrita $W(x)$ com número de senha $=\gamma$ então:

- Se $\gamma$ maior que SEUWRITE $(x)$ e SEUREAD(x)

- então processe a escrita e SEUWRITE $(x)=\gamma$

- senão rejeite a escrita e submeta novamente a transação.

-As transações novamente submetidas recebem um número de senha maior que a anterior.

Entretanto esta implementação básica apresenta três problemas:

- armazenamento das variáveis SEUREAD(x) e SEUWRITE(x) para cada objeto $\mathrm{x}$ do sistema;

- interação com o protocolo bifásico de comunicação (2PL) responsável pelas operações de atualização dos demais nós da rede;

- as transações submetidas novamente podem entrar em reinícios cíclicos, e nunca serem processadas.

Uma possível solução para evitar-se a atribuição das variáveis $\operatorname{SEUREAD(x)~e~}$ SEUWRITE( $\mathrm{x}$ ), para cada objeto consiste em manter-se duas tabelas com uma quantidade limitada dos valores de $\operatorname{SEUREAD}(\mathrm{x})$ e $\operatorname{SEUWRITE}(\mathrm{x})$, desconsiderando os valores mais antigos. Os mais recentes deverão ser armazenados em variáveis auxiliares. Assim, para cada objeto ter-se-iam as seguintes estruturas de dados:

- TabRead: tuplas da forma $(x, \operatorname{SEUREAD}(\mathrm{x}))$;

- TabWrite: tuplas da forma(x,SEUWRITE(x));

- MaxRead: maior valor de $\operatorname{SEUREAD(x)}$ que foi eliminado da tabela TabRead;

- MaxWrite: maior valor de SEUWRITE(x) que foi eliminado da talela TabWrite.

Estas tabelas funcionam através da substituição de tuplas, caso operem sobre um mesmo objeto. Se a tabela estiver cheia para inserção de uma nova tupla, retirar-se-á a 
tupla mais antiga e sua senha será comparada com MaxRead ou MaxWrite para possível atualização.

Como exemplo, seja uma transação que solicite do objeto $\mathrm{x}$ uma leitura. Logo, a tupla $(\mathrm{x}, \mathrm{w})$ terá que ser adicionada à tabela TabRead. Caso já exista uma tupla $(\mathrm{x}, \mathrm{u})$, esta será substituída por $(\mathrm{x}, \mathrm{w})$.

Se a tabela estiver completa, uma tupla(z,r) será selecionada segundo um critério pré-estabelecido, para ser retirada e sua senha r será comparada com MaxRead para atualização, se necessário.

Isto posto, quando solicita-se a consulta do valor da senha de determinado objeto, pesquisa-se inicialmente a tabela de leitura ou escrita. Existindo uma tupla $(x, t)$ que satisfaça à pesquisa, $t$ é tomado como senha. Caso não exista o objeto em questão, então MaxRead ou MaxWrite é tomado como valor da senha, que corresponderá sempre a um valor igual ou maior ao da verdadeira senha que se deseja encontrar.

Para o segundo problema, no qual o protocolo bifásico é utilizado para atualização dos demais nós da rede, dois tipos de mensagens são exigidos: Prepare e Confirme.

No início do protocolo, mensagens de "Prepare" são enviadas aos nós. Caso a transação seja aceita, as mensagens de "Confirme" são enviadas liberando as atualizações. Dessa maneira, o tempo exato para avaliação da transação será no recebimento da mensagem Prepare e não no início das atualizações propriamente ditas. Assim o mecanismo de controle de concorrência deverá avaliar as transações na medida em que receber mensagens Prepare, e garantir que nenhuma transação de leitura ou escrita será efetuada no objeto que está sendo atualizado pelo protocolo bifásico. Caso contrário, ocorrerá inconsistência dos dados. Uma das possíveis maneiras de implementar a idéia anteriormente citada é fazer com que as operações de leitura e escrita, pertencentes a transação em fase de atualização pelo protocolo bifásico, recebam valores infinitos de senha, provocando o reinício de todas as outras transações que solicitem o mesmo objeto. Terminada a operação de atualização, as senhas voltam a ter seus valores verdadeiros. Esta solução pressupõe um bloqueio para garantir a consistência dos dados, no momento da atualização dos diversos nós.

Com relação ao terceiro problema, uma transação pode não terminar se for 
reiniciada ciclicamente. Isto pode acontecer quando o acréscimo do tempo para atribuição das senhas gerar um sincronismo entre as transações conflitantes causando um reinício mútuo entre as mesmas. Por exemplo, seja a seqüência de transações $\mathrm{T}=\left\{\mathrm{T}_{0}, \mathrm{~T}_{1}, \mathrm{~T}_{2}, \ldots \ldots, \mathrm{T}_{\mathrm{m}-1}, \mathrm{~T}_{\mathrm{m}}\right\}$ de tal maneira que Ti força o reinício de $\mathrm{Ti}+1$.

Se o incremento do tempo da senha for constante, então tem-se a repetição da situação indefinidamente. Pode-se minimizar 0 reinício das transações utilizando incrementos aleatórios para as senhas. Esta solução não evita completamente o reinício cíclico, entretanto diminui sua probabilidade de ocorrência.

\section{Implementação Conservativa}

A implementação conservativa [CERI_84] utiliza filas para leitura e escrita em cada nó i pertencente a rede. $\mathrm{O}$ controle de concorrência é feito localmente, onde o gerente de transações (GT), é encarregado de enviar os subcomandos para as filas acima mencionadas.

FilaRead(GT): fila com subcomandos enviados por GT para um determinado nó para leitura na respectiva base de dados.

FilaWrite(GT): fila com subcomandos enviados por GT para um determinado nó que atualizam a respectiva base de dados.

Cada elemento da fila contém a especificação da senha. O mecanismo para controle de concorrência se limita portanto a:

- esperar que todas as filas contenham algum comando;

- selecionar o subcomando com a menor senha e processá-lo.

Com isto, a implementação conservativa elimina o problema do protocolo bifásico que ocorre na implementação básica, e nunca força o reinício das transações. Entretanto, exigirá uma comunicação mais intensa entre os gerentes de transações de cada nó para selecionar o subcomando de menor senha e durante esta escolha, as transações ficam bloqueadas.

Caso um nó i não receba transações, o protocolo pode ficar paralizado, pois o mecanismo de controle de concorrência pressupõe subcomandos na fila referente ao nó i. Se a fila permanecer vazia, ocorrerá um bloqueio perpétuo

Este problema pode ser contornado, fazendo-se com que cada gerente de transação envie periodicamente mensagens de controle a todos os nós com que se 
comunica, contendo a senha corrente, mesmo que os nós não recebam subcomandos das transações.

Dessa maneira, é possivel fazer com que não haja bloqueio perpétuo. Entretanto, devido à comunicação adicional entre os gerentes e os nós, torna-se proibitiva tal implementação num ambiente de grande porte.

\section{Implementação Baseada em Versões Múltiplas}

O objetivo da implementação baseada em Versões Múltiplas [CERI_84] [DATE_88] [CASANOVA_84] é manter um histórico com todas as versões de atualizações dos objetos, juntamente com seus respectivos valores de senha.

Pretende-se com isto minimizar o reinício das transações, na medida em que dispõe-se de um histórico do objeto. Quanto maior o número de versões registradas, menor será o índice de rejeição das transações de escrita e praticamente nulo o reinício das transações de leitura.

Estrutura de Dados para implementação de versões múltiplas:

SeqRead(x): seqüência de todas as senhas das ações de leitura para o objeto $\mathrm{x}$.

Versões $(\mathrm{x})$ : seqüência contendo todas as versões de $\mathrm{x}$, com tuplas da forma $(\mathrm{s}, \mathrm{V})$; onde $\mathrm{s}$ representa a senha $\mathrm{e} \mathrm{V}$ a versão de $\mathrm{x}$.

Mecanismo de Controle de Concorrência para versões múltiplas:

a) Seja $R(x)$ uma leitura com senha $r$. Selecione a tupla(s,V) onde sé a maior senha em Versões $(x)$, entretanto menor que $r$ :

-Vé o valor de x para $R(x)$;

-Insere-se $r$ em SeqRead(x), respeitando a ordenação.

b) Seja $W(x)$ uma escrita com senha w, e ainda $t(x)$ a menor senha em Versões $(x)$ maior que w:

-Se existe alguma versão de x e alguma senha $r$ em SeqRead(x), tal que $w<r<t(x)$,

então a operação gerará inconsistência e terá que ser rejeitada; -caso contrário, processe a atualização, criando um novo par $(w, V)$ em $\operatorname{Versões}(x)$.

Esta implementação, poderá utilizar uma quantidade de memória adicional que a tornará proibitiva. Pode-se atenuar esta sobregarga, mantendo cópias apenas das 
últimas versões criadas, limitando assim o tamanho das tabelas $\operatorname{SeqRead}(\mathrm{x})$ e Versões(x) e permitindo, a um custo plausível, diminuir o volume das transações reiniciadas.

Nesta implementação o problema com o protocolo bifásico, ocorrerá da mesma forma que na implementação básica, sendo resolvido de forma semelhante.

\subsubsection{Síntese dos modelos de concorrência de dados convencionais.}

Um quadro geral, comparando os métodos de gerenciamento e controle de concorrência extraído de [CASANOVA_84], é apresentado através da figura 3.7. Nesta figura mostram-se todos os métodos, comparados em função da Estrutura de Dados, Mensagens Adicionais, Existência de Cópias e Problemas de Conclusão da Transação.

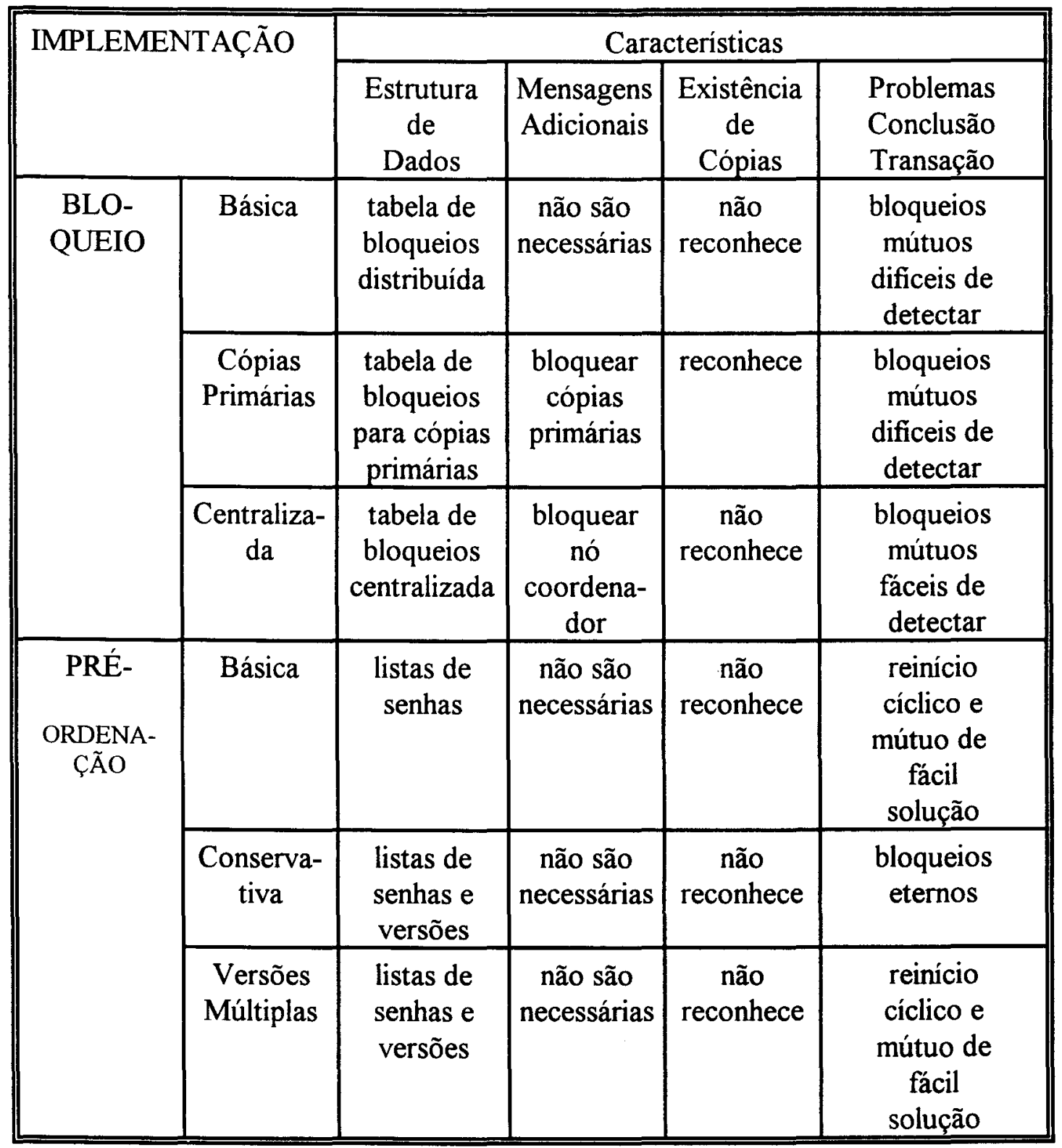

Fig.3.7: Quadro comparativo dos Mecanismos de Controle de Concorrência 
É muito dificil comparar as várias formas de controle de concorrência apresentadas, sem especificar o ambiente e as características da base de dados em que se insere tal controle de concorrência. Entretanto pode-se levantar alguns parâmetros que auxiliam na decisão, tais como:

-custo adicional de comunicação: número de mensagens necessárias utilizadas

para o controle de concorrência;

-custo adicional de processamento local: tempo gasto em processamento para 0 controle de concorrência;

-custo adicional de processamento de transações: tempo que uma transação é bloqueada ou número de vezes que é reiniciada.

Existem duas abordagens para analisar os mecanismos de controle de concorrência:

-pessimista: alto nível de transações conflitantes;

-otimista: baixo nível de transações conflitantes.

Numa abordagem pessimista, considera-se que a porcentagem de conflitos é muito alta. O objetivo então é diminuir o custo para resolver tais conflitos. Deve-se escolher um mecanismo que minimize as transações reiniciadas. Na abordagem otimista, considera-se uma taxa pequena de conflitos, e deve-se portanto escolher um mecanismo que minimize o custo para gerenciar ou prever tais conflitos.

No caso de pré-ordenação tem-se duas opções: uma é a conservativa, e nunca reinicia as transações, mas em contrapartida gera um volume considerável de mensagens adicionais; a outra é a de versões múltiplas, que utiliza uma estrutura de dados que ocupará mais memória.

No caso do bloqueio em duas fases, o protocolo centralizado é o mais indicado pois num cenário pessimista bloqueios mútuos serão muito freqüentes, e a forma centralizada permite fácil deteção/solução dos bloqueios mútuos.

No caso otimista, de modo geral, as opções do mecanismo de controle de concorrência se igualam na eficiência, pois a percentagem de ocorrência de conflitos é muito baixa. Dessa maneira, quando ocorre o conflito, o tempo que o sistema gastará para atender tal conflito, será pequeno em relação as operações realizadas sobre a base de dados. 


\subsection{Modelo de Autorização em Base de Dados Orientadas a Objetos.}

O mecanismo de autorização é um dos importantes controles de sistemas de bases de dados convencionais. Os modelos de autorização que suportam as bases de dados existentes convencionais [FERNANDEZ 75] estão intimamente ligados aos modelos relacional, hierárquico ou de redes. Estes modelos assumem que a unidade de autorização é uma relação (tabela), ou um atributo da relação (campo). Isto é insuficiente quando necessita-se controlar as abstrações dos conceitos orientados a objetos, tais como hierarquia de classes, métodos e a composição de objetos.

O modelo de autorização proposto por Rabitti, [RABITTI_88] tem como pressuposto fundamental o conceito de autorização implícita já apresentada e formalizada por Fernandez, [FERNANDEZ_75] para os modelos de dados convencionais. A concepção convencional de autorização implícita é baseada em deduções e combinações dos poderes dos usuários para agirem sobre uma determinadade base de dados, a partir das definições iniciais de tipos de usuários e unidades de base ou subbases de dados acessiveis. A proposta de Rabitti extende o conceito de autorização implícita para os conceitos de modelagem de dados orientada a objetos introduzindo três níveis para autorização: usuários (um usuário ou grupo de usuários); tipo de autorização(escrita, leitura, criação) e objetos ( objetos simples, grupos de objetos ou bases de dados). Dessa maneira o conceito de autorização é analisado em três dimensões: autorização para usuários, tipos de autorizações e autorizações para objetos. Naturalmente, como essa extensão pressupõe uma base de dados com um poder semântico maior, a autorização implícita torna-se mais complexa.

Para controlar de maneira mais precisa as autorizações implícitas decorrentes da hierarquia de composição de objetos em uma base de dados orientadas a objetos, Won Kim [KIM_9la] apresenta os mecanismos de autorização apresentados em [RABITTI_88]. Entre outros aspectos importantes, pode-se destacar a substituição do conceito de tipos de autorização pelos conceitos de "autorização forte(strong) e fraca(weak)" e "autorização positiva(positive) e negativa(negative)". Os principais conceitos do modelo de autorização para a base de dados e seus respectivos formalismos, proposto por Won Kim, são apresentados a seguir. 


\subsubsection{Definição dos Conceitos para o Modelo de Autorização.}

\section{Autorização Explícita}

A autorização explícita é definida como uma tupla, autorização $<u, 0, a>$ onde:

$u \in U$, onde $U=\left\{U_{1}, U_{2}, \ldots, U_{n}\right\}$ é a coleção de usuários do sistema; $o \in O$, onde $O=\left\{O_{1}, O_{2}, \ldots, O_{n}\right\}$ é a coleção de objetos do sistema; $a \in A$, onde $A=\left\{A_{1}, A_{2}, \ldots, A_{n}\right\}$ é a coleção de tipos de autorização.

A função $\mathscr{F}$ é definida para determinar se a autorização $<u, 0, a>$ é verdadeira ou falsa:

\section{F: U X O XA --> \{True, False\}.}

Dada uma determinada tupla $\langle\boldsymbol{u}, \boldsymbol{o}, \boldsymbol{a}\rangle$, se $\mathscr{F}(\boldsymbol{u}, \boldsymbol{o}, \boldsymbol{a})=$ True então:

o usuário u tem autorização do tipo a sobre o objeto $\mathbf{0}$.

\section{Autorização Implícita}

O conceito de autorização implícita é fundamental no modelo de autorização para uma base de dados orientadas a objetos. $\mathrm{Na}$ medida em que a autorização $<\mathrm{u}, \mathrm{o}, \mathrm{a}>$ está explicitamente definida em vários nós da

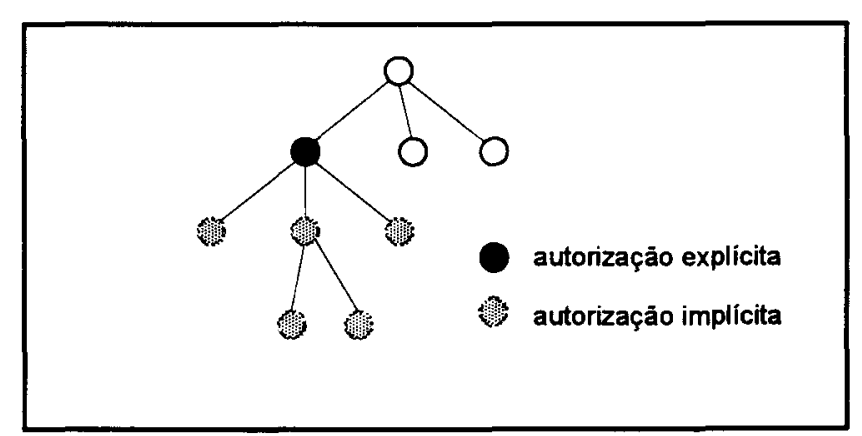

Figura 3.8: Autorização Explícita e Autorizações Implicitas decorrentes.

hierarquia de classe, então pode-se

utilizar o conceito de autorização implícita para controlar as operações em nós dos níveis hierárquicos inferiores. Se em um determinado nó $\alpha$ do nível hierárquico for definido $\mathscr{F}(\mathrm{u} 1, \mathrm{o} 1, \mathrm{a} 1)$, em outro nó $\beta$ for definido $\mathscr{F}(\mathrm{u} 2, \mathrm{o} 2, \mathrm{a} 2)$ e ainda, se $\alpha$ e $\beta$ mantém um vínculo entre si na hierarquia de composição da base de dados então, baseado em regras deduzidas a partir da hierarquia de composição, os possíveis conflitos entre autorizações são tratados de modo a permitir a propagação de autorizações não conflitantes nos mais variados níveis da hierarquia. A figura 3.8 ilustra o conceito de autorização explícita e as suas respectivas autorizações implícitas decorrentes. 


\section{Autorização Positiva e Negativa}

0 mecanismo de autorização assume um valor positivo quando eventualmente um usuário pode acessar um determinado objeto. $\mathrm{O}$ conceito de autorização negativa é complementar a autorização positiva. Quando um determinado usuário ul tem acesso negado para um determinado objeto ol, pelo fato de outro usuário u2 ter autorização sobre o objeto ol, então diz-se que o usuário ul tem autorização negativa sobre o objeto 01.

\section{Autorização Forte e Fraca}

$\mathrm{O}$ conceito de autorização forte significa que num contexto de uma rede hierárquica nenhuma outra autorização pode sobrepor uma autorização forte já definida e suas autorizações implícitas decorrentes. A autorização fraca, ao contrário da forte, pode ser substituída por uma outra autorização fraca ou uma autorização forte. Isto permite afirmar que uma autorização implícita ou explícita fraca pode ser substituída por uma autorização explícita forte.

A combinação das autorizações Explícitas/Implícitas, Positiva/Negativa e Forte/Fraca permite a obtenção de uma semântica de acesso no contexto de uma rede hierárquica. Cabe observar que quanto mais autorizações fracas houverem na hierarquia, maior $o$ poder de alteração do sistema do controle de autorização. Quanto maior o número de autorizações fortes,

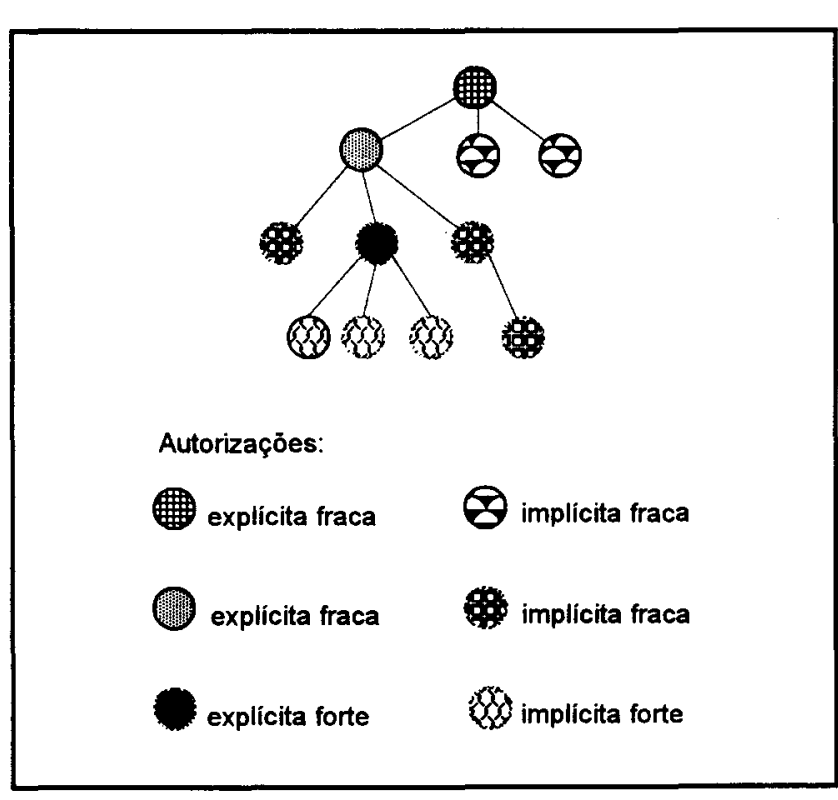

Figura 3.9: Combinações das autorizações . menor será o poder de alteração do sistema de controle de autorização, pois uma autorização forte, não pode ser substituída nem por outra autorização forte. Para sobrepor uma autorização forte é necessário primeiro removê-la. A figura 3.9 ilustra uma hierarquia com as combinações das autorizações sendo utilizadas. 


\subsubsection{Regras de Derivação.}

\section{Para cada elemento a} ser gerenciado pela autorização (usuário, objeto e tipo de autorização) existe uma semântica de derivação que pode ser traduzida num grafo acíclico direcionado, de acordo com o poder de atuação de cada nó. No caso de usuários, um grafo pode ser construído ligando-se um nó origem, no qual representa-se o poder de atuação de um tipo de usuário (papel) com outro nó destino, no qual o tipo de

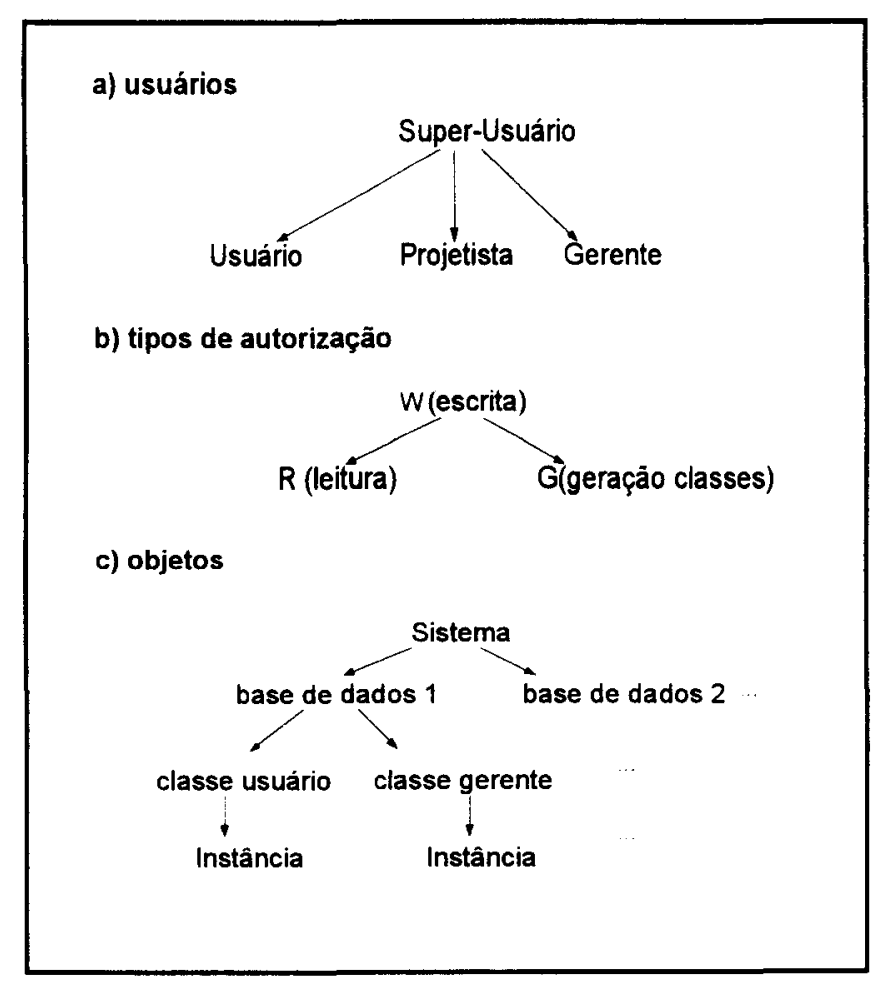

Figura 3.10: Grafos aciclicos usuários, tipos de autorizações e objetos.

usuário (papel) possui um poder de atuação hierarquicamente inferior. A técnica de utilização de dígrafos acíclicos também é devidamente extendida para a hierarquia de objetos de uma base de dados (super-classes, classes, sub-classes, atributos) e para hierarquia do tipo de autorização (leitura, escrita e criação).Este modelo permite a criação dos nós que comporão cada elemento do controle de autorização: usuários, objetos e tipos de autorização estabelecendo uma hierarquia de poder de acesso(papel). Apoiando-se nestas considerações é possivel mostrar algumas regras de derivação imediatas para o dígrafo acíclico. As figuras 3.10a, 3.10b, 3.10c, ilustram os dígrafos acíclicos para usuários, tipos de autorizações e objetos respectivamente.

Definição 1: A notação $u_{i}>u_{j}$ onde $u_{i}$ pertence a $U$ e $u_{j}$ pertence a $U$ significa que existe uma ligação direcionada de $u_{i}$ para $u_{j}$ no dígrafo acíclico, de modo que se $u_{i} \geq$ $u_{j}$ implica que ${ }_{j} u \bar{j}_{j} u$ ou $\mu>u$ ou então existe $_{h}, \ldots, u$ em $U$ de modo que $u_{i}>u_{1}>\ldots>u_{n}>u_{j}$.

Regra 1: Se para $\forall o \in O$ e $a_{\mathrm{n}} \in A$, se $\mathbf{u}_{\mathrm{i}} \geq \mathbf{u}_{\mathrm{j}}$ então

$$
\left(u_{\dot{p}} 0, a_{n}\right) \rightarrow\left(u_{\dot{p}} 0, a_{n}\right)
$$


Isto significa que o poder de acesso (papel) de um usuário $\mathbf{u}_{\mathrm{j}}$, sobre um objeto o está contido no poder de acesso do usuário $\mathbf{u}_{i}$ sobre o objeto $\mathbf{0}$.

Definição 2: A notação $a_{i}>a_{j}$ onde ai pertence a $A$ e aj pertence a A significa que existe uma ligação direcionada de ai para aj no grafo aciclico, de modo que se $\mathrm{a}_{\mathrm{i}} \geq$ $a_{j}$ implica que $a_{i}=a_{j}$ ou $a_{i}>a_{j}$ ou então existe $a_{1}, \ldots, a_{n}$ em $A$ de modo que $a_{i}>a_{1}>\ldots>a_{n}>a_{j}$.

Regra 2: Se para qualquer $\boldsymbol{u}$ pertencente $U$ e $\boldsymbol{o}$ pertencente $O$, se $\mathbf{a}_{\mathbf{i}} \geq \mathbf{a}_{\mathrm{j}}$ então $\left(u, o, a_{i}\right) \rightarrow\left(u, o, a_{j}\right)$.

Isto significa que o poder de acesso do usuário u sobre o objeto o é maior na autorização $\mathbf{a}_{\mathbf{i}}$ comparada com a autorização $\mathbf{a}_{\mathbf{j}}$.

Analogamente às definições 1 e 2, pode-se apresentar a definição3 e a regra 3 para objetos pertencentes a um dígrafo acíclico. Para esta definição é necessário incluir o conceito de propagação ascendente e descendente das autorizações. No caso da autorização de leitura sobre uma classe de objetos, a qual inclui autorização de leitura das propriedades e instâncias da classe, significa que a autorização de leitura támbem estará permitida para todas as instâncias da classe em questão. Neste caso tem-se a autorização com propagação descendente ("A.down"). Inversamente se for dada autorização de leitura para instâncias de objetos, ler a instância implica em ler a definição do objeto. Neste caso tem-se a autorização com propagação ascendente (“A.up"). Dessa maneira a coleção de tipos de autorização $A=A$ down $\cup$ A.up.

Definição 3: A notação oi > oj onde oi e oj $\in$ a $O$, significa que existe uma ligação dirigida de oi para oj no dígrafo acíclico, de modo que se oi $Z$ oj implica que oi $=$ oj ou oi $>$ oj, ou então existe $o 1, \ldots .$, on em $\mathrm{O}$ de modo que oi $>01>\ldots .>0 n>0 j$.

\section{Regra 3:}

a) Se para qualquer $\boldsymbol{u}$ pertencente a $\boldsymbol{U}$ e an pertencente a $\boldsymbol{A}$.down, se oi $\geq \mathbf{o j}$, e ainda as autorizações an sobre os objetos oi e oj estão definidas, então:

$$
\left(u, o_{i} a_{n}\right) \rightarrow\left(u, o_{j} a_{n}\right)
$$


b) Se para qualquer $\boldsymbol{u}$ pertencente a $U$ e an pertencente a $A \cdot u p$, se oi $Z \mathbf{o j}$, e ainda as autorizações an sobre os objetos oi e oj estão definidas, então:

$$
\left(u, o_{j} a_{n}\right) \rightarrow\left(u, o_{\dot{p}} a_{n}\right) .
$$

\subsection{Distribuição de Dados em Base de Dados Orientadas a Objetos.}

As plataformas que suportam grupos de trabalhos e as redes locais têm atendido com eficiência a várias necessidades de suporte aos usuários, em particular ao desenvolvimentos de projetos. Nesses ambientes um importante uso das estações de trabalho são as aplicações que utilizam os dados locais (base de dados local) e eventualmente se conectam ao sistema servidor para completar as informações não disponíveis no local em questão. Este modo de operação das plataformas, aliada à necessidade de uma maior capacidade semântica de representação de dados apontam para a necessidade de distribuição de dados em bases de dados orientadas a objetos.

Alguns trabalhos como [KIM_91b] [BERTINO_93], apresentam especificações de necessidades e soluções para a distribuição de dados em base de dados orientadas a objetos. Estes trabalhos ressaltam a necessidade de uma arquitetura de base de dados na qual exista um determinado número de base de dados privadas (locais) - para atendimento do trabalho local; e bases de dados remotas públicas, compartilhadas pelas bases de dados locais.

De maneira geral, uma base de dados privada (local) pode ser criada de duas maneiras. A primeira através da criação dos dados dos próprios usuários locais. A outra pela cópia, através de processos de separação, dos objetos pertencentes a bases de dados públicas disponíveis nos servidores. Quando os objetos são criados na base de dados local, estes não estão disponíveis a outras bases pertencentes a rede. Para a replicação ou particionamento de objetos utiliza-se o conceito de objeto complexo [LORIE_83]. Portanto a unidade de cópia pode ser um simples objeto ou então uma coleção de objetos.

Após esta fase de separação, as alterações ocorridas nos objetos são repassadas para a base pública se durante tais alterações, os objetos na base pública permanecerem bloqueados. Os objetos posteriormente podem retornar a base pública ou serem copiados. Em síntese esta arquitetura de base de dados permite a migração de objetos 
numa arquitetura de base de dados orientada a objetos. Consequentemente são definidos tipos de objetos em função de: seu tipo de utilização na base de dados; gerenciadores de esquemas; e identificadores de objetos - para permitir que os conflitos causados pelas migrações sejam minizados e solucionados.

\subsection{Distribuição de Objetos.}

A distribuição de objetos origina-se da necessidade de diversos aplicativos necessitarem compartilhar objetos armazenados em repositórios comuns, sendo que os diversos aplicativos podem estar escritos em diversas linguagens, bem como não conhecer à priori a estrutura de armazenagem dos objetos. Assim é necessário generalizar as chamadas dos objetos independentemente da linguagem de programação, da base de dados que os armazena, e de maneira indendente da arquitetura e protocolos das redes de informação. As linguagens de programação orientadas a objetos utilizam o conceito de encapsulamento de códigos e dados, em classes de objetos que podem ser especializadas em subclasses permitindo a utilização da propriedade de herança de dados. A distribuição de objetos estabelece um padrão para chamadas genéricas de objetos, independentes do compilador ou da localização fisica dos objetos na rede. Estas chamadas precisam conhecer apenas o identificador e a interface do objeto.Inicialmente utilizou-se uma plataforma cliente-servidor num ambiente homogêneo [BETz_94] para implementar a distribuição de objetos. Atualmente considerando a heterogeneidade dos ambientes, têm surgido padrões para arquiteturas cliente/servidor para o gerenciamento de objetos. Um dos padrões mais importantes é o CORBA ("Commom Object Request Brocker Architecture"), permitindo a "interoperabilidade" de objetos em arquiteturas heterogêneas. Os elementos principais da arquitetura CORBA para gerenciamentos de objetos são: 


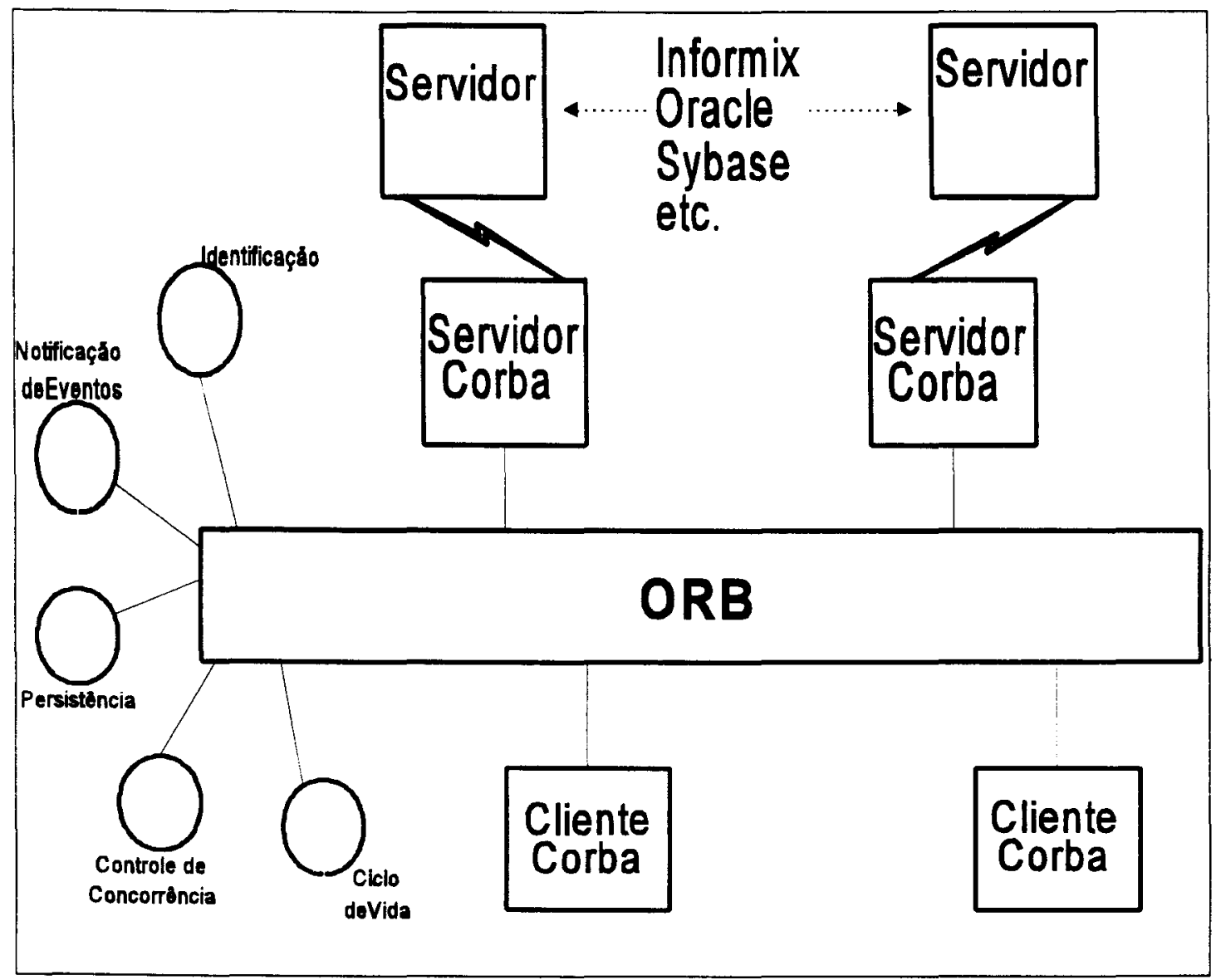

Figura 3.11: Elementos da Arquitetura CORBA.

ORB(“Object Request Broker"): é o canal comum de comunicação entre os aplicativos onde os objetos são requisitados e transferidos. Clientes acionam os mecanismos de comunicação para localizar os objetos através de uma linguagem de definição de interface.

Serviços de Objetos: Estes serviços estendem à capacidade da linguagem de definição de interface. Os serviços básicos suportados pela versão 1 do padrão CORBA são: gerenciamento de eventos, controle de persistência, gerenciamento do ciclo de vida, controle de transações, controle de concorrência, suporte à relacionamentos e gerenciamento de identificadores dos objetos. De acordo com a evolução da arquitetura distribuída novos serviços estão sendo incorporados numa versão 2 , como por exemplo suporte à proteção de consultas, propriedades, segurança e suporte de tempo. 
Regras Comuns: Consiste num conjunto de componentes escritos em linguagem de definição de interface que especificam regras para interação das aplicações desenvolvidas utilizando objetos.

Aplicações: Criação de aplicativos para o usuário final. Utiliza-se de uma linguagem de programação comum para o desenvolvimento de aplicações de acordo com a plataforma na qual se insere o usuário. Para a interação das diversas aplicações, utiliza-se uma linguagem específica denominada Linguagem de Definição de Interfaces (IDL), que estende as linguagens tradicionais de programação, as quais através de chamadas padrões efetuadas via IDL, passam a ser capazes de utilizar os objetos armazenados nos repositórios de dados da rede. A figura 3.11 ilustra tal arquitetura e seus componentes.

\subsection{Conclusão.}

Embora as soluções apresentadas em [KIM-91a] [KIM-91b] atendam as necessidades caracterizadas, estas não abordam os problemas decorrentes da composição de objetos para compartilhamento de dados e nem dos relacionamentos entre os objetos compostos. A fase de separação está limitada a um conjunto muito reduzido de tipos de utilizações, tais como: pública e privada, que os objetos sofrerão. Outro ponto que precisa ser melhor estudado é a fase de retorno dos objetos à base pública. Esta fase deveria ser melhor especificada para permitir um significado semântico mais genérico. Processos de integração de dados poderiam ser definidos em função dos tipos de operações realizadas na base privada (local). O capítulo 4 apresenta nossa proposta para compartilhamento de dados através da composição de objetos em base de dados orientadas a objetos, onde busca-se um modelo de compartilhamento capaz de ultrapassar os limites impostos pela arquitetura da base de dados proposta em [KIM9lb]. 


\section{Capítulo 4}

\section{Controle de Compartilhamento em GBDOO Baseado em Composição de Objetos}

\subsection{Introdução.}

Em Bases de Dados não convencionais [BERTINO_93] [CHORAFAS_93] [KIM_95], nas quais o ambiente de trabalho é essencialmente voltado para desenvolvimento de projetos, as necessidades de distribuição têm características distintas das de uma Base de Dados Convencional. Embora possa haver situações em que o sistema deva incorporar o tratamento de concorrência dos dados, o desenvolvimento deste recurso é apenas mais um, face a outras necessidades de distribuição específicas para esses ambientes, tais como o isolamento de parte de um projeto para desenvolvimento independente. Nesses ambientes, a distribuição dos dados envolve ainda o tratamento da concorrência, versão e partição [KIM_91], na medida em que ocorrem as mais variadas formas de cópias dos dados.

As principais necessidades de distribuição que uma Base de Dados voltada para um ambiente de desenvolvimento de projetos deve atender são: 1)suportar transações longas (que podem levar meses); 2) permitir que muitos projetistas participem de uma mesma tarefa dentro do projeto; 3) possibilitar que parte do trabalho seja de uso exclusivo de um determinado projetista e outras partes compartilhadas por outros projetistas; 4) 
possibilitar que a parte compartilhada, que em geral tem acesso permitido apenas para leitura, esporadicamente possa ser liberada para alteração; 5) permitir que a base suporte conflitos, considerando que estes serão resolvidos externamente; 6) permitir ao projetista operar isoladamente na sua estação de trabalho, com poucas intervenções ou consultas à base "oficial" do projeto; 7) permitir a integração de um subprojeto, após sua conclusão, com outros subprojetos afins.

Dado que as necessidades de distribuição nesses ambientes são mais amplas do que as tradicionalmente estudadas e suportadas em ambientes relacionais, será utilizado aqui o termo "Compartilhamento" de dados, considerando-se que a Distribuição de dados é um dos casos particulares do Compartilhamento de Dados.

Caracteriza-se assim a necessidade de um Modelo de Compartilhamento de Dados capaz de estabelecer divisões em uma base de dados, formas de vinculação para a evolução das partes, grau de compartilhamento, e formas para possiveis reintegrações de divisões, de acordo com as exigências das aplicações.

\subsection{Objetos Compostos no Modelo de Compartilhamento de Dados.}

Para tratar a base de dados como uma "massa" de dados que pode ser dividida é necessário também um conceito que defina como agrupar os dados, envolvendo os dados em unidades referenciáveis, que serão denominadas aqui Divisão de Compartilhamento. As unidades Divisão de Compartilhamento são os elementos que o sistema utilizará, para estabelecer o vínculo entre divisões da própria base, ou de outras bases de dados no ambiente compartilhado.

No contexto de compartilhamento de dados, agrupar significa envolver ou colecionar um conjunto de dados. Se estes dados são concebidos sob o paradigma de Orientação de Objetos, tratar-se-á de uma coleção de objetos reunidos em uma unidade que pode ser denominada Objeto Composto. Para qualquer processo de compartilhamento de dados, primeiro é necessário definir os objetos compostos que serão envolvidos no processo. Esse conceito é necessário com uma variação sobre o 
que usualmente é considerado em modelos de objetos. Assim, este trabalho introduz dois novos conceitos: uma redefinição do termo "Objeto Composto" e "Colônias de Objetos".

No âmbito de Modelos de Dados Orientados a Objetos, o termo Objeto Composto usualmente tem sido empregado para indicar que dois ou mais objetos associam-se, e que essa associação é representada através de uma referência ao outro objeto, em pelo menos um dos objetos envolvidos. 0 significado dessa associação nem sempre tem o significado real de composição. Por exemplo, havendo um objeto pessoa que mora em objeto do tipo residência, isso caracteriza pessoa como um objeto composto, pois possui uma referência a outro objeto. No entanto, pessoas não são de fato compostas por residências. As situações usuaimente consideradas como objetos compostos nos modelos em geral, são tratadas aqui como Relacionamentos. O termo “Objeto Composto" é então utilizado para caracterizar situações em que objetos são realmente "compostos por" outros, como quando descreve-se que um prédio é "composto por" salas e corredores. Compor inclui a idéia de agrupamento, que é fundamental para o Modelo proposto.

O Modelo considera a base de dados como uma divisão composta por diversos objetos, que corresponde à única colônia de tipo Global. De acordo com a forma de evolução dos dados, com a incorporação crescente de dados e das necessidades da aplicação, esta base poderá eventualmente dividir-se, tendo como critérios a semântica, a eficiência e a disponibilidade dos dados.

Sempre que ocorre uma divisão, estabelecem-se tipos de vínculos entre as partes separadas. Tal separação poderá replicar, particionar ou replicar/particionar os dados da base inicial.

\subsection{Tipos de Vínculos Entre as Bases de Dados na Fase de Separação.}

Para o Processo de Compartilhamento dos Dados é necessário uma fase inicial de separação de dados que criará as possíveis partições ou replicações da base 
de dados. $\mathrm{Na}$ separação definem-se vínculos entre as colônias envolvidas nas bases original e produto, os quais permanecem enquanto as bases original e produto existirem. Tal vínculo delimitará e definirá o conjunto de permissões, associadas a cada operação de escrita e leitura, sobre os dados pertencentes a cada colônia de cada base (conjunto que é chamado aqui de "poder das operações" de escrita e leitura).

Considerando as várias possibilidades de vínculos entre as partições ou replicações de uma base de dados, no que se refere ao poder das operações de escrita e/ou leitura sobre cada colônia, podemos considerar a existência dos seguintes tipos de vínculos mais significativos:

\begin{tabular}{ccc}
\hline Thros de Vinculos & Base Originat & Base \\
\hline apenas leitura & & Produto \\
flagrante & leitura & leitura \\
isolado & leitura & leitura/escrita \\
mutuamente exclusivo & leitura/escrita & leitura \\
independente & leitura/escrita & leitura/escrita \\
"on-line" & leitura/escrita & leitura/escrita \\
\hline
\end{tabular}

Figura 4.1 : Tipos de vínculos possíveis entre as colônias das bases de dados original e produto.

- apenas leitura: as operações permitidas restringem-se apenas a leitura tanto na base original como na base produto.

- flagrante: na base original apenas as operações de leitura são permitidas, enquanto que na base produto são possíveis as operações de leitura e escrita.

- isolado: apenas a base original possui permissão para escrita e leitura, restando para a base produto apenas as operações de leitura.

- mutuamente exclusivo: operações de escrita e leitura são permitidas em ambas as bases, entretanto apenas a base original ou a base produto será tomada como referência para o processo de integração, sendo desconsiderada a não selecionada. Tal escolha deverá ser feita pelo usuário no instante da integração. 
- independente: tanto a base original como a base produto podem evoluir de maneira independente. Isto equivale a dizer que estão autorizadas as operações de escrita e leitura para ambas as bases. Os conflitos que eventualmente ocorram num possível processo de re-integração das bases original e produto deverão ser evitados e/ou resolvidos de acordo com o significado desta integração, pelo usuário. É possivel escolher um tipo de integração dentre as opções, na qual os conflitos serão resolvidos ou evitados pelo usuário.

- "on-line": tanto a base original como a base produto podem ter as operações de escrita e leitura autorizadas. Entretanto qualquer alteração em uma das bases implica que tal alteração é repassada o mais breve possivel para as demais bases vinculadas. Isto acarretará a necessidade do controle de concorrência dos dados pertencentes as bases, as quais devem comunicar-se sem a ocorrência de interrupções.

\subsection{Núcleo de Acesso do Objeto Composto.}

\subsubsection{Granularidade da Base de Dados para o Processo de Separação de Dados.}

O conceito de granularidade ou atomicidade significa a unidade (indivizivel) do particionamento ou da replicação, originado do processo de separação de dados tratado pelo Sistema de Gerenciamento para Compartilhamento de Dados. No caso convencional, a granularidade em geral é fixa e no modelo proposto por nós é variável. Isto é possível pois a granularidade recai sobre objetos compostos, que podem constringir outros objetos compostos ou então objetos simples. Esta granularidade, normalmente conhecida pelo nome de granularidade por predicado, torna-se não mais absoluta mas sim relativa à quantidade de informação contida numa colônia. Se o usuário desejar compartilhar apenas um objeto composto, a granularidade e a base produto terá o tamanho do objeto em questão. Caso exista mais de um objeto composto compartilhando dados organizados em níveis hierárquicos, então a granularidade terá o tamanho da base de dados que contém os objetos compostos, pertencentes a hierarquia, desde o topo até o nível hierárquico onde se encontra o último objeto alvo do compartilhamento. 


\subsubsection{Controle de Acesso para Processo de Compartilhamento.}

O controle de acesso no Modelo de Compartilhamento de Dados é feito através de objetos compostos, e de relacionamentos entre objetos de colônias distintas, denominados aqui Inter-relacionamentos.

Para o controle das operações de escrita e leitura sobre as bases de dados é necessário uma estrutura de dados, em cada objeto composto, sobre o qual os níveis de autorização para objetos, inter-relacionamentos e atributos, serão estabelecidos. Como essa é uma informação necessária ao gerenciamento da base, e não do objeto em si, essa informação é repassada à colônia constrita por esse objeto, na forma de registros de autorização, conforme mostra a figura 4.2 .

As permissões de acesso (autorizações) podem ser controladas através de atributos que indiquem cada permissão atribuída à colônia e inter-relacionamentos que dela originem-se. Esses atributos informam, além das operações autorizadas, sobre quais elementos dos objetos que fazem parte do objeto composto, ou do próprio objeto composto elas são autorizadas. Os elementos que devem ser controlados são os objetos que compõem o objeto composto (e que habitam a colônia em questão), seus atributos e os inter-relacionamentos.

$\mathrm{Na}$ operação de Compartilhamento é necessário e suficiente considerar apenas os objetos que compõem outros objetos, hierarquicamente envolvidos na base de dados. Assim o poder das operações sobre a base de dados dependerá de cada registro das colônias constritas pelos objetos compostos em questão, respeitando a hierarquia estabelecida entre os mesmos. Isto possibilita o tratamento de herança para os registros de autorização, de modo que o poder estabelecido para o objeto composto no topo da hierarquia tem que ser maior ou igual aos objetos subalternos na hierarquia.

Para o registro de autorização cada campo é subdividido de modo que, para os objetos existem dois sub-campos (Cria, Apaga), quatro sub-campos para as colônias (Cria, Apaga, Modifica, Bloqueia), três para atributos (Cria, Apaga, 
Modifica) e dois sub-campos para inter-relacionamentos (Apaga, Modifica) como mostra a figura 4.2. Cada sub-campo com exceção do sub-campo bloqueia colônia(colbloq), possui dois tipos de valores que representam o tipo de acesso para operações:

0 : bloqueia as operações de escrita do sub-campo em questão permitindo apenas leitura.

1: libera as operações de escrita e leitura do sub-campo em questão.

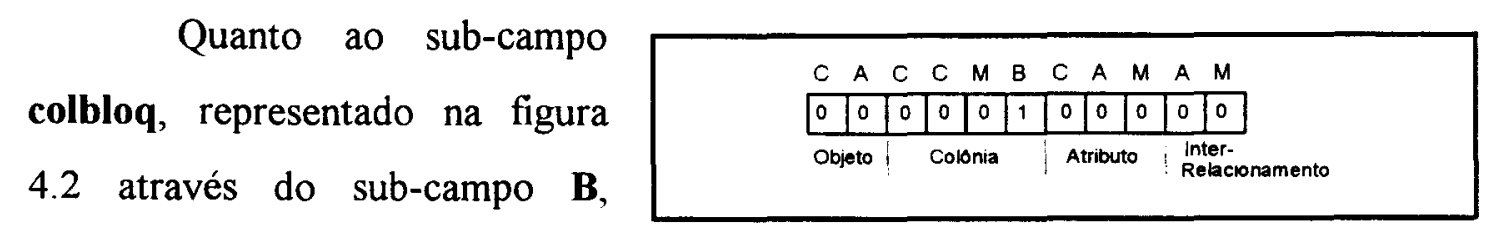
responsável por bloquear qualquer Figura 4.2 :Sub-campos do Registro de Autorização.

colônia, se o conteúdo for igual a 1 significa que a colônia pode ser acessada, se for 0 significa que todas as operações inclusive as de leitura não são permitidas.

\subsection{Operação Compartilhamento.}

A Operação de Compartilhamento em uma base de dados apoiada num Modelo Orientado a Objetos é constituída de três fases: separação, evolução e integração. A fase de separação deve ser realizada partindo-se do registro de autorização original, de cada colônia constrita pelos objetos compostos que se deseja separar. Nesta fase pressupõe-se a interferência do usuário, para especificar as colônias a serem separadas e o tipo de vínculo que cada colônia da base original estabelecerá com cada colônia da base produto. O usuário definirá o tipo de vínculo entre cada colônia das bases original e produto, que participarão da operação de compartilhamento, de acordo com as necessidades do domínio de aplicação a ser implementado e do nível de autorização da base de dados original.

Sempre que uma colônia for indicada para participar da operação de compartilhamento, o processo de separação precisa considerar todos os objetos 
compostos, pertencentes à hierarquia de composição da base de dados. Para isso é preciso definir o conceito de Contexto para Compartilhamento.

\subsubsection{Contexto para Compartilhamento.}

Para manter a estrutura da base de dados na operação de compartilhamento, é necessário e suficiente considerar apenas os objetos que hierarquicamente constrigem as colônias da base de dados envolvidas na operação de compartilhamento. Denominase Contexto para compartilhamento de um objeto composto o caminho hierárquico de objetos, que constringem outros objetos compostos desde a raiz da hierarquia até atingir o objeto que se deseja compartilhar.

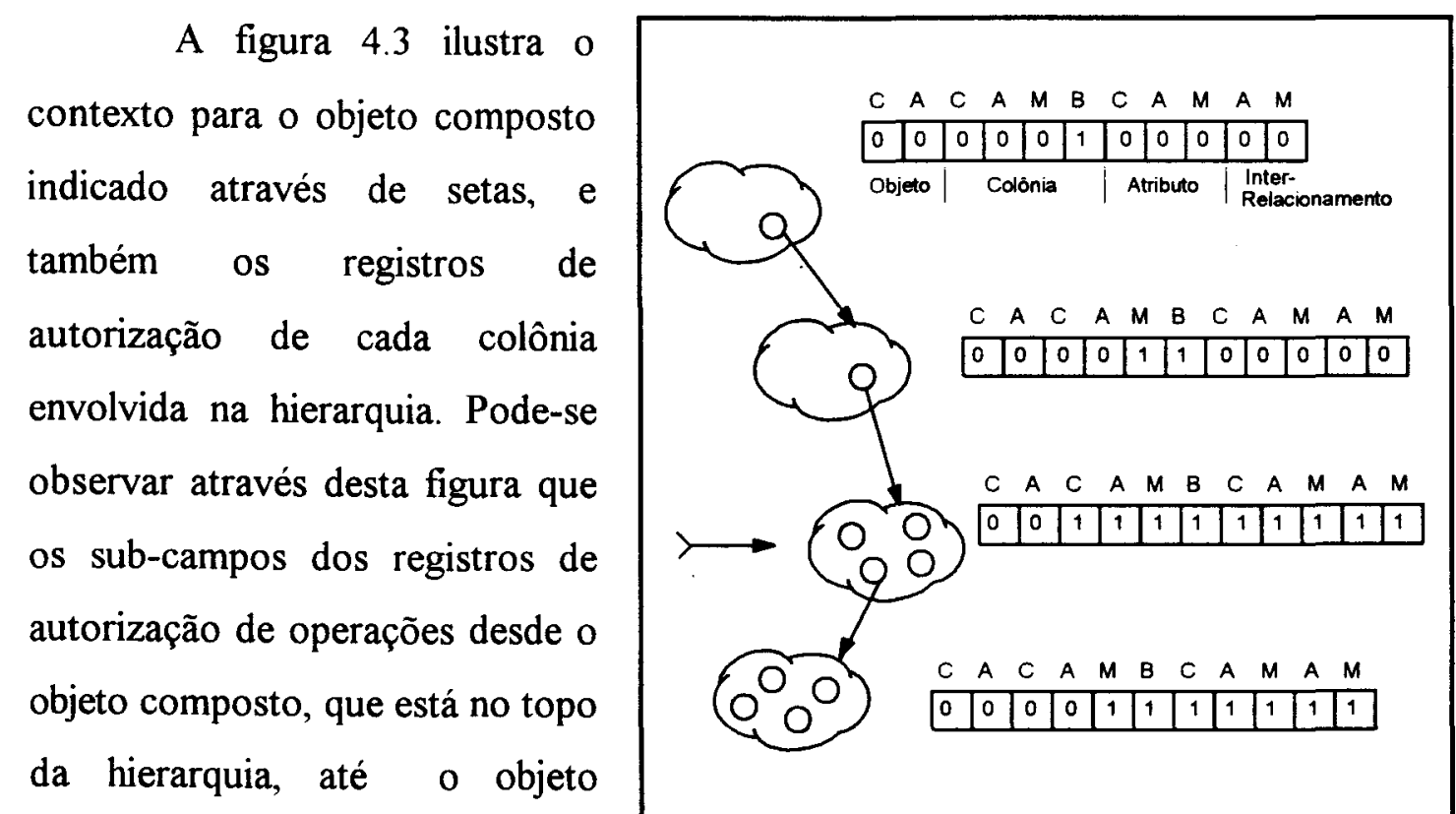

imediatamente acima do qual se Figura 4.3: Contexto para Compartilhamento. deseja realizar as operações de atualização, são bloqueados para escrita, ou seja, todos os sub-campos contêm o valor zero. $O$ registro de autorização do objeto imediatamente acima da seta também tem todos os seus sub-campos zerados, com exceção dos sub-campos \{modifica e bloqueia objeto composto\}, que têm valor 1 como conteúdo. Isto significa que os objetos pertencentes a este objeto composto têm permissão para realizar atualizações. A abrangência das operações de atualização desse objeto composto em particular estará sempre condicionada ao seu registro de autorização. 
Especificamente na figura 4.3, no objeto indicado pela flecha, as operações de: \{cria e apaga objetos; cria, apaga e modifica atributos; modifica e bloqueia objeto composto\} estão autorizadas. Entretanto as operações \{cria e apaga objetos\} não estão permitidas. A autorização \{modifica objeto composto\} significa que qualquer objeto hierarquicamente inferior está liberado para as operações de atualização, caso contrário o sub-campo estaria com valor zero, impedindo assim o acesso para as operações de escrita.

Todas as colônias de uma base têm um registro de autorização, independente da colônia estar participando de uma operação de separação ou não. Quando uma colônia é envolvida numa operação de separação, seu registro, bem como os registros do contexto de compartilhamento da base original, são reproduzidos na base produto. Assim, para cada objeto composto é necessário copiar o esquema que o rege, os objetos pertencentes à hierarquia com seus respectivos esquemas e identificadores, $\mathrm{e}$ ainda impedir que o objeto compartilhado seja apagado em ambas as bases, atribuindo o valor 0 para o sub-campo \{objeto composto apaga\} do respectivo registro de autorização.

\subsubsection{Fase de Separação.}

A fase de separação de objetos compostos possui um subprocesso de separação. Denominamos aqui de subprocesso, pois este se insere num processo maior que é o de compartilhamento de objetos compostos. Este subprocesso tem por objetivo a reprodução de objetos, atributos, inter-relacionamentos e objetos compostos subordinados a hierarquia. Portanto, além de considerar o Contexto para Compartilhamento, é necessário avaliar os inter-relacionamentos, ou seja, relacionamentos entre objetos que tenham como origem algum objeto que habita colônias envolvidas no Contexto de Compartilhamento, e como destino objetos que não habitam essa colônia. Esses relacionamentos são denominados Relacionamentos de Interface do processo de separação ou inter-relacionamentos, ao passo que aqueles 
que ocorrem entre objetos que habitam a mesma colônia denomina-se de Relacionamentos Internos ou intra-relacionamentos

Para efeito da separação, cada campo do registro de autorização deverá ser analisado de forma independente. Se apenas estiverem permitidas as operações de leitura em determinados campos, então tanto o objeto composto da base original, como da base produto, permitirão apenas as operações de leitura. Neste caso o tipo de vínculo estabelecido é de apenas leitura.

Caso o campo em questão esteja liberado para as operações de escrita e leitura, existirão seis possibilidades no processo de separação para estabelecer o tipo de vínculo entre a base original e produto: apenas leitura(r-); isolado(is); flagrante(fl); mutuamente exclusivo(me); independente(in); on-line(on).

A figura 4.4 mostra apenas um campo do registro de autorização, com os devidos valores para as operações permitidas tanto na base original como na base produto. Nessa figura convencionou-se o valor 1 para indicar que as operações de escrita e leitura estão autorizadas e 0 para indicar que apenas as operações de leitura estão autorizadas. Em um campo do registro de autorização para a Operação de Compartilhamento de dados existem três sub-campos: um que indica o tipo de vínculo, um que indica a autorização resultante do objeto composto da base original, e outro que indica a

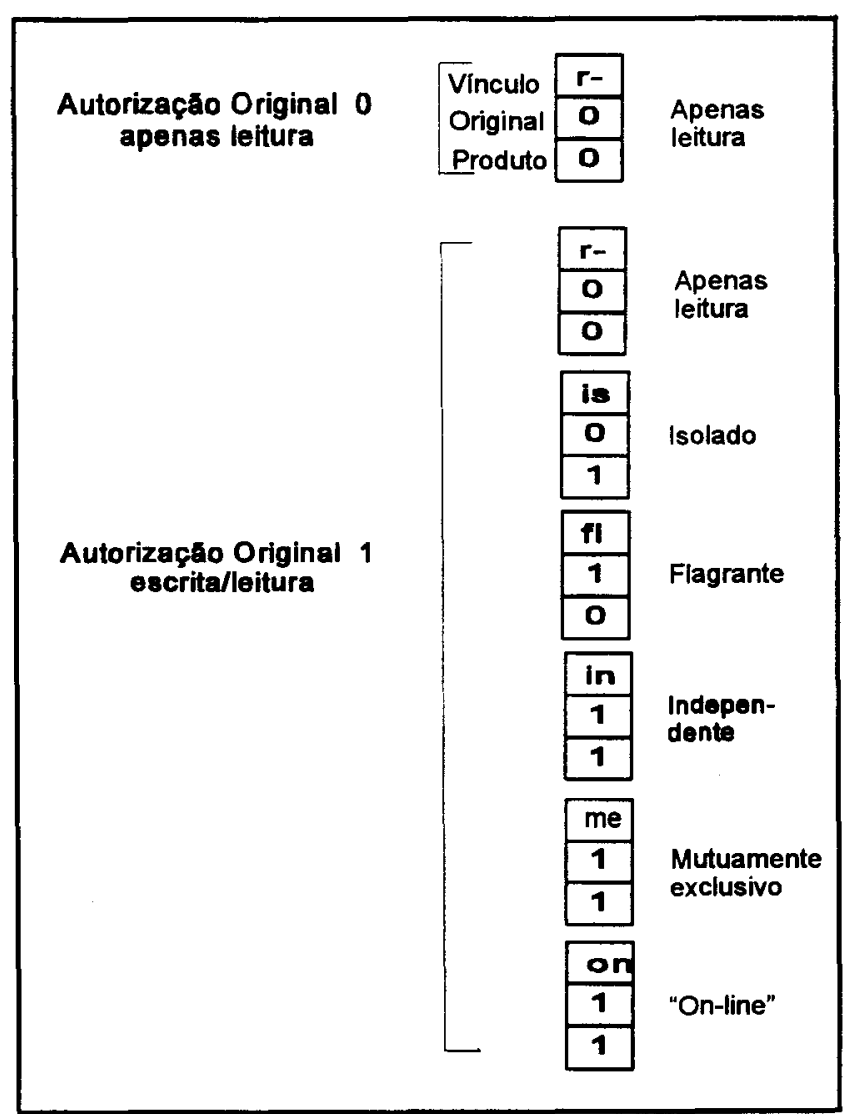

Figura 4.4: Vínculos para a Operação Separação. 
autorização resultante para o objeto composto da base produto.

Quando uma informação na base original estiver com leitura proibida, o processo de separação não irá levar esta informação para a base produto. Portanto toda a informação levada para a base produto estará liberada para leitura ou para leitura e escrita.

No tipo de vínculo apenas leitura( r-) tem-se dois sub-campos de autorização zerados. No isolado(is) tem-se zero para o sub-campo da base original e 1 para o subcampo da base produto, permitindo assim apenas operações de leitura para a base original, e escrita e leitura para a base produto. $\mathrm{O}$ tipo flagrante(fl) apresenta o subcampo da base original com valor 1 e 0 para a base produto, permitindo escrita e leitura para a base original e apenas leitura para a base produto. $\mathrm{O}$ tipo mutuamente exclusivo(me), com valor 1 para as bases original e produto, permite a escrita e leitura em ambas, com a restrição de que apenas uma configuração deverá ser considerada Tal decisão deve ser postergada para o processo de integração. $O$ tipo independente(in), com valor 1 para base original e produto, permite a evolução de ambas. Isto exigirá a definição e a caracterização de processos de integração padrões, diminuindo ou resolvendo conflitos dos inúmeros caminhos de evolução proporcionados pelo tipo de vínculo estabelecido entre as bases. O tipo on-line(on) terá valor 1 para base original e produto, entretanto, de maneira distinta do vínculo Independente, o on-line resolve os conflitos à medida que estes ocorrem, facilitando a manutenção das bases, desde que estas possam estar em constante comunicação.

Dentre os processos de integração ressalta-se a existência de um que ficará sob a responsabilidade do usuário, para a solução de possíveis conflitos entre dados, num possível processo de re-integração das bases. No tipo de vínculo independente não é possível garantir a atomicidade, e portanto a serialização no processo de integração. Isto se deve ao fato de que, a não manutenção da ordem temporal das operações de integração entre as várias operações de compartilhamento pode gerar resultados distintos. Este aspecto será melhor detalhado na seção 4.5.4. 
No tipo de vínculo on-line, as operações de escrita e leitura como no caso independente são também permitidas. Entretanto os conflitos oriundos da concorrência dos dados são resolvidos através de gerenciadores de transações e escalonadores de operações sobre os dados, de modo que o processo de integração torna-se simples pois os possiveis conflitos já foram resolvidos anteriormente.

\subsubsection{Inter-Relacionamento.}

Para avaliar as operações de escrita e leitura permitidas nos inter-relacionamentos é necessário verificar o poder das operações das colônias, que constringem os objetos associados por esse relacionamento. Considerando que na base original os registros de autorização permitem as operações de escrita e leitura, existem três casos de tratamento de permissões quanto aos objetos

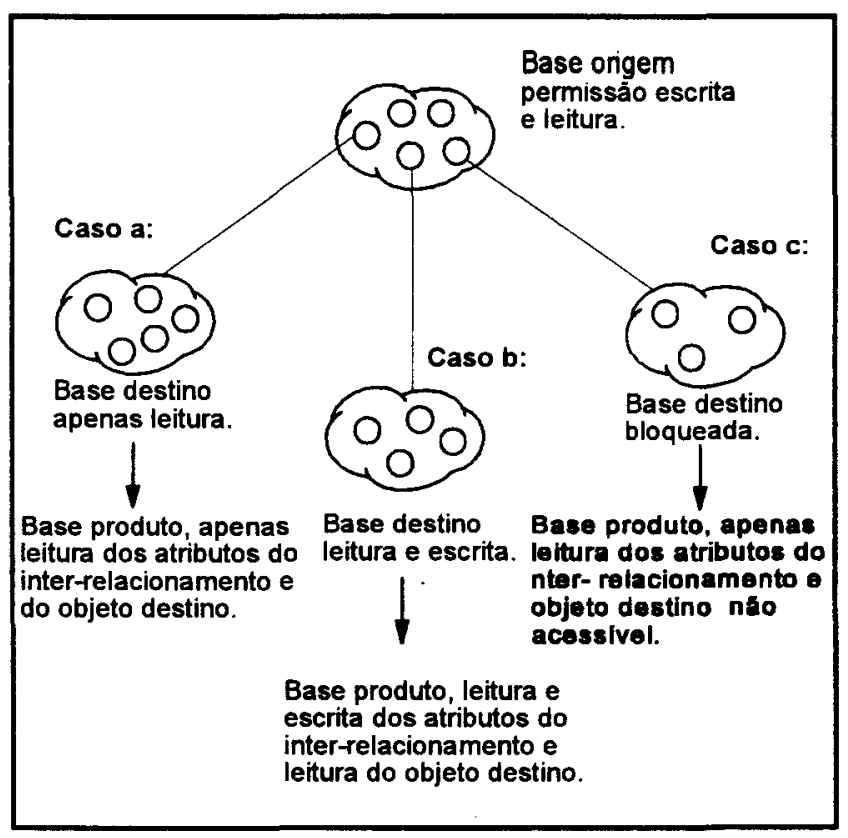

Figura 4.5: Alterações possíveis nos inter-relacionamentos conforme autorização da base destino. destinos dos inter-relacionamentos, ilustrados na figura 4.5:

a) o registro de autorização da colônia onde habita o objeto destino indica que a mesma está liberada apenas para leitura. Neste caso, a colônia onde habita o objeto destino não permite as operações de criar e apagar objetos e nem as alterações nos atributos e colônias. Com isto, no registro de autorização da colônia onde habita o objeto origem, não serão permitidas alterações nos atributos do inter-relacionamento e nem eliminação do mesmo. Apenas as operações de leitura serão permitidas nas informações do inter-relacionamento. Da colônia constrita pelo objeto destino, somente será copiado o objeto destino juntamente com seus atributos para a base produto. 
b) o registro de autorização da colônia onde habita o objeto destino permite as operações de escrita e leitura. Para manter a prioridade e exclusividade das operações de escrita e leitura da colônia na qual habita o objeto destino, os subcampos do registro de autorização da colônia na qual habita o objeto produto, serão configurados de modo a não permitir as alterações nos objetos e atributos. Para a base produto será copiado o objeto destino e seus atributos, porém as operações de alterações serão proibidas. Somente serão permitidas as alterações nos atributos do inter-relacionamento (entre o objeto origem e produto) e a eliminação desse interrelacionamento.

c) o registro de autorização da colônia onde habita o objeto destino não permite leitura. Isto significa que a colônia na qual habita tal objeto não pode ser acessada. Neste caso, os sub-campos do inter-relacionamento serão configurados de modo a não permitir o acesso ao objeto destino e nem as alterações nos interrelacionamentos. $\mathrm{Na}$ base produto não serão copiados os objetos destinos, mas cria-se um marcador para representá-lo no inter-relacionamento.

\subsubsection{Fase de Evolução.}

Independente de ter havido ou não um processo de compartilhamento, o controle de acesso às colônias é definido pelo registro de autorização de cada colônia. Havendo um processo de compartilhamento, cada base é tratada independentemente, sendo que o subprocesso de separação terá previamente definido em cada colônia da base original e da base produto os registros adequados.

Durante a evolução da base, as operações de manutenção seguirão normalmente, restritas pelo poder das operações de escrita e leitura que estão limitadas àquelas definidas pelo registro de autorização de cada colônia das bases original e produto. Esta fase se prolongará até que o usuário decida realizar a reintegração das bases, ou anular o vínculo de compartilhamento, tornando cada base autônoma. 
$\mathrm{Na}$ fase Evolução do Sistema de Compartilhamento de Dados, uma operação adicional deve ser realizada sobre as operações usuais da base, criando uma estrutura para armazenamento dos eventuais objetos eliminados, na base original ou produto. Isto se faz necessário pois na fase de re-integração a base original ou a base produto deve ser atualizada, de acordo com a tabela de objetos eliminados na fase de Evolução.

\subsubsection{Fase de Integração.}

Os subprocessos pertencentes a fase de integração dependem de dados gerados durante a fase de separação, que são mantidos tanto na base original como na base produto. Esses dados consistem dos registros de autorização de cada base, do registro de autorização que existia no momento imediatamente anterior da fase de separação da base de dados, e a informação sobre o tipo de vínculo estabelecido. Para cada tipo de vínculo deverá existir um subprocesso que seja capaz de integrar a base produto com a base original, levando-se em consideração as alterações ocorridas em cada base.

Como a separação foi especificada através do conjunto de sub-campos do registro de autorização, a análise para a integração também será feita em função desses sub-campos. Para cada configuração de um sub-campo, busca-se especificar primitivas para o tratamento de objetos, atributos e colônias com suas respectivas operações autorizadas: criar, apagar ou modificar.

A figura 4.6 mostra resumidamente os tipos de vínculos (configurações entre as colônias original e produto), autorizações possíveis geradas na fase de separação de dados e subprocessos de integração. Conforme mostra essa figura, existem seis configurações.

$\mathrm{Na}$ primeira configuração tem-se apenas leitura(r-), onde não existe a necessidade de primitivas especiais. Neste caso, o subprocesso de integração resumese apenas em apagar a base produto e a estrutura de dados para Compartilhamento de 
Dados. Isto é suficiente, pois na fase de evolução, tanto a base original como a base produto, permaneceram inalteradas.

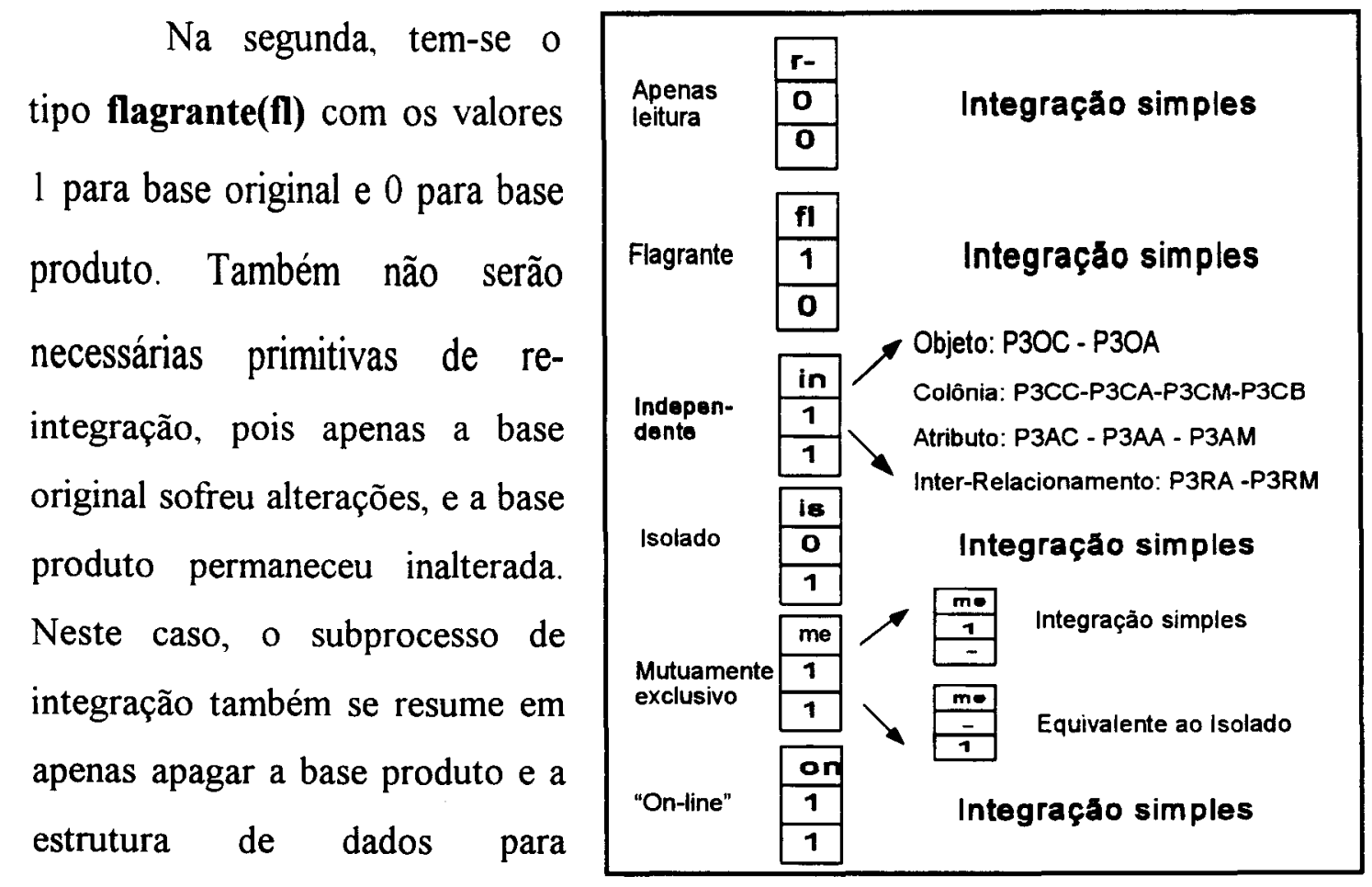

Compartilhamento de Dados.

Figura 4.6: Processos de Integração.

$\mathrm{Na}$ configuração três, o tipo de vínculo entre a base original e produto é independente(in), permitindo a evolução paralela das bases original e produto. Neste caso, o subprocesso de integração utilizará um conjunto de primitivas capaz de tratar os possíveis conflitos (cria, apaga ou modifica) sobre objetos, atributos e colônias. Utiliza-se uma notação para facilitar a identificação das primitivas necessárias: por exemplo P3OC e P3OA, que significam Primitiva da configuração 3 para integração de Objetos Criados e Primitiva da configuração 3 para integração de Objetos Apagados. A notação inclui primitivas para Atributos e Colônias incluindo a operação Modifica.

$\mathrm{Na}$ quarta configuração, onde o tipo de vínculo é isolado(is), permite-se a evolução da base produto enquanto a base original não pode sofrer alterações. Também não serão necessárias primitivas de re-integração, pois apenas a base produto sofreu alterações, enquanto que a base original permaneceu inalterada. Neste caso, o subprocesso de integração se resume em copiar a colônia da base produto substituindo 
a da base original e ainda apagar a base produto e a estrutura de dados para Compartilhamento de Dados.

$\mathrm{Na}$ quinta, onde tem-se o tipo de vínculo mutuamente exclusivo(me), são possíveis duas situações:

a) a base original é eleita para ser mantida. Neste caso, o subprocesso de integração resume-se em desconsiderar-se a base produto, eliminando-a.

b) a base produto é eleita para ser mantida. O Sistema de Compartilhamento de Dados no subprocesso de integração deverá desconsiderar a base original e transcrever integralmente a base produto para a base original. Esta situação é análoga à quarta configuração.

$\mathrm{Na}$ sexta configuração, onde o tipo de vínculo é on-line(on), como os conflitos são resolvidos na medida em que ocorrem, através dos algoritmos de controle de concorrência e escalonadores, o processo de integração resume-se em desconsiderar a base produto, pois esta deverá estar igual à base original. Esta configuração é análoga as configurações 1 e 2 .

\subsection{Modelagem da Operação Compartilhamento Através do Modelo SIRIUS.}

\subsubsection{Registros da Operação Compartilhamento.}

Numa operação de Compartilhamento, os registros de autorização devem ser combinados com os tipos de vínculos existentes entre a base original e a base produto. Cada operação de criar, apagar ou modificar os vários sub-campos do registro de autorização, serão redefinidos em função do tipo de vínculo especificado na fase de separação das bases. 
Quando as operações de escrita e leitura são permitidas para a base original, não significa necessariamente que todos os sub-campos das bases original e produto, no Processo de Compartilhamento, terão as mesmas permissões. Estes subcampos são redefinidos através da combinação do registro de autorização inicial (reg_inicial) e o tipo de vínculo das bases, gerando dois novos registros de autorizações para o Compartilhamento dos Dados: um

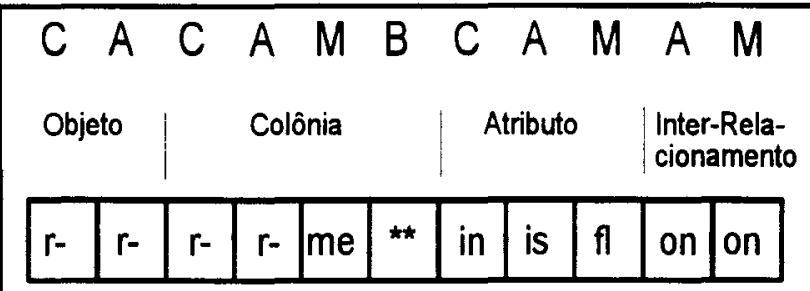

Registro Tipo de Vínculo

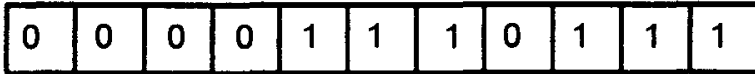

Registro de autorização objeto compartilha original

\begin{tabular}{|l|l|l|l|l|l|l|l|l|l|l|}
\hline 0 & 0 & 0 & 0 & 1 & 1 & 1 & 1 & 0 & 1 & 1 \\
\hline
\end{tabular}

Registro de atuorização objeto compartilha produto

Figura 4.7: Registros para Operação Compartilhamento. registro para as colônias da base original (reg_compartilha_original); e um registro para as colônias da base produto (reg_compartilha_produto)

Além dos novos registros de autorizações gerados para as bases original e produto, é necessário também um registro que armazene as informações referentes ao tipo de vínculo entre a base original e produto (reg_vínculo), no qual cada sub-campo possa ter como conteúdo um dos possíveis vínculos: $\mathbf{r}-$, is, $\mathbf{f l}$, me, in, on. Assim, para modelagem da Operação Compartilhamento dos Dados é necessário considerar três registros utilizados nas fases de separação, evolução e integração dos dados: reg_vínculo, reg_compartilha_original e reg_compartilha_produto; e mais o registro de autorização inicial da base original (reg_inicial), que deve ser armazenado para a recuperação do poder de autorização inicial, da base em questão, após a fase de integração de dados ter sido concluída. A figura 4.7 ilustra a especificação de todos os registros necessários. 


\subsubsection{Diagrama da Modelagem da Operação Compartilhamento.}

\begin{abstract}
A operação de Compartilhamento pode ser modelada utilizando Modelos de Dados que suportem objetos compostos e agregações. Aqui, utilizaremos o Modelo de Dados SIRIUS, para exemplificar a viabilidade de um Modelo de Dados suportar o Compartilhamento de Dados.
\end{abstract}

As figuras $4.8 \mathrm{a}-\mathrm{b})$ e 4.9

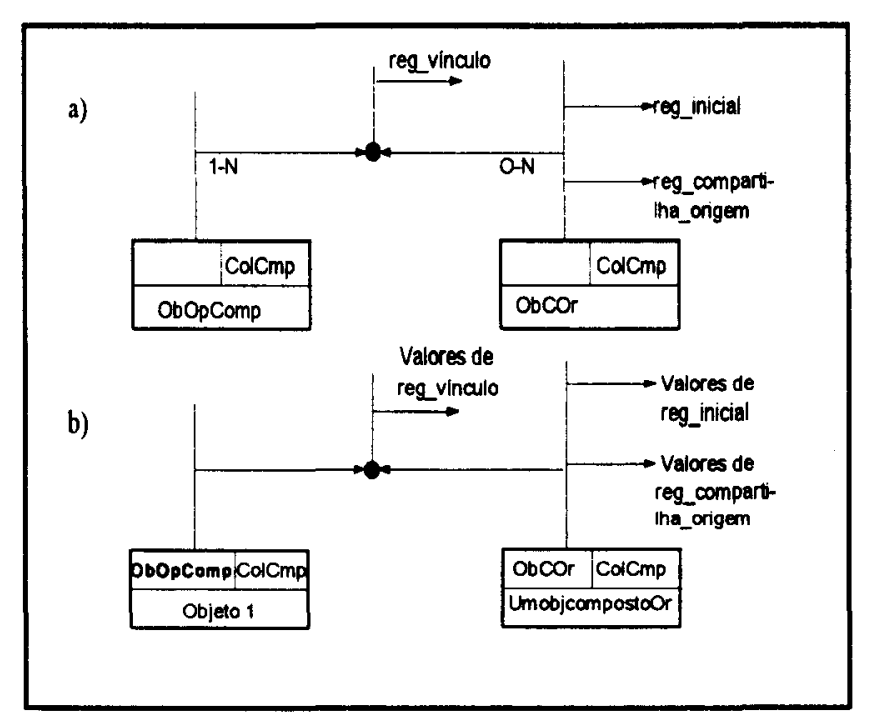

Figuras: 4.8a - Modelagem Operação Compartilhamento Objeto Origem; $4.8 b$-Instâncias dos Objetos da Modela gem.

\section{a-b) apresentam a Colônia}

Compartilhamento(ColCmp) que contém as informações para a Operação Compartilhamento, respectivamente para as bases original e produto. Esta colônia é constrita por um objeto do sistema que habita a colônia global, e é utilizada pelo sistema de gerenciamento de dados como um meta-esquema para guiar os processos de separação, evolução e integração das bases. Ambas apresentam relacionamentos entre os tipos de objetos, operação compartilhamento e tipos de objetos compartilhamento origem e produto. Os dois relacionamentos possuem como atributo o registro reg_vínculo que armazena as informações do tipo de vínculo entre a base original e produto.

A figura 4.8a) mostra a operação compartilhamento através do modelo SIRIUS, onde esta operação é representada pela colônia compartilhamento, controlada pelo sistema, a qual constringe objetos de meta-tipo Operação Compartilhamento(ObOpComp). Esses objetos relacionam-se com outros objetos do metatipo Objeto Original Compartilhado(ObCOr), e que por sua vez constrigem uma ou mais colônias submetidas à Operação de Compartilhamento de Dados. A multiplicidade é de $\mathbf{1 - N}$ no relacionamento do Objeto Operação Compartilhamento(ObOpComp) para o Objeto Original Compartilhado (ObCOr) (mínimo 1 e máximo N) e 0-N do relacionamento ObCOr-ObOpComp. Cada objeto 
que será compartilhado possui dois atributos: 1) o registro de autorização inicial da colônia constrita pelo objeto que será compartilhado(reg_inicial); 2) registro gerado a partir da combinação entre o registro da autorização original e o tipo de vínculo (reg_compartilha_original). A figura 4.8b) representa a instância do objeto operação compartilhamento (Objeto1) e também a instância do objeto original compartilhado (Umobj CompostoOr), que tem como atributo os valores de reg inicial e reg_compartilha_original. 0 registro reg_compartilha_original também será repassado para colônia constrita por esse objeto.

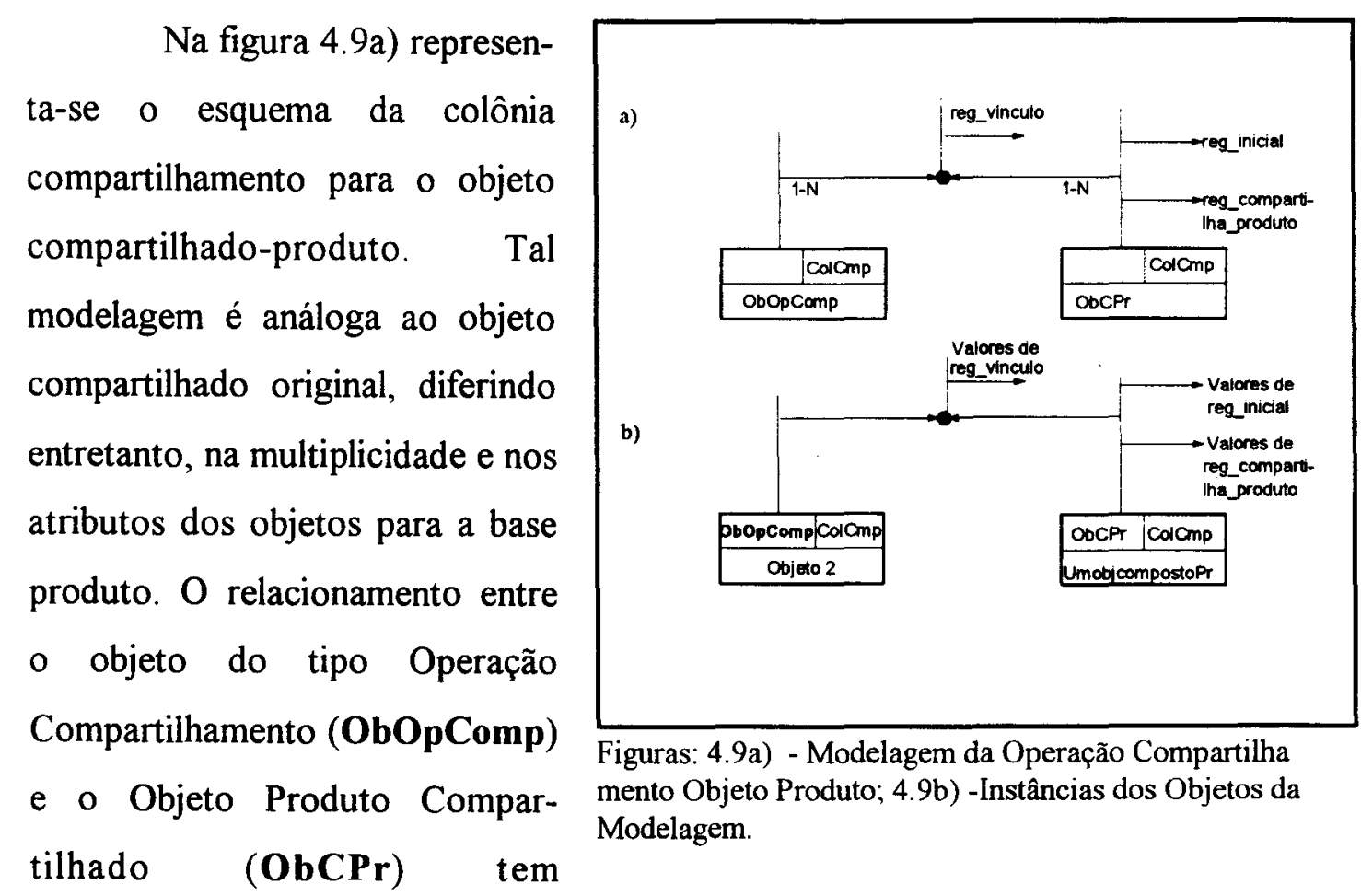

multiplicidade 1-N que é a mesma para o relacionamento ObCPr-ObOpComp. Isto se deve ao fato que, existindo um objeto compartilhado-produto, necessariamente deve existir uma operação de compartilhamento correspondente. No caso da operação compartilhamento do objeto original, independente da existência do Objeto Produto Compartilhado, a operação compartilhamento existe e está definida. O Objeto Produto Compartilhado possui os registros reg_inicial e reg_compartilha_produto. Na figura 4.9b) representa-se a instância do Objeto Operação Compartilhamento (Objeto2) e a instância do Objeto Produto Compartilhado(UmobjCompostoPr), o qual possui os valores dos registros. 


\subsection{Conclusão.}

A definição do registro de autorização para as operações nas colônias constritas por objetos, a definição da sintaxe para inter-relacionamentos, o conceito de composição de objetos para distribuição de dados, 0 conceito de compartilhamento de uma base de dados através de compartilhamentos de objetos (compostos) que constrigem colônias, fases de separação, evolução e integração de bases de dados criando bases original e produto, tipos de vínculos entre as bases original e produto, são algumas contribuições importantes deste capítulo para a área de Modelagem de Dados usando o paradigma de Orientação a Objetos.

O conceito de compartilhamento de dados adquire uma conotação diferente do modelo de distribuição de dados convencional. Os tipos de vínculos entre a base original e produto estabelecem uma semântica de compartilhamento de dados, que atende de forma mais completa a um ambiente de desenvolvimento de projetos. Esta semântica de compartilhamento suporta também a propriedade da coexistência dos dados num ambiente "on-line", que é a característica predominante do modelo distribuído de bases de dados convencionais.

Neste modelo de compartilhamento de dados, buscou-se tornar um problema complexo que é o compartilhamento de dados em bases de dados orientadas a objetos, em um sistema que compartilha dados entre vários profissionais - que é o caso de ambientes de desenvolvimento de projetos de engenharia - em aspectos mais simples que possam ser abordados em detalhes. Para isso, a operação de compartilhamento de dados foi desmembrada em diversos processos bem localizados: separação, evolução e integração de dados. $O$ resultado dessa análise procura atender a um espectro bastante amplo de necessidades dentro do domínio destes ambientes alvo. $O$ particionamento $e$ a modularidade que se buscou para a solução proposta, permitem afirmar que, mesmo as necessidades não atendidas pela solução adotada, podem ser analisadas e resolvidas com muito mais facilidade, uma vez que torna-se possivel localizar com maior precisão 
onde qualquer nova operação ou alteração das operações já tratadas, devem ser empreendidas.

Estes conceitos foram implementados através de uma ferramenta que emula 0 modelo de dados SIRIUS. Tal ferramenta utiliza como repositório de objetos tanto um SGBD Oracle quanto um SGBD Access, para demonstrar a capacidade desses conceitos de permitir a interoperabilidade dos dados compartilhados, em ambiente Windows NT. Os detalhes são apresentados no capítulo 5 da tese em questão. 


\section{Capítulo 5}

\section{Implementação de uma Ferramenta para o Compartilhamento de Objetos Compostos no modelo SIRIUS}

\subsection{Introdução.}

Para validar os conceitos propostos no capítulo 4 foi desenvolvida uma ferramenta, cuja implementação teve como objetivos: proporcionar e fornecer informações, atendendo às necessidades de incorporação de compartilhamento de dados em um Gerenciador de Objetos apoiado no modelo SIRIUS, além de avaliar a viabilidade de utilização dos referidos conceitos, nos gerenciadores de dados comerciais atualmente disponíveis.

Considerando a grande complexidade para desenvolvimento de um gerenciador de objetos de acordo com os conceitos do modelo SIRIUS, para que pudesse ser utilizado como plataforma básica para suportar o modelo de compartilhamento de dados, optou-se pelo desenvolvimento de um protótipo com um conjunto básico de conceitos do modelo SIRIUS, de modo a permitir a validação do modelo de compartilhamento de dados. Cabe ressaltar que um gerenciador de objetos apoiado em SIRIUS, denominado SIRIUS/GO, está sendo implementado pelo Grupo de Base de Dados do ICMSC.

Para implementar a ferramenta utilizou-se um repositório de dados relacional (servidores Access e Oracle) e como linguagem para programação de interface com o 
usuário o software MicrosoftVisual Basic(versão 3.0), em uma plataforma Windows NT. Por outro lado, diversas características dessa implementação foram construídas visando manter uma compatibilidade de conceitos com o gerenciador SIRIUS/GO.

\subsection{Gerenciadores de Objetos.}

Gerenciadores de Objetos provêm um meio de armazenagem persistente e compartilhamento de objetos entre múltiplos aplicativos em execução concorrente, ou mesmo entre diversas execuções sucessivas de um aplicativo. Assim, a geração e o controle dos identificadores de objetos deve atender a requisitos mais rígidos comparado a um programa, ou linguagem de programação, que não levam em conta a persistência dos objetos, como é o caso de linguagens de programação orientadas a objetos não persistentes, tais como $\mathrm{C}++$ ou Eifell.

Existem duas maneiras pelas quais pode-se definir que dois objetos são iguais: quando o valor de todos os seus atributos são iguais - chamada de Identificação Lógica ou LOId ("Logical Object IDentification”); ou quando ambos são representações do mesmo objeto - chamada Identificação Física, Identificação por Referência ou OId ("Object Identification") [KHOSHAFiAN-89]. Neste trabalho trata-se apenas do aspecto de identificação fisica dos objetos, o que é feito atribuindo-se uma referência unívoca a cada objeto, a qual o acompanha durante todo seu tempo de vida, independentemente da maneira como esse objeto é armazenado ou manipulado, ou mesmo de quantas cópias simultâneas possam existir desse objeto.

É comum que linguagens de programação refiram-se a objetos através de seu endereço em memória: o endereço (ou ponteiro como é chamado, por exemplo, em $\mathrm{C}+$ ) é usado como sendo o identificador fisico (OId) do objeto. Não se considera serem iguais objetos que tenham o mesmo valor, se estiverem ocupando diferentes endereços de memória. Por outro lado, Sistemas de Gerenciamento de Bases de Dados - SGBDs tradicionalmente consideram que dois objetos (tuplas, registros, dependendo do modelo de dados envolvido) são o mesmo se tiverem o mesmo valor em seus atributos chave. Assim, é comum que linguagens de programação adotem a identificação fisica de objetos, enquanto SGBDs adotem a identificação lógica [BERTINo-93] [KIM-90]. 
Gerenciadores de Objetos são uma maneira de prover armazenagem persistente a linguagens de programação, ou uma maneira de prover comportamento (descrito numa linguagem de programação) a objetos armazenados em uma base de dados. Assim, é necessário unificar os diferentes conceitos de identificação [CATTELL_94], uma vez que:

sob o ponto de vista de uma linguagem de programação, podem existir diversas cópias de um mesmo objeto - na base de dados em si e nos diversos programas aplicativos em execução - impedindo que seu identificador seja sua referência em memória.

sob o ponto de vista de um SGBD, um objeto pode estar em diferentes estágios de atualização, e portanto com diferentes valores em seus atributos e ainda ser o mesmo objeto. É possível mesmo que um objeto tenha seus atributos chaves alterados, e ainda assim continuar sendo o mesmo objeto - impedindo que a identificação seja feita pela comparação dos valores de seus atributos chave.

Para contornar tais requisitos conflitantes, Gerenciadores de Objetos realizam a identificação de objetos atribuindo-se um Identificador de Objetos - OId - unívoco para cada objeto, cuja criação é solicitada, que é mantida durante todo o tempo de vida do objeto. É também único em todo o sistema, independentemente do tipo do objeto, e não pode ser reaproveitado quando um objeto deixa de existir (para evitar conflito com referências antigas, possivelmente existentes em objetos contemporâneos remanescentes).

Os Gerenciadores de Objetos cuidam da armazenagem e recuperação de objetos em disco. Por motivos de eficiência de acesso, quando um objeto é passado para um aplicativo, cria-se uma cópia em memória, e através de um processo de conversão OId $\rightarrow$ referência-em-memória [KIM-90] (denominado "swisling"), os aplicativos podem internamente referenciar-se à sua cópia do objeto através de seu endereço em memória, voltando a referenciar-se através do OId sempre que houver necessidade de referenciarse externamente ao objeto (por exemplo, para atualizar o objeto no Gerenciador de Objetos ou para referenciar-se a objetos que mantêm algum relacionamento com o objeto já em memória) [ОВsectrvity-91]. 
Do ponto de vista do Gerenciador de Objetos, diversos fatores impedem que o endereço de armazenagem do objeto em disco seja utilizado como seu OId: objetos eliminados liberam espaço que deve ser reaproveitado; operações de reacomodação de arquivos que cresceram muito e depois tiveram muito espaço liberado podem deslocar objetos para outras posições; embora não estritamente necessário, o sistema pode ganhar agilidade mudando as posições de objetos que tiveram transações efetivadas.

Desvinculando o OId de um objeto de seu endereço físico, surge a necessidade de obter um meio tal que, dado um OId, seja possível obter seu enderę̧o de armazenagem $\mathrm{ORe}$ (Object Reference) de maneira eficiente. Isso tem sido feito criandose estruturas de dados de busca especiais, dedicadas para essas atividades. Embora o custo dessas buscas seja pequeno para cada busca em particular, o custo total advindo dessa atividade pode ser significativo para o desempenho do Gerenciador, uma vez que a taxa de requisição dessa operação é elevada.

\subsubsection{A estrutura interna de SIRIUS/GO.}

O núcleo do SIRIUS/GO efetua todas as operações de alocação de espaço para os objetos, gerenciando o uso de espaço em disco e cuidando das operações de transferência dos objetos para a memória. Provê o gerenciamento dos identificadores de objetos e cuida dos aspectos de Controle de Transação, aspectos de segurança física, $\mathrm{e}$ coopera com as camadas semânticas para o Controle de Acesso e Concorrência, garantindo a concorrência de acesso aos registros.

O Núcleo é também montado numa estrutura de camadas, que é detalhada na figura 5.1. A camada superior do núcleo (SG-Atr) é a única que pode interfacear com as camadas que implementam a semântica do Modelo de Dados do Gerenciador. Provê 
suporte para manipular atributos concatenados em formato de tupla ou em estrutura de lista, com possibilidade de suporte para estruturas de indice sobre esses atributos, suporte para campos longos não estruturados e suporte

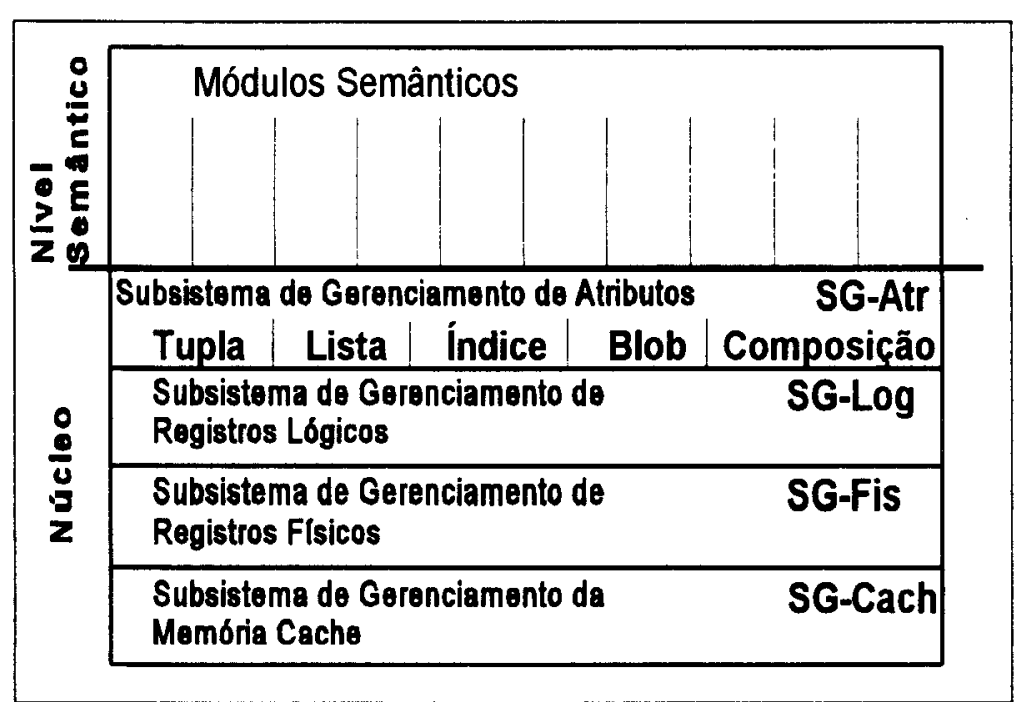

Figura 5.1: Estrutura em camadas de SIRIUS, com destaque para seu núcleo.

para composição de objetos identificáveis individualmente.

A camada seguinte (SG-Log) suporta a alocação e recuperação de espaços contínuos, em registros lógicos, para a camada SG-Atr. A estrutura em camadas é construída de maneira que cada camada mais baixa reconheça cada vez menos a semântica dos dados manipulados. Nessa camada, já não se reconhece a estrutura interna dos blocos de memória manipulados, apenas cuida-se de alocar e manter coesos e recuperáveis os blocos de memória solicitados, bem como de permitir a recuperação de espaços liberados.

A camada Subsistema de Gerenciamento de Registros Físicos (SG-Fis) efetua as operações de controle de acesso, controle de transação e alocação de espaço fisico em disco para os elementos dos objetos. A camada inferior (SG_Cache) efetua a bufferização dos registros físicos do disco em memória através de um algoritmo de emulação de memória cache, suprindo também as operações fisicas de acesso ao disco.

\subsubsection{O Esquema de Gerenciamento de OIds no SIRIUS/GO.}

OIds são códigos de acesso unívocos, não reaproveitáveis, gerados automaticamente pelo sistema para identificar e localizar cada objeto. Conforme descrito anteriormente, a maneira mais eficiente de utilizar um OId para localizar um objeto é 
utilizar o endereço de armazenagem do objeto como seu OId - no caso de objetos armazenados em disco, seu endereço de armazenagem em disco. No entanto, essa alternativa viola a regra de que o OId não pode ser reaproveitado se o objeto deixar de existir, pois a memória sem dúvida tem que ser reaproveitada.

As alternativas usualmente empregadas consistem em utilizar-se pares OIdendereço armazenados em estruturas de busca, tais como árvores B-tree. Estruturas em Hash, embora aplicáveis em casos particulares, não são adequadas para Gerenciadores de Objetos genéricos, pois a quantidade de objetos é em geral muito grande, e as chaves de partição não são eficientes. Árvores propiciam um acesso rápido, até por que a chave de busca é um campo numérico, porém não evitam um determinado número de iterações para que a localização seja obtida. Dada a elevada taxa de acesso a objetos que solicita-se de um gerenciador de objetos, esse mecanismo causa uma sobrecarga significativa em seu desempenho.

O Núcleo do SIRIUS/GO procura resolver a incompatibilidade entre os requisitos de não reaproveitamento dos OIds e o uso do endereço de armazenagem, de maneira a poder utilizar esse eficiente mecanismo e ao mesmo tempo tornar o reuso de OIds impossível. Basicamente, a solução consiste em utilizar como OId uma estrutura que agrega dois atributos: o endereço fisico de armazegem do objeto em disco (EndObj), e um contador do número de vezes que esse endereço foi utilizado(ContObj). Armazenase como parte da estrutura interna de manutenção de cada objeto na base o contador de utilização ContObj. Assim, sempre que um OId for passado como referência ao objeto, seu endereço EndObj é diretamente utilizado para acessar o objeto. A seguir, o ContObj do OId é comparado com aquele armazenado na estrutura do objeto. Sendo o mesmo, considera-se o OId válido e o acesso é atendido. Sendo diferentes, considera-se que o OId é inválido e rejeita-se o acesso. 


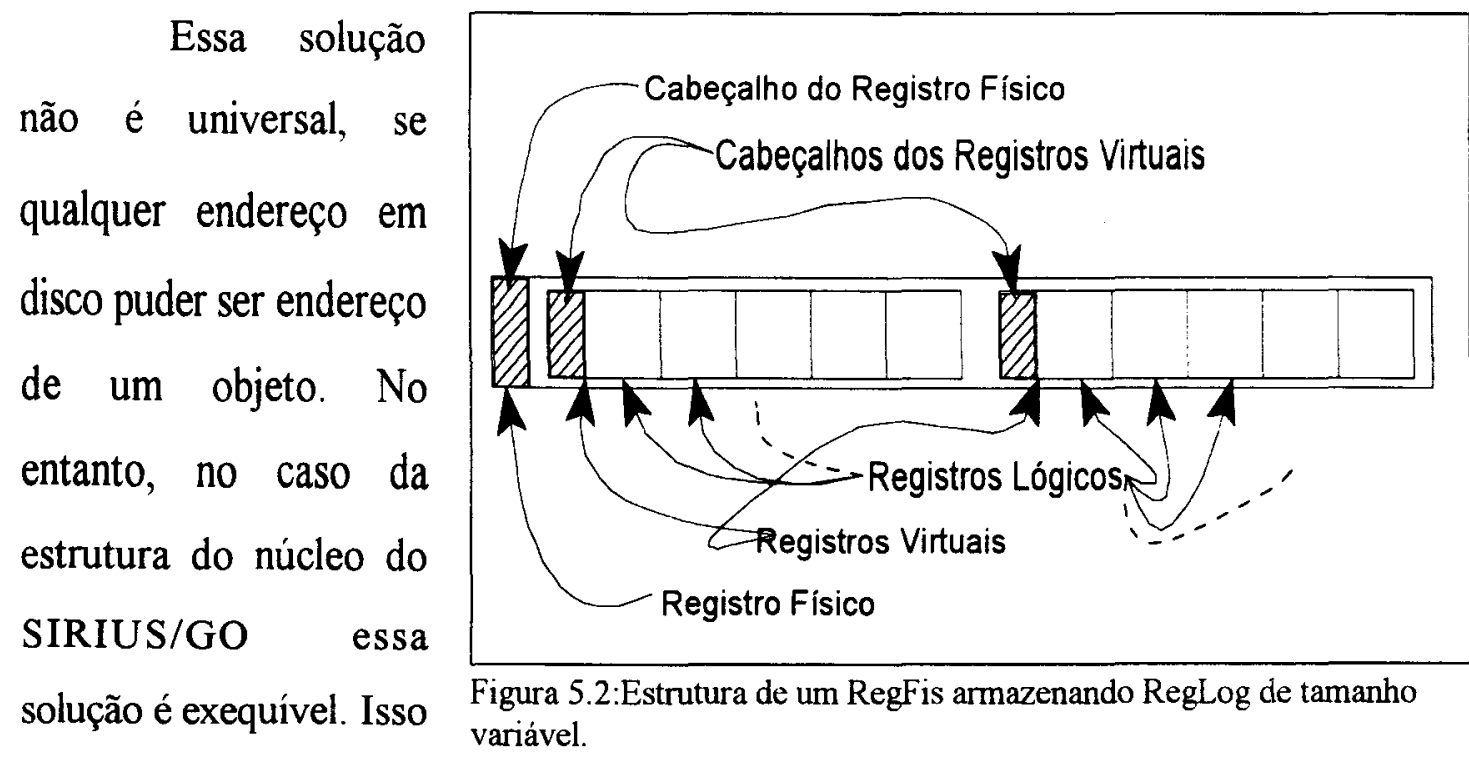

porque o que se utiliza

como o EndObj de um OId é o índice do RegLog que armazena o registro desse objeto o atributo ContObj é mais uma informação contida nos RegLogs. A figura 5.2 ilustra os conceitos de registros físicos, virtuais e lógicos. Sendo uma estrutura de tamanho fixo, se um objeto é removido seu espaço é mantido, e a estrutura de RegVirtual, onde o RegLog está inserido, passa a indicar que o objeto está disponivel para reuso, mas o atributo ContObj permanece disponível para ser incrementado e utilizado para o próximo objeto que vier a utilizar esse RegLog.

O gerenciamento dessa estrutura acrescenta uma sobrecarga na atividade do Núcleo, porém ela consiste de alguns poucos testes, sempre sobre valores numéricos em registros já pré-alocados e nunca ocorrem iterações.

Essas tarefas seriam dispendiosas se tivessem que ser incluídas especialmente para esse gerenciamento. No entanto, as tarefas se diluem naturalmente em operações do núcleo necessárias a outros propósitos, e apresentam uma sobrecarga total muito baixa. 


\subsubsection{O Sistema de Gerenciamento de Transações subsidiando o Gerenciamento de OIds.}

Um ponto que deve ser avaliado é o impacto do Sistema de Gerenciamento de Transações sobre o Gerenciamento de OIds. É interessante destacar que as operações de finalização de transação, seja com êxito ou não, não têm nenhuma influência sobre o gerenciamento de OIds. Quando uma transação que alterou informações na base é finalizada com êxito, o endereço em disco do RegFis é alterado. No entanto o índice do RegFis, utilizado para o cálculo nas operações que envolvem os EndObj associados aos OIds, não é alterado. Isso de fato desvincula a localização real do objeto em disco de seu OId. No entanto, como essa operação está naturalmente embutida no mecanismo de transferência de registros físicos entre o disco e o cache, o custo advindo dessa desvinculação é nulo.

É interessante notar que a habilidade de poder escrever um RegFis em diferentes endereços, dentro do espaço físico da base de dados, foi feito para aumentar sua eficiência: ao invés de criar um arquivo temporário, que armazena as alterações de maneira permanente em disco antes de passar cópias desse arquivo para a base propriamente dita, armazenam-se as alterações já diretamente na base e confirma-se a atualização, alterando-se o endereço fisico onde considera-se estar cada nova cópia de RegFis. Ou seja, a desvinculação entre endereço fisico e OId, que usualmente é um fator de degradação na estrutura desse gerenciador, torna-se um fator de aumento de eficiência.

Esse esquema permite ainda resolver um problema até agora não discutido, que usualmente ocorre quando o endereço de um objeto é utilizado como seu OId. Tal problema surge quando um objeto deve ser movido na memória.

Em operações usuais de armazenagem e recuperação de objetos, o local onde um objeto é armazenado não é de interesse para os aplicativos, e assim o mecanismo de gerenciamento de OIds é adequado e suficiente. No entanto, existem operações de gerenciamento da base de dados como um todo que pode solicitar a mudança de posição de um objeto. Essas operações ocorrem em função da necessidade de se compactar uma 
base de dados, ou desmembrar a base para que passe a ocupar mais do que um disco ou partição, ou para distribuí-la entre diversos servidores. $\mathrm{O}$ desmembramento da base pode ser atendido sem dificuldade com o esquema de gerenciamento de transações adotado, bastando incluir-se nas tabelas de endereço fisico de cada RegFis a informação sobre o(s) disco/partição ou Servidor onde o RegFis pode ser encontrado.

A operação de compactação necessita de um tratamento mais elaborado. A compactação torna-se necessária quando uma base cresceu muito num determinado período, e depois encolheu, deixando espaços vazios em seu interior. Em SIRIUS/GO, as operações de alocação são mais "esbanjadoras" de espaço, devido à política de manutenção das Linhas de informação. Por exemplo, a criação de uma nova colônia determina a requisição de dois RegFis (um para a linha de objetos da colônia e um para o nó raiz da B-Tree de identificadores de objetos dessa colônia, definidos pelo usuário), e mais dois RegFis para o primeiro objeto criado na colônia (para armazenar o primeiro RegVirtual das linhas de atributos de i-tuplas desse objeto). No entanto, novos objetos irão ocupando os quatros RegFis já alocados, aumentando a taxa de ocupação, até que novos RegFis devam ser incorporados.

Considerando a grande complexidade para desenvolvimento de um gerenciador de objetos, com as características da estrutura interna do SIRIUS/GO, a ser utilizado como plataforma básica para suportar o modelo de compartilhamento de dados, optou-se pelo desenvolvimento de um protótipo com um conjunto básico de conceitos do modelo SIRIUS, de modo a permitir a validação do modelo de compartilhamento de dados. Por outro lado, essa estrátegia de construção de um protótipo utilizando como repositório de dados um gerenciador disponível no mercado, possibilitará a viabilidade do modelo de compartilhamento proposto nesses gerenciadores. Nas seções seguintes apresentam-se os detalhes da implementação da ferramenta para compartilhamento de dados. 


\subsection{Aspectos Considerados no Desenvolvimento do Aplicativo para}

\section{Compartilhamento de Dados.}

Atualmente, no desenvolvimento de aplicativos para atendimento a usuários nos mais variados domínios de aplicações (automação de escritórios, sistemas de apoio à decisões, controle de reservas de recursos, controle e planejamento de produção, alocação e estoque de recursos, etc.) alguns aspectos relevantes devem ser considerados para se atingir a eficiência e a eficácia do sistema informatizado:

a) Os Projetos Lógico e Funcional do Banco de Dados devem ser capazes de prever o volume de informações armazenadas a curto, médio e longo prazo. Os projetos devem ter uma grande capacidade de adaptação para os três casos mencionados;

b) Generalidade e alto grau de abstração de dados, possibilitando confiabilidade e eficiência no armazenamento dos dados e permitindo a utilização de diferentes tipos de gerenciadores de dados, através de linguagens de consulta padronizadas;

c) Projeto de uma interface ágil e com uma "rampa ascendente" de aprendizado suave para o usuário;

d) Implementação de um Projeto de Interface compativel com múltiplas plataformas (UNIX, Windows NT, Windows WorkGroup, etc);

e) Independência da Implementação da Interface em relação aos servidores de dados (ORACLE, SYBASE, INFORMIX, PADRÃO XBASE, etc.) que darão suporte às operações de armazenamento de informações.

f) Conversão e mapeamento da diferença semântica entre os paradigmas utilizados no desenvolvimento de interfaces (Imperativo, Orientado a Objeto e Orientado a Evento), servidores de dados (Relacional) e programação dos aplicativos (Imperativo e Orientado a Objetos). 


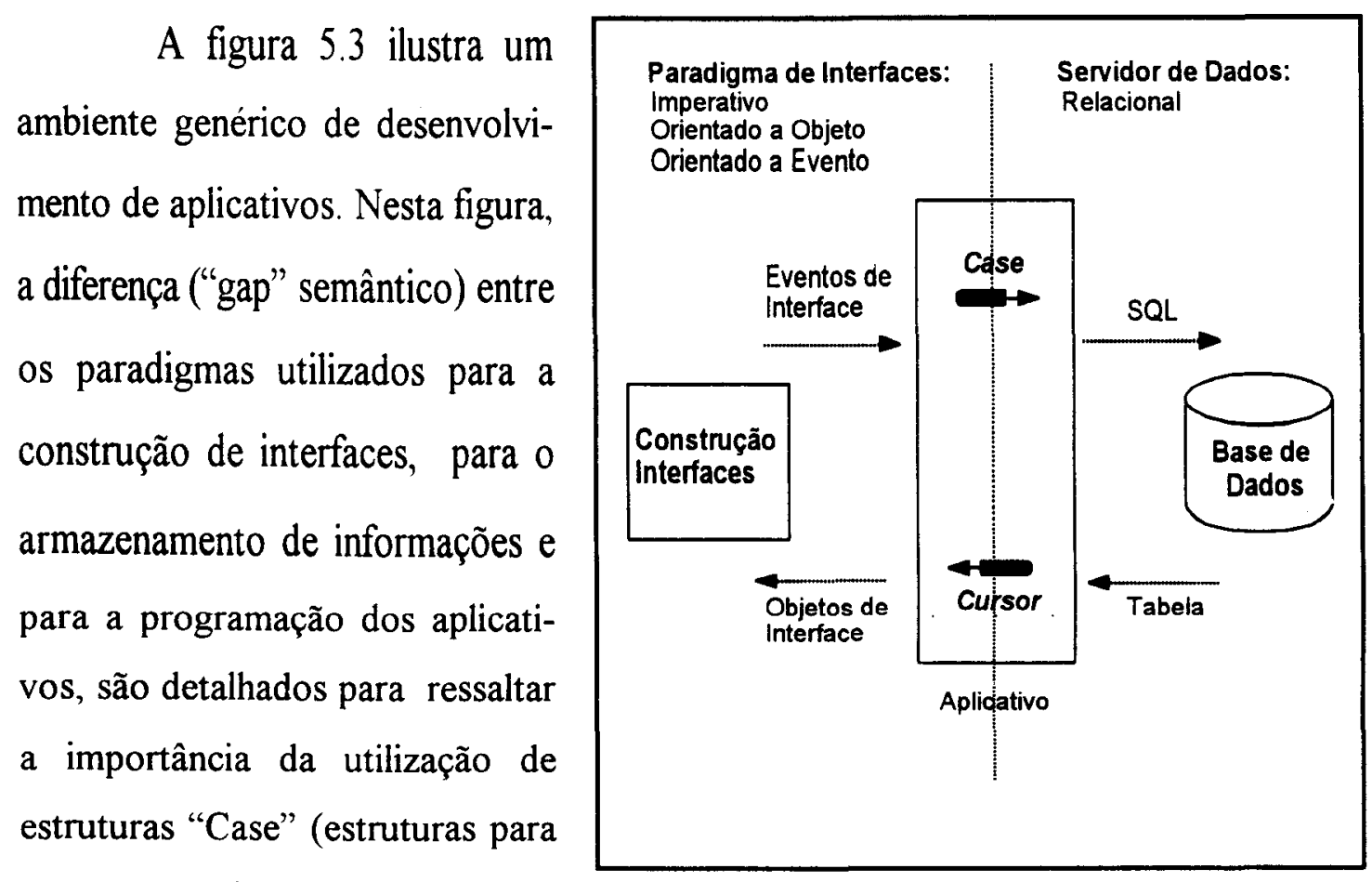

conversão de solicitações da Figura 5.3: Ambiente de desenvolvimento.

interface em uma linguagem para o

servidor de dados) e "Cursores" (estrutura de dados em memória que recebe os resultados originados das tabelas fornecidos pelos servidores de dados). As estruturas "Case" são utilizadas para converter as alterações e solicitações ocorridas na interface do aplicativo em uma linguagem que seja capaz de ser processada pelos servidores de dados. A construção da linguagem é feita através da composição de cadeias de caracteres, usualmente utilizando o padrão "SQL" (Structured Query Language) utilizado nos servidores de dados relacionais. Após o processamento da cadeia de caracteres (que forma uma requisição em SQL), o resultado é fornecido pelo servidor de dados através de tabelas. Com a utilização de "Cursores" apresentam-se esses dados como resultados da consulta, através de itens que representam os elementos de interface com o usuário, atendendo aos preceitos impostos pelos diferentes paradigmas possivelmente envolvidos (orientado a evento, orientado a objeto e imperativo).

$\mathrm{Na}$ implementação da ferramenta para o controle de compartilhamento de objetos compostos, utilizou-se uma arquitetura de base de dados relacional que fosse independente de um determinado repositório de dados (gerenciadores Access, Oracle, Sybase, Informix, etc.), e para a construção da interface com usuário utilizou-se uma ferramenta (Visual Basic), baseada no paradigma orientado a eventos. Para isso foram 
construídas rotinas para manipulação de bases de dados e rotinas para apresentação dos resultados das solicitações, fornecidas pelos servidores de dados, de acordo com os objetos disponibilizados pela ferramenta da construção da interface. Todas as rotinas foram desenvolvidas atendendo à uma especificação padrão, permitindo seguir um método para a construção de aplicativos nesse domínio de aplicações. Assim, as rotinas de solicitação de dados foram construídas indicando-se os comandos a serem solicitados para execução no servidor de dados, montados automaticamente em cadeias de caracteres, tornando a implementação da interface com o usuário independente das operações de acesso ao servidor de dados utilizado.

A implementação das
rotinas de apresentação de
resultados e de interface com o
usuário atuam através da
transformação dos eventos
ocorridos na interface com usuário
(consultas, inserções, alterações e
remoções) em procedimentos
padronizados (cadeia de caracteres
SQL), que serão executados no
servidor de dados. "Cursores" são
utilizados para percorrer o "buffer"
temporário que armazena o

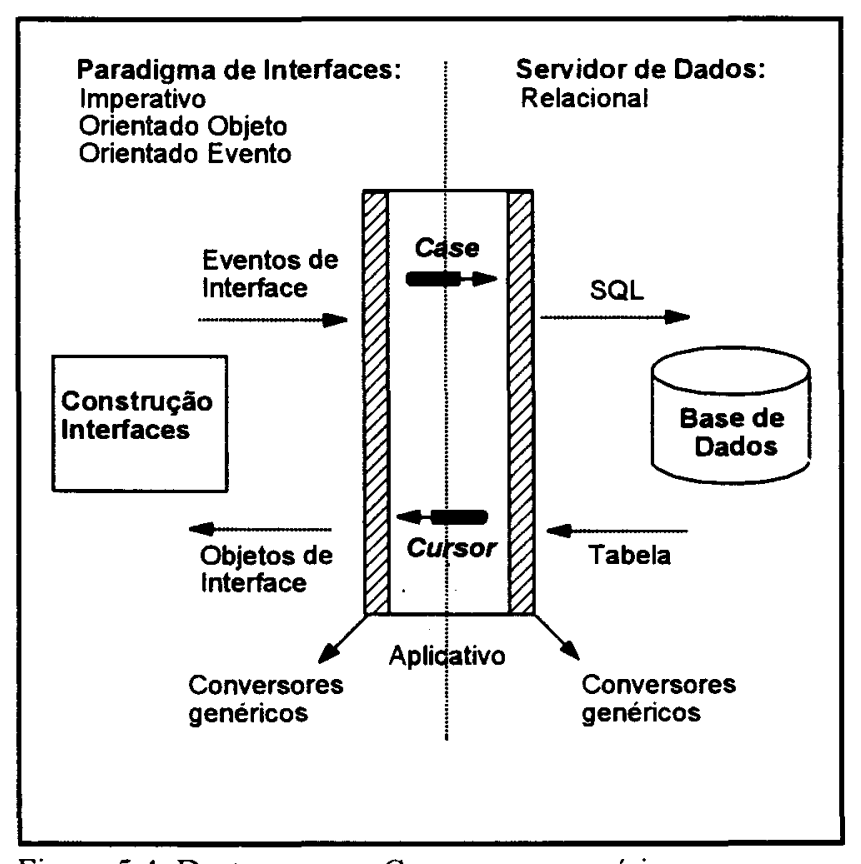

Figura 5.4: Destaque para Conversores genéricos. resultado da execução dos comandos solicitados. Finalmente os resultados são mostrados utilizando os objetos padrão da interface, disponíveis nas ferramentas de construção de interfaces. Dessa forma, o ciclo de busca da informação nos mais variados servidores tem seu "ponto de partida e chegada" na interface com usuário.

É de fundamental importância a construção de aplicativos cujo projeto de implementação da interface seja "ortogonal" ao projeto de implementação de acesso aos servidores de dados, pois isto permite o desenvolvimento e a manutenção, tanto da interface como do servidor de dados, de maneira independente. Num ambiente cliente- 
servidor utiliza-se a denominação "front-end" para caracterizar as tarefas eminentemente relacionadas com as interfaces e os eventos dela decorridos, e "back-end" para caracterizar os serviços e procedimentos realizados pelos servidores de dados. A figura 5.3 também ilustra a necessidade da independência do projeto de construção da interface com usuário ("front-end") em relação ao projeto de implementação de acesso aos servidores de dados ("back-end"), que são interligados através de conexões com a base de dados (execução do comando SQL) no sentido "front-end" $\rightarrow$ "back-end" e com cursores no sentido "back-end" $\rightarrow$ "front-end".

A figura 5.4 ilustra a utilização de conversores genéricos tanto para interfaces como para os servidores de dados. Estes conversores poderiam ser construídos para padronizar o controle de compartilhamento de dados, independente da ferramenta de interface ou do servidor de dados. Em situações práticas esses conversores são denominados comumente de "drivers". Por exemplo, em arquitetura Windows, o padrão WOSA pode ser utilizado para a comunicação com o servidor de dados (ODBC) e com a interface (TAPI). $\mathrm{O}$ objetivo da construção da ferramenta para compartilhamento de dados, não pressupõe tal generalização em virtude da não disponibilidade de vários servidores e ferramentas de construção de interfaces. Adiciona-se ainda o fato de que o trabalho de implementação, fundamentalmente, objetiva viabilizar e validar os conceitos de compatilhamento de dados em gerenciadores de bases de dados, e não necessariamente criar produtos, em particular integrando sistemas de interface com o usuário como aqui descrito. 
5.4 Desenvolvimento de um Gerenciador de Objetos emulando conceitos Básicos do Modelo SIRIUS.

\subsubsection{Remodelagem dos Conceitos Básicos utilizando o Modelo Entidade-Relaciona- mento.}

$\mathrm{Na}$ construção da ferramenta foram utilizados os conceitos do SIRIUS correspon dentes a Objetos, Tipos de Objetos, Atributos, Relacionamentos, Tipos de Atributos e de Relacionamentos, Colônias, Tipos de Colônias. Esses conceitos do modelo SIRIUS foram "remodelados" utilizando o Modelo Entidade-Relacionamento

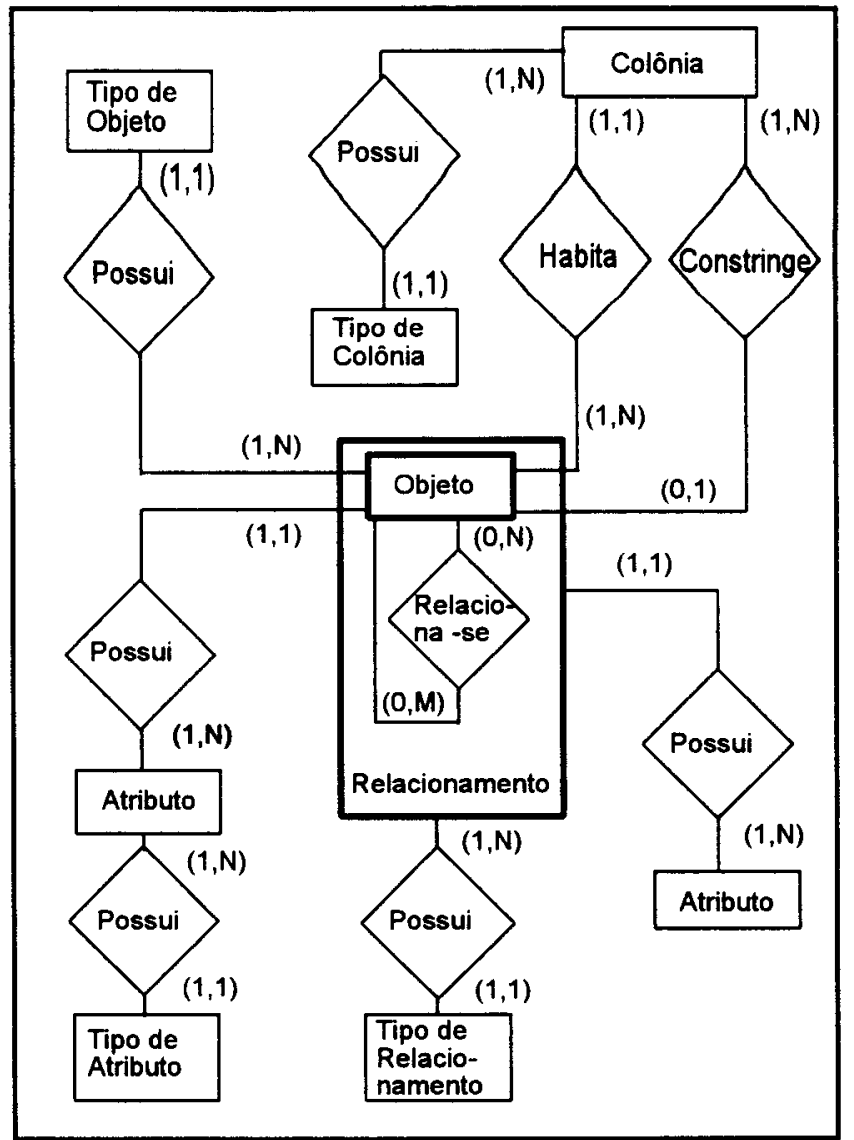

Figura 5.5: Remodelagem SIRIUS utilizando MER. (ME-R), que é um modelo mais simples, no que se refere a capacidade semântica, e atualmente bastante conhecido na área de modelagem de dados. A implementação da ferramenta foi feita então mapeando essa modelagem para o Modelo Relacional, segundo as técnicas usuais de mapeamento ME-R $\rightarrow$ MRel [NAVATHE-94]. 
A figura 5.5 apresenta a remodelagem de SIRIUS utilizando o MER. Em SIRIUS, os elementos de meta-dados modelados (tipo de objeto, tipo de atributo e relacionamento, tipo de colônia) são concretizados em esquemas de dados armazenados em colônias especializadas, cujo tipo é controlado pelo sistema, denominadas colônias esquemas.

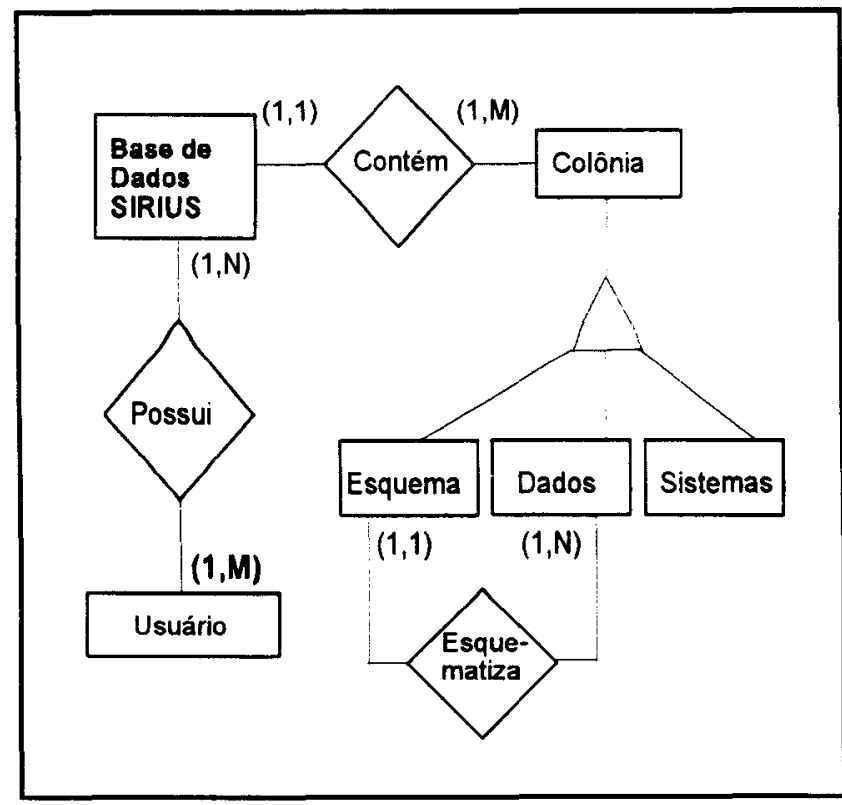

Figura 5.6: Modelagem da Base de Dados SIRIUS Já as instâncias das colônias, objetos, atributos e relacionamentos são armazenadas em colônias de dados, cujos tipos são definidos pelos programadores de aplicativos.

Para complementar a base de dados em SIRIUS é necessário considerar as colônias que armazenam características específicas, controladas pelo sistema, como por exemplo as necessárias para o controle de versão. Essas colônias são denominadas colônias do sistema. Além disso, o conjunto dos usuários que utilizam a base de dados são também controlados pelo sistema de gerenciamento de dados. Na ferramenta ora desenvolvida, a base de dados foi modelada conforme mostra a figura 5.6. Nesta figura, utilizando o ME-R, modelou-se o citado sub-conjunto de conceitos de SIRIUS, e as especializações das colônias utilizadas. Existe um relacionamento entre as colônias especializadas em esquemas e as colônias de dados. Esse relacionamento estabelece o vínculo entre a base de informação (dados) e seus respectivos esquemas. 


\begin{abstract}
A figura 5.7 ilustra a modelagem da operação compartilhamento para as bases original e produto, apresentada no Capítulo 4. Os esquemas de compartilhamento, tanto para os objetos compostos da origem como do destino, são armazenados em suas respectivas bases de dados, para serem utilizados durante o processo de compartilhamento de dados que se inicia na fase de separação, e tem seu término numa eventual fase de integração.
\end{abstract}

A figura 5.8 ilustra 0

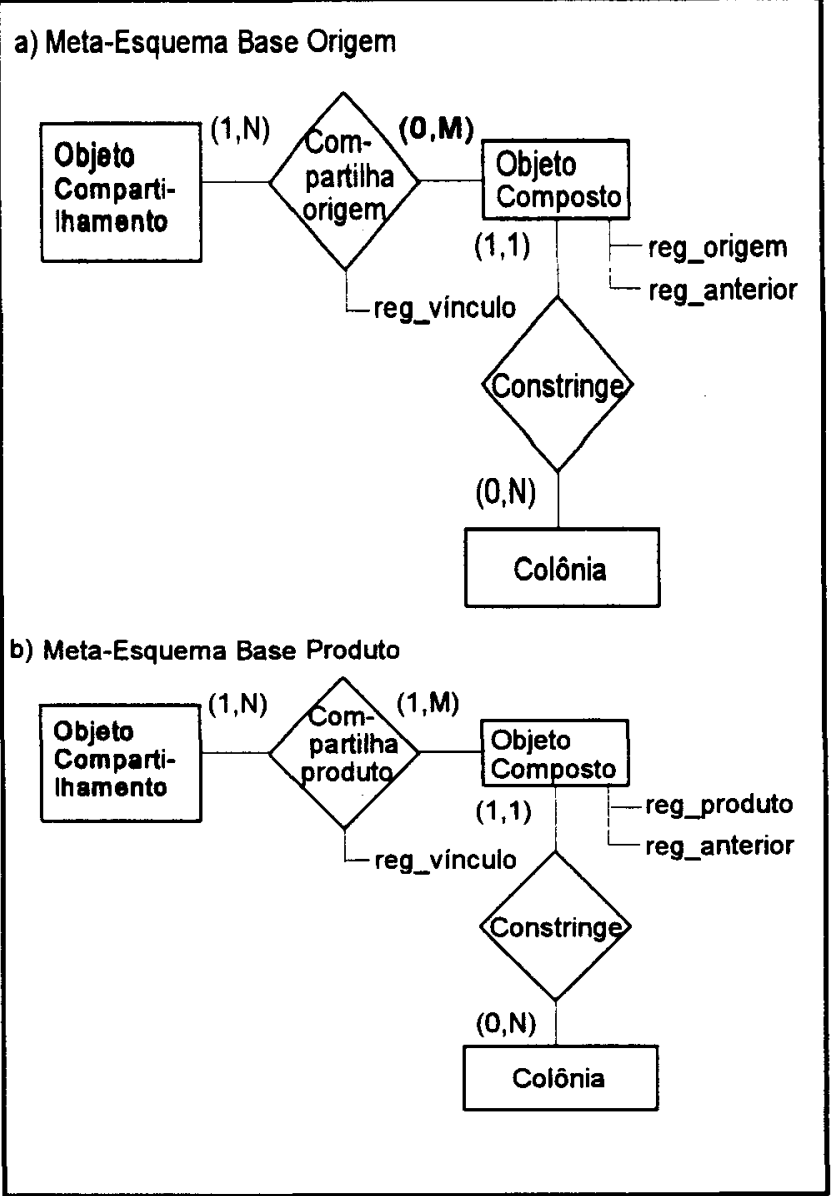

Figura 5.7: Modelagem Operação Compartilhamento.

resultado do mapeamento para o modelo relacional da figura 5.5. Cabe observar que para cada tabela criada definiu-se um campo a mais, que é o identificador da tupla. Convencionou-se utilizar a notação ID_(nome da tabela) para cada campo criado. Foi definida uma tabela extra (ID_TABELAS) para controlar os identificadores que são gerados em cada tabela, que armazena o valor do último identificador. Desse modo, é gerado um identificador unívoco na tabela para cada nova tupla a ser inserida em uma determinada tabela. Naquela mesma figura apresentam-se também as restrições de integridade referencial. As tabelas foram criadas com seus respectivos campos nos gerenciadores de dados relacional Access e Oracle. 


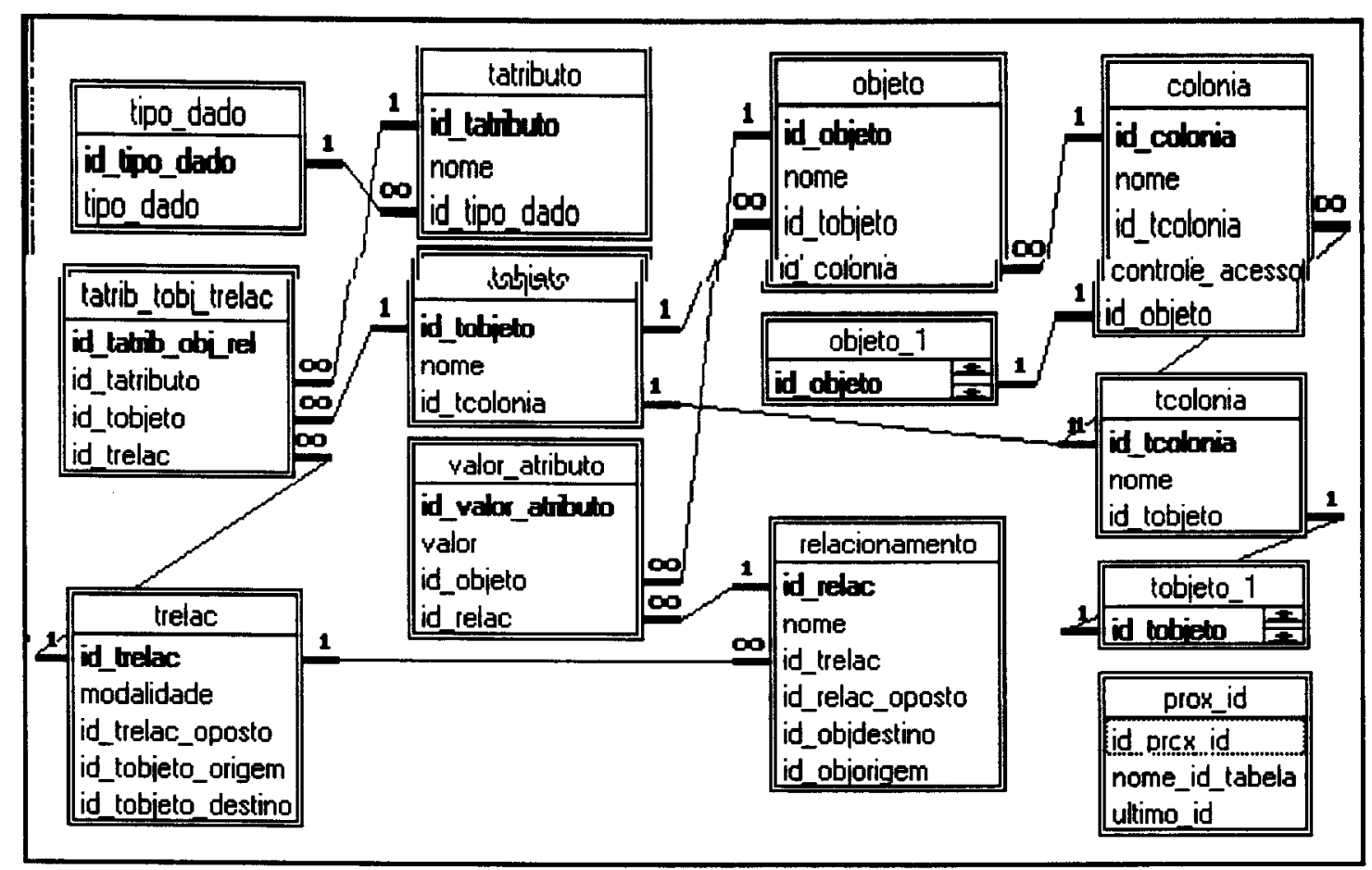

Figura 5.8: Diagrama das tabelas e seus respectivos campos. 


\subsection{Construção de Um Padrão de Interface para Desenvolvimento da Ferramenta.}

Não cabe neste contexto apresentar todas as telas da ferramenta desenvolvida. Entretanto para ilustrar tal ferramenta, apresenta-se o padrão adotado para construção das telas. A figura 5.9 mostra a tela principal do sistema, com Colônias, Objetos, Atributos, Relacionamentos, Usuários, Bases. Para cada um desses elementos foram construídas as telas para criação do esquema e da instância.

O padrão adotado foi o de criar uma tela de seleção para cada elemento da ferramenta (esquema e instância de Colônia, Objeto, Atributo, etc), na qual concentrouse as operações de Consultar, Alterar, Novo e Excluir como mostra a figura 5.10.

Nas figuras 5.11 e 5.12 , tem-se o padrão das telas de cada elemento propriamente dito ( Objeto, Colônias, etc). Nessas telas encontram-se os dados pertencentes aos objetos, relacionamentos, colônias, atributos das bases de dados. 


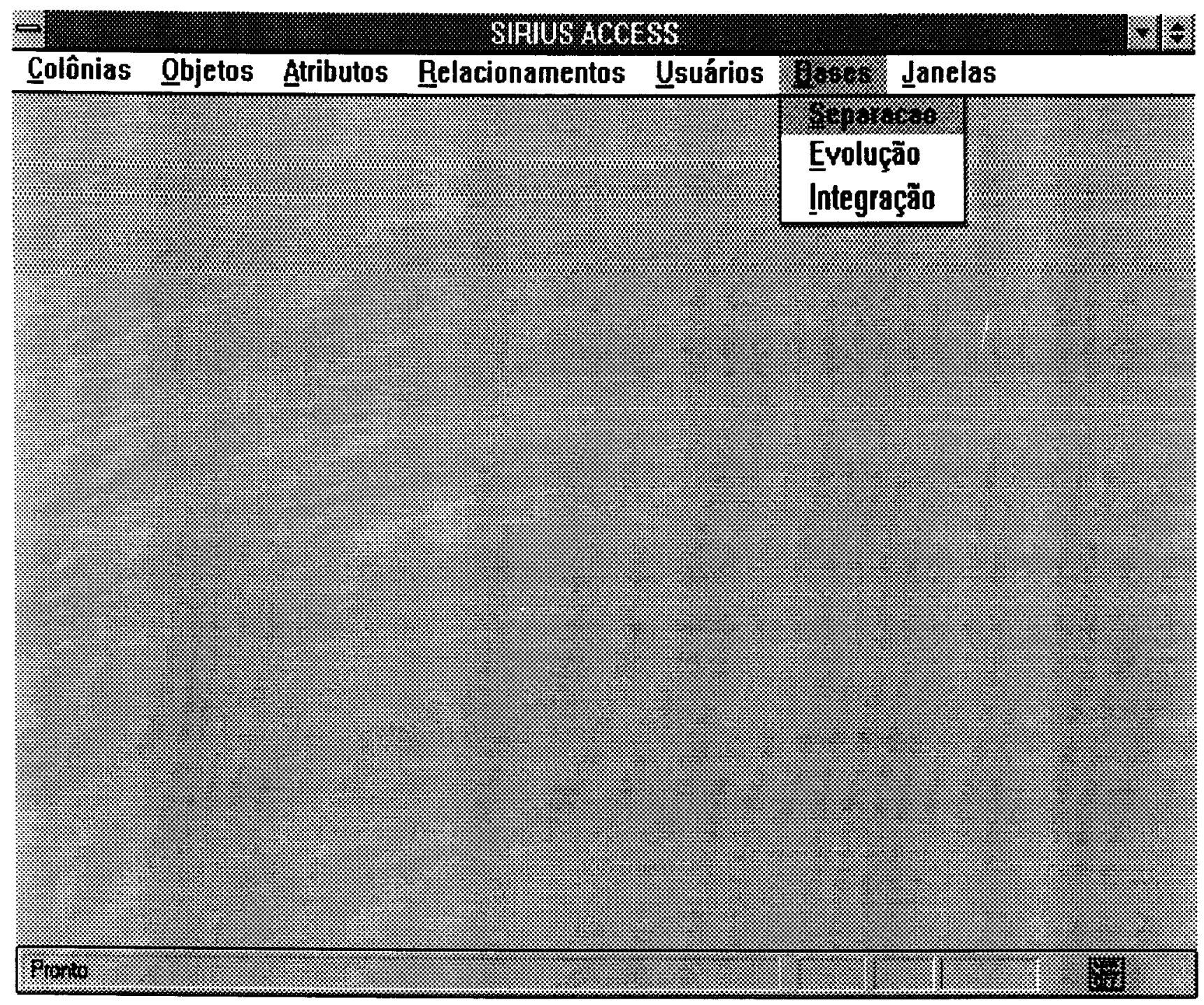

Figura 5.9: Tela Principal do Sistema. 




Figura 5.10: Telas de seleção de esquemas e instâncias de Colônias, Objetos, Atributos, etc. 


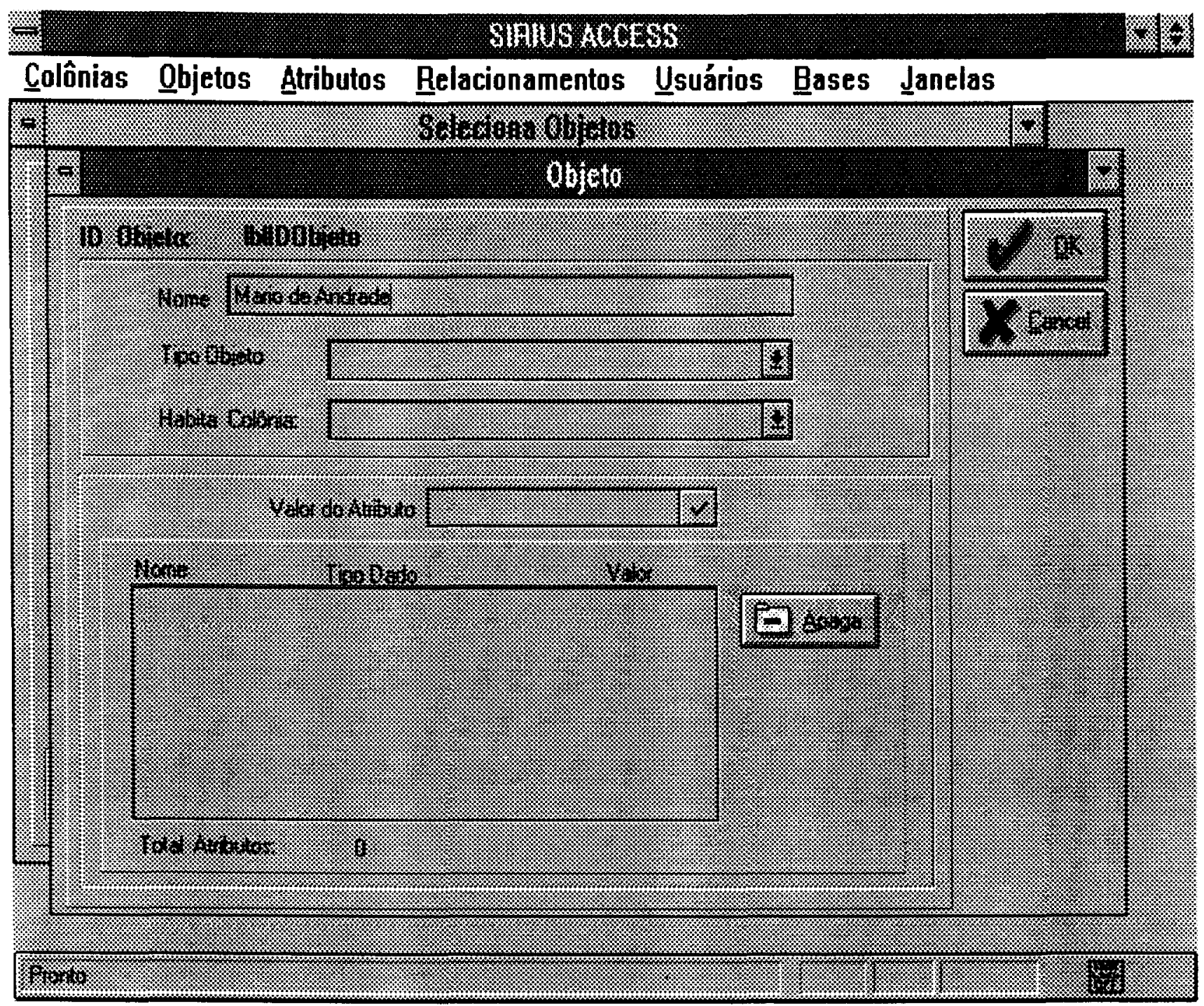

Figura 5.11: Um exemplo de tela padrão para objetos. 


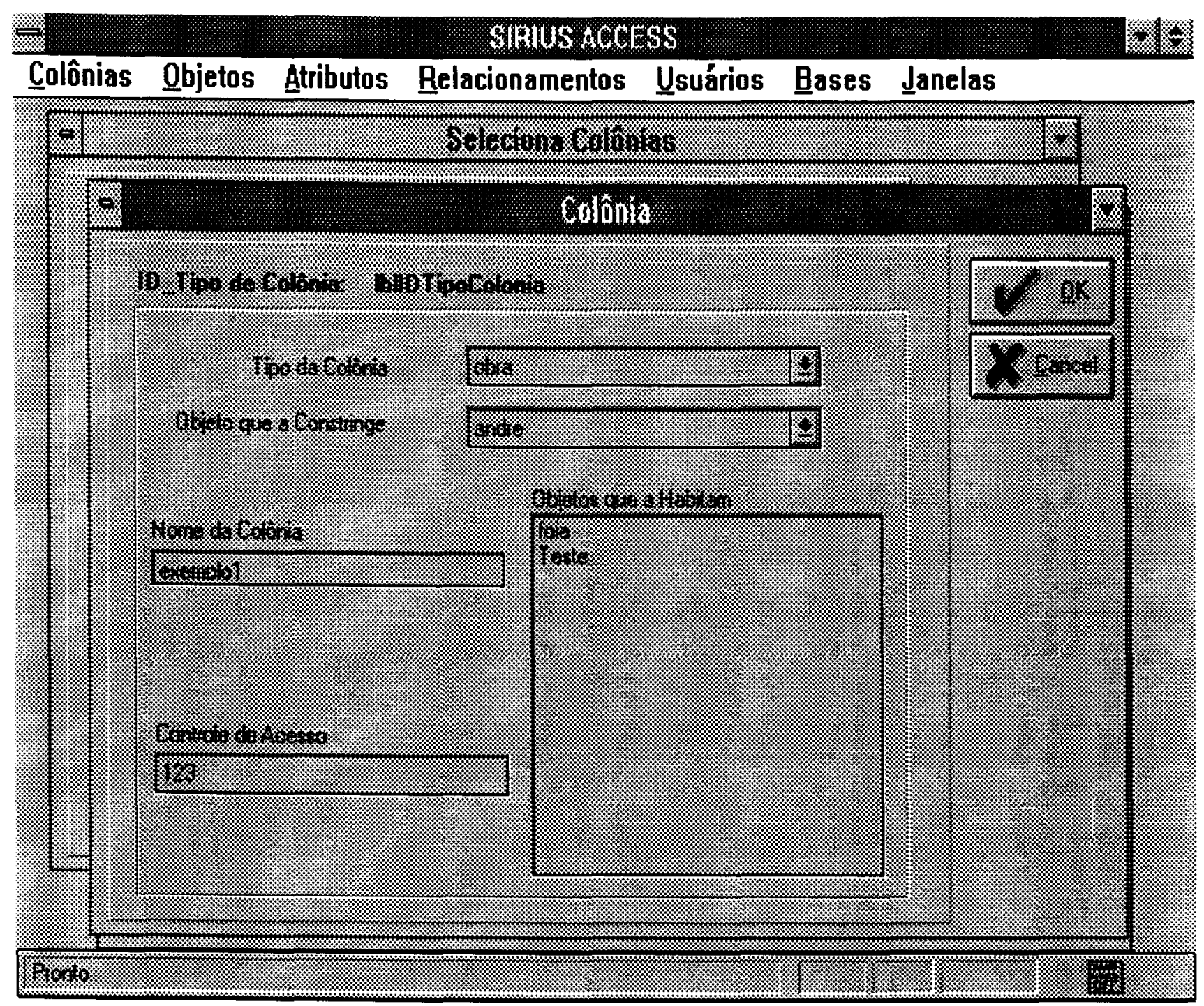

Figura 5.12: Um exemplo de tela padrão para colônias. 


\subsection{Conclusão.}

Uma característica da ferramenta desenvolvida que não foi originalmente planejada, mas proporcionou um resultado importante, foi a adoção de uma interface padronizada para o acesso à base de dados. Isso foi feito, criando-se um método para 0 acesso às informações, apoiado na existência de rotinas especializadas na preparação das cadeias de caracteres. Essas cadeias formam os comandos da linguagem de consulta do gerenciador utilizado, no caso a linguagem SQL. Através desse método, a construção dos comandos não apenas ficou facilitado, como o acesso ao gerenciador pôde ser construído independente do restante da aplicação. Isso cria como que um "driver" na aplicação, que pode ser modificado para acessar outras bases de dados, sem modificar a aplicação em si. Embora existam efetivamente "drivers" específicos padronizados para realizar tal tarefa, como o ODBC ("Open Database Connectivity"), esse tipo de "driver" impõe de fato uma sobrecarga ao processamento, tornando a conexão com o gerenciador de dados mais lenta. O método adotado não permite a substituição do "driver" escrito, como rotinas de preparação de cadeias, sem a disponibilidade do código fonte do aplicativo, o que é uma desvantagem em relação aos "drivers" padrão tipo ODBC. Porém pode ser tão flexível quanto aquele, sem causar a mesma sobrecarga de processamento. 


\section{Capítulo 6}

\section{Conclusão}

\section{Decisões de Projeto, Contribuições e Futuras Pesquisas}

\subsection{Decisões de Projeto.}

Considerou-se que os conceitos apresentados nesta tese deveriam ser suportados por uma implementação, que teria os seguintes objetivos:

1) validação dos conceitos e demonstração de sua exeqüibilidade prática;

2) demonstração de sua aplicabilidade a diferentes gerenciadores de dados, bem como a possibilidade da incorporação dos conceitos diretamente em aplicativos, caso o gerenciador utilizado não suporte tais conceitos;

3) servir como uma ferramenta didática para a demonstração dos conceitos;

4) avaliação e demonstração de técnicas de implementação dos conceitos.

O primeiro objetivo pôde ser atingido pela implementação de uma ferramenta que abrange os conceitos principais descritos na tese, quais sejam:

a possibilidade de definir objetos compostos (no sentido que um objeto composto seja efetivamente "composto por" outros objetos); 
- que os objetos componentes tenham sua existência dependente do objeto composto do qual é parte ou ao menos controlada por este;

- que a composição seja "fisica", isto é, cada objeto componente somente é parte de um objeto composto, criando uma hierarquia de composição;

- que o esquema de uma aplicação possa ser "exportado", ou que esse esquema possa ser passado para outras bases, e de preferência que tipos sejam definidos como objetos também. Se isso não for possível, o método de compartilhamento descrito ainda pode ser usado, desde que o esquema seja o mesmo para todas as bases que compartilham objetos de uma mesma base original.

O segundo objetivo pôde ser atingido implementando-se a ferramenta sobre um Gerenciador de Dados Relacional Comercial. O uso de um gerenciador comercialmente disponivel facilita, entre outros aspectos, a manutenção de um "Gerenciador de Objetos", que no caso pode ser construído como uma lâmina sobre o Gerenciador Relacional. Os conceitos apresentados foram desenvolvidos tendo como ferramenta conceitual o paradigma de Orientação a Objetos. Porém, desde que os conceitos desse paradigma, necessários ao suporte dos conceitos de compartilhamento apresentados sejam suportados, não é necessário o suporte a todos os conceitos do paradigma para que a ferramenta seja construída.

Assim, construiu-se sobre dois Gerenciadores Relacionais uma lâmina que emula os conceitos listados acima, e sobre essa lâmina a ferramenta foi construída. Com essa solução atingiu-se o objetivo de demonstrar sua aplicabilidade mesmo utilizando gerenciadores de dados não orientados a objetos. Demonstrou-se também a possibilidade dos aplicativos incorporarem tais conceitos diretamente, mesmo quando o gerenciador utilizado não os suporta.

Foram utilizados dois gerenciadores relacionais: Oracle e Access. Embora apenas um pudesse ter atendido ao objetivo inicialmente proposto, a utilização de dois deles foi interessante para demonstrar que bases de dados totalmente distintas podem efetivamente 
compartilhar dados, tal como sugerido neste trabalho.

O terceiro objetivo é atingido construindo-se a ferramenta de maneira que cada operação realizada seja "visível" pelo usuário, mesmo quando isso não é necessário. Esse objetivo pode tornar a ferramenta imprópria para uma operação "em produção", pois faz com que os passos necessários tenham que ser todos indicados pelo usuário, mesmo quando eles poderiam ser automatizados, além de efetivamente mostrar muito mais informações que o necessário. Porém, dessa maneira, o usuário acompanha todas as operações efetuadas e/ou necessárias. Esse é o motivo de os formulários (telas) utilizados terem sido individualizados um para cada operação de compartilhamento e atualização/consulta aos dados das bases de dados. Por outro lado, é muito fácil agora remover as informações que não são necessárias, bem como aglutinar dois ou mais formulários em um, criando uma ferramenta própria para produção.

O quarto objetivo foi atingido com uma implementação modular, que pudesse servir como ponto de partida de um produto para uso em produção, e que cada módulo fosse suficientemente independente de maneira que pudesse ser facilmente separado, tanto para ser utilizado individualmente numa outra implementação, quanto para ser substituído por outro, desempenhando o mesmo papel mas com outra funcionalidade.

Uma característica da ferramenta que não foi originalmente planejada, mas proporcionou um resultado importante, foi a adoção de uma interface padronizada para o acesso à base de dados. Isso foi feito criando-se um método para o acesso às informações que apoia-se na existência de rotinas especializadas na preparação das cadeias de caracteres, que formam os comandos da linguagem de consulta ao gerenciador utilizado, no caso a linguagem SQL. Através desse método, a construção dos comandos não apenas ficou facilitado, como o acesso ao gerenciador pôde ser construído independente do restante da aplicação. Isso cria como que um "driver" na aplicação, que pode ser modificado para acessar outras bases de dados, sem modificar a aplicação em si. Embora existam efetivamente "drivers" específicos para isso, padronizados tal como o ODBC ("Open Database Connectivity"), esse tipo de "driver" impõe de fato uma 
sobrecarga ao processamento, tornando a conexão com o gerenciador de dados mais lento. O método adotado não permite a substituição do "driver" escrito como rotinas de preparação de cadeias sem a disponibilidade do código fonte do aplicativo, o que é uma desvantagem em relação aos "drivers" padrão tipo ODBC, porém pode ser tão flexível quanto aquele, sem causar a mesma sobrecarga de processamento.

\subsection{Contribuições Inovadoras.}

\subsubsection{Aspectos de Modelagem de Dados.}

A definição do registro de autorização para as operações nas colônias constritas por objetos, a definição da sintaxe para inter-relacionamentos, o conceito de composição de objetos para distribuição de dados, o conceito de compartilhamento de uma base de dados através de compartilhamentos de objetos (compostos) que constrigem colônias, fases de separação, evolução e integração de bases de dados criando bases original e produto, tipos de vínculos entre as bases original e produto, são algumas contribuições importantes deste trabalho para a área de Modelagem de Dados usando o paradigma de Orientação a Objetos.

A definição do registro de autorização identificou numa estrutura única e bem definida, como as operações de consulta e manipulação de objetos afetam e/ou interagem com as operações necessárias ao gerenciamento de acesso e concorrência de uma Base de Dados Orientada a Objetos.

A definição da sintaxe para inter-relacionamentos identificou como as operações de consulta e manipulação sobre um objeto composto propagam-se para os objetos que agregam-se a esse objeto composto, inclusive levando-se em conta como essa agregação dá-se entre os múltiplos níveis que existem numa hierarquia de composição. 
O conceito de composição de objetos foi definido mais claramente neste trabalho, distingüindo-se entre o que constitui-se numa mera Agregação de Objetos (associando objetos através de relacionamentos que não são do tipo é-parte-de), do que constitui-se efetivamente numa composição, quando o relacionamento é do tipo é-partede. Essa distinção permite restringir a semântica da composição, além de definir claramente o que é uma composição fisica e o que é uma composição lógica. Este trabalho explorou apenas a composição fisica, pois por um lado ela garante a dependência existencial dos objetos componentes (característica necessária ao desenvolvimento deste trabalho), e por outro, representa uma situação real que sempre ocorre, qual seja, a de que um objeto sempre é parte de algo maior, nem que seja o próprio empreendimento (modelado no caso pela base de dados como um todo).

O conceito de compartilhamento de uma base de dados identificou a existência de três fases para que objetos possam ser compartilhados. Demonstrou-se (informalmente) que o compartilhamento de objetos (compostos) deve ser efetuado tomando-se por base uma unidade de compartilhamento que possa ser utilizada para o controle de acesso (e de concorrência). Assim este trabalho apoiou-se no conceito de colônias de objetos, justificando sua necessidade.

As três fases de uma operação de compartilhamento (separação, evolução e integração de bases de dados) operam criando duas bases: original e produto. Cada base produto, gerada na fase de separação de uma operação de compartilhamento, mantém permanentemente um vínculo com a base original de onde foi gerada. É definido também um conjunto de permissões de acesso para que ambas as bases, original e produto, possam admitir alterações durante a fase de evolução. $O$ tipo de vínculo estabelecido na fase de separação caracterizará os métodos utilizados na fase de integração. Embora existam diversos trabalhos envolvendo aspectos de distribuição de dados, poucos abordam aspectos de distribuição de objetos e um número menor ainda identifica a operação de separação e re-integração de dados. Nenhum trabalho de que temos conhecimento trata da existência de uma fase de evolução de dados dependente da 
caracterização do processo de separação e nenhum estabeleceu a existência de tipos de vínculos entre as bases original e produto.

\subsubsection{Aspectos de Implementaç̃o.}

A consulta de dados em bases apoiadas em modelos relacionais é feita por procedimentos de busca em tabelas que, dependendo do volume de dados, podem assumir grandes proporções. Para determinadas consultas, muito freqüentes em ambientes de projeto e de engenharia, longas seqüências de consultas aplicam-se a um conjunto reduzido de dados, devido a própria característica das aplicações em questão. No entanto, na base de dados, essas informações estão misturadas com outras nas mesmas tabelas, pois o critério para a organização dos dados é sua semelhança estrutural. $O$ conceito de composição é um critério semântico para o re-agrupamento das informações, que foi trabalhado nesta tese para ser útil como um critério de organização fisica dos dados. Isso facilita aspectos de processamento, mas principalmente de gerenciamento dos dados, além do gerenciamento de concorrência e acesso, pois a estrutura de composição pode permear muitos níveis de organização dos dados, desde sua concepção lógica, ligada à aplicação em si, até a alocação física de espaço em memória para a armazenagem dos dados correspondentes.

A manutenção de consistência dos dados em bases de dados distribuídas é um problema permanente, mesmo que a interligação entre os diferentes nós seja feito por elos de grande confiabilidade, pois eventualmente diferentes partes da rede podem permanecer durante algum tempo isoladas. Os vínculos "lógicos" tratados neste trabalho são uma maneira eficaz de manter os nós operando durante muito tempo de maneira independente de alguma conexão física. Isso diminiu também a carga da rede e contribui para distribuir a carga de processamento, permitindo maior flexibilidade na alocação de dados, bem como oferece para o gerente critérios de distribuição/particionamento/replicação baseados na semântica das aplicações. 
Os conceitos desenvolvidos nesta tese foram criados a partir de conceitos de orientação a objetos, mas tal como foi exemplificado no capítulo 5, estes podem igualmente ser aplicados em gerenciadores relacionais. A propriedade das estruturas de composição, de fluir intocadas entre vários níveis de abstração, indicam a possibilidade de que sejam incorporados em gerenciadores comerciais, trazendo para o domínio de ferramentas já disponiveis os beneficios deste estudo.

\subsection{Sugestões para Futuras Pesquisas.}

\section{Formalismo para criação da Operação Compartilhamento.}

Neste trabalho procurou-se tratar os conceitos com algum rigor, embora muitas das discussões estivessem vinculadas em grande parte aos aspectos semânticos. Uma vez que a operação de compartilhamento está completamente definida, uma atividade futura corresponde à sua formalização, tanto sob o ponto de vista de uma extensão a um determinado modelo de dados, quanto independentemente, como uma operação complementar a qualquer modelo subjacente.

\section{Incorporação da Operação Compartilhamento de Objetos no SIRIUS/GO.}

O gerenciador SIRIUS/GO está sendo desenvolvido para suportar o modelo SIRIUS, o qual contempla todos os recursos necessários para suportar a operação de compartilhamento. Assim, SIRIUS/GO constitui-se num ambiente muito adequado para suportar esses conceitos de maneira nativa.

"Drivers" genéricos para estender SQL para suportar compartilhamento de dados.

Aliando a técnica de separação da "montagem" de comandos para acesso aos gerenciadores de bases de dados do código da aplicação em si, com as técnicas descritas no capítulo 5 para a construção de uma lâmina de emulação do suporte ao compartilhamento de dados, torna-se possível a construção de "drivers" que apresentem para as aplicações uma interface programacional, com recursos para suportar a 
manipulação dos dados como parte das operações da fase de evolução da operação compartilhamento. Assim, propõe-se aqui que seja especificado e implementado um padrão de interface programacional (API), para que as operações de manipulação de dados, em um gerenciador relacional, possam contemplar as necessidades de operações de compartilhamento em andamento em uma base de dados, de maneira transparente para as aplicações que utilizem essa interface. As fases de separação e integração devem ser supridas por utilitários desenvolvidos adequadamente para atender ao padrão suportado pelos "drivers" desenvolvidos, os quais estabelecerão os diversos registros necessários ao compartilhamento, como descritos no capítulo 4 .

\section{Finalizar uma Operação de Compartilhamento sem a fase de integração.}

Este trabalho tratou de operações de compartilhamento em que as 3 fases ocorrem de maneira normal. No entanto, é possível que uma base que tenha sido separada de outra por uma operação de compartilhamento possa não vir a ser integrada. Nesse caso, os vínculos devem ser "cortados", e as permissões de acesso devem ser redefinidas, incluido-se a liberação de bloqueios efetuados para um processo de separação normal (mas não os bloqueios existentes anteriormente ao compartilhamento). Uma interrupção de uma operação de compartilhamento deve levar em conta se as atualizações já realizadas, desde o início da fase de evolução, devem ser repassadas entre ambas as bases.

Uma conseqüência que deve então ser estudada advém da existência de duas bases com origem comum, com pelo menos parte do esquema compatível. $O$ principal motivo desse estudo deve ser a possibilidade de um re-acoplamento no futuro, como por exemplo para a troca de informações compatíveis.

Um exemplo dessa situação pode ser quando uma empresa projeta, constrói e vende componentes, cuja especificação pode ser repassada para empresas (independentes) que usam esses componentes. Nesse caso, a parte da base da empresa produtora correspondente àquele componente poderia ser compartilhada com uma base produto de uma operação de compartilhamento, que seria repassada para a empresa usuária e ambas 
as empresas prosseguem seus negócios independentemente. Eventualmente, sugestões de melhorias nos componentes, incluidas na cópia da base da empresa usuária (uma vez base produto de um processo de compatilhamento interrompido), podem por exemplo ser absorvidas pela empresa produtora.

\section{Integração de Bases com Dados Compativeis.}

Uma conseqüência da proposta anterior corresponde à sugestão de estudar-se meios para o compartilhamento de dados entre bases de dados com origens distintas. Nesse caso, apenas a fase de integração estaria envolvida, porém é necessário para isso uma nova fase, anterior, que busque os elos de compatibilidade entre porções dos esquemas de ambas as bases. Isso poderia permitir que partes de uma base de dados, cujo esquema é conceitualmente semelhante ao de outra base possam integrar-se. Esse estudo recai em técnicas que têm sido bastante estudadas na área de Bases de Dados Federadas, porém poderia ser avaliado novamente sob o enfoque da arquitetura de compartilhamento desenvolvida nesta tese

\section{Compartilhamento de Objetos Independentes.}

Este trabalho desenvolveu-se sob o pressuposto de que porções significativas de uma base deveria ser compartilhada. Levando-se em consideração que um processo de compartilhamento pode ser terminado sem a fase de integração, ou que uma fase de integração poderia ocorrer independente da existência de um processo de compartilhamento anterior, então deve-se levar em conta também a possibilidade de que objetos possam ser compartilhados entre bases de maneira independente. Ou seja, pode-se considerar que um objeto isolado (levando encapsulado seu esquema) poderia ser extraído de uma base e inserido em outra. Para que isso possa ser possível, é necessário que ambas as bases possam reconhecer a estrutura do objeto, a qual deveria estar no próprio objeto. Surge assim o conceito de "Objeto Vetor", pois permite levar informações de uma base para outra e a interoperabilidade de ambas, sem que as duas bases necessitem ter uma origem e portanto um esquema comum. 
Um exemplo de utilização pode ser empresas que necessitam trocar documentos, tais como pedidos de compra, faturas e recibos, sem que para isso precisem ter ambas seus sistemas de bases de dados conectados ou mesmo compativeis, inclusive permitindo que essas operações ocorram de maneira esporádica.

\section{Especialização do objeto Operação Compartilhamento.}

Criação de uma hierarquia de classes para especialização do objeto Operação Compartilhamento. Uma maneira de especialização da operação de compartilhamento é tratando-a como um todo. Pode-se prever uma forma específica de compartilhamento entre bases para permitir que parte da informação de uma base "navegue" entre diversas bases, ou pode-se desejar uma forma de compartilhamento em que partes de uma base sejam difundidas amplamente entre diversas bases.

Por outro lado, pode-se especializar individualmente fases, como as de separação e integração. Por exemplo, pode-se especializar a fase de integração, sobrecarregando seus métodos, para que esta contemple determinada forma de integração. Numa aplicação de coleta de dados pode-se desejar que bases com evolução independentes sejam integradas, acumulando-se todos os dados obtidos por ambas as bases. Por outro lado, numa aplicação de concorrência de preços, bases com evolução independentes podem ser integradas selecionando-se apenas as informações que atendem ao critério de escolha definida no lançamento da concorrência (a fase de separação).

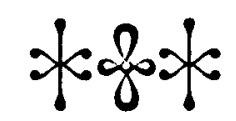




\section{Bibliografia}

\section{Referências Bibliográficas}

[ATKINSON_89] ATKINSON, M. et al. The Object oriented database system manifesto. Rapport Technique Altair, INRIA-LRI, October 1989.

[BERNSTEIN_80a] BERNSTEIN, P.A.; SHIPMAN, D.W.; ROTHNIE JR.,J.B. Concurrency control in a system for distributed database (SDD-1). $A C M$ Transactions on Database System, v.5, n. 1, p.18-25, 1980.

[BERNSTEIN_80b] BERNSTEIN, P.A.; SHIPMAN, D.W. The Correctness of a concurrency control mechanism in a system for distributed databases (SDD-1). ACM Transactions on Database System, v.5, n.1, p.52-68,1980.

[BERNSTEIN_81] BERNSTEIN, P.A.; GOODMAN, V. Concurrency control in distributed database system. Computing Surveys, v. 13, n.2, p.186-221, 1981.

[BERTINO_93] BERTINO, E.; LORENZO, M. Object oriented database systems. International Computer Science Series, Addison-Wesley, 1993.

[BETZ_94] BETZ, M. Omg's corba: an emerging standard for real-world implementations. Dr. Dobbs's Special Report, p.8-12, 1994.

[BIAJIZ_96] BIAJIZ, M. Desenvolvimento de um meta-modelo de representação de modelos de dados orientados a objetos. São Carlos. Tese (Doutorado) - Instituto de Física de São Carlos, Universidade de São Paulo. [a ser apresentada].

[CASANOVA_84] CASANOVA, M.A.; MOURA, A.V. Princípios de sistemas de gerência de banco de dados distribuídos. Texto publicado na Quarta Escola de Computação - Sociedade Brasileira de Computação. IME-USP, 1984.

[CATTELL_94] CATTELL, R. Object data management: Object-Oriented and Extended Relational. Addison-Wesley Ed., 1994. 
[CERI 84] CERI, S.; PELAGATTI, G. Distributed database: principles and systems. New York, MacGraw-Hill, 1984.

[CHORAFAS_93] CHORAFAS, D. N. Manufacturing databases and computer integrated systems. Crc Press, Inc./Lewis Publishers, 320 p., 1993.

[CORREA_94] CORREAA, R. V. Um Tradutor de consultas para um sistema de gerenciamento de banco de dados orientado para objetos: linguagem de consulta e processo de transformação. Dissertação de Mestrado. PPG-CG/UFSCar, São Carlos, agosto 1994.

[DATA_88] DATE, C. J. Banco de dados (tópicos avançados). Rio de Janeiro, Campus, 1988.

[DEUX_90] DEUX, O. et al. The Story of $\mathrm{O}_{2}$. IEEE Transactions on Knowledge and Data Engineering - Special Issue on Database Prototype Systems, v. 2, n. 1, p. 91107, março 1990.

[DEUX_91] DEUX, O. et al. The $\mathrm{O}_{2}$ system. Communications of the ACM, v. 34, n. 10 , p.34-48, October 1991.

[ESWARAM_76] ESWARAN, K.P. et al. The Notions of consistency and predicate locks in a relacional database system. Communications of the ACM Transactions on Information Systems, v.19, n.11, p.624-34, 1976.

[FERRARI_92] FERRARI Jr., R. Um Subsistema de armazenamento de objetos e sua utilização em geoprocessamento. Dissertação de Mestrado. PPG-CG/UFSCar, São Carlos, agosto 1992.

[FERNANDEZ_75] FERNANDEZ, E. B.; SUMMERS, R. C.; LANG, T. Definition and evaluation of access rules in data management systems. In: Proceedings of the INTERNATIONAL CONFERENCE ON VERY LARGE DATA BASES, 1., Boston, Mass., p. 129-148, 1975.

[KHOSHAFIAN_89] KHOSHAFIAN, S.; COPELAND, D. Object identity. In: ZDONIK, B.; MAIER, D. Readings in object-oriented database systems. Morgam Kaufmann Ed., p. 37-46, 1989.

[KIM-87] KIM, W.; CHOU, H. T.; BANERJEE, J. Operations and implementation of complex objects, In: IEEE INTERNATIONAL CONFERENCE ON DATA ENGINEERING, 3., Addison-Wesley, p. 67-85, 1987. Anais.

[KIM_89] KIM, W. et al. Composite objects revisited. ACM SIGMOD, p. 337-47, 1989. 
[KIM_90] KIM, W. Introduction to object-oriented database. Cambridge - Mass., MIT Press, 1990.

[KIM_91-a] KIM, W. et al. A Model of authorization for next-generation database systems. ACM Transactions on Informations Systems, v. 16, n.1, p.88-131, mar 1991

[KIM_9l-b] KIM, W. et al. A Distributed object-oriented database system supporting shared and private databases". ACM Transactions on Informations Systems, v.9, n. 1, p.31-51, jan 1991 .

[KIM_95] KIM, W. The Object Model, Interoperability and Beyond. New York, Addison-Wesley Publishing Company, 1995.

[KORTH_82] KORTH, H.F. Deadlock freedom using edge locks. ACM Transactions on Database Systems, v.7, n.4, p.632-652, 1982.

[KORTH_82] KORTH, H.F. Locking primitives in a database system. Journal of the $A C M$, v.30, n. 1, p.55-79, 1983.

[LORIE_83] LORIE, R.; PLOUFFE, W. Complex objects and their use in design transactions. In: Proceedings of the DATABASES FOR ENGINEERING APPLICATIONS. Database Week 1983, ACM Transactions on Informations Systems, New York, p. 115-121, 1983.

[NAVATHE_94] NAVATHE, S.B.; ELMASRI, R. Fundamentals of database systems. 2.ed. The Benjamin/Cummings Publishing Company, Inc., 1994.

[OвJестrviтY-90] Menlo Park Objectivity, Inc. Objectivity database system overview, Objectivity Inc., 1990.

[RABITTI_88] RABITTI, F.; WOELK, D.; KIM, W. A Model of authorization for object-oriented and semantic databases. In: Proceedings of the INTERNATIONAL CONFERENCE ON EXTENDING DATABASE TECHNOLOGY, Venice, Italy, p. 85-127, mar 1988.

[STONEBRAKER_89] STONEBRAKER, M.; ROWE, L.; HIROHAMA, M. The implementation of postgres. IEEE Trans. on Knowledge and Data Engineering, v. 2, n. 1, p. $125-142,1990$.

[STONEBRAKER_90] STONEBRAKER, M. et al. Third-generation database system manifesto. The Committee for Advanced DBMS Function, Sigmod Record, v.19, n.3, september 1990. 
[TRAINA-94] TRAINA JR., C.; TRAINA, A.J.M.; BIAJIZ, M. O Papel da abstração de instanciação em um meta-modelo de abstrações para BDOO. In: SIMPÓSIO BRASILEIRO DE BANCO DE DADOS, 9., São Carlos, set. 1994. Anais. São Carlos, ICMSC-USP, p. 173-187, 1994.

\section{Bibliografia Consultada}

ADLER, R. M. Distributed coordination models for client/server computing. IEEE Proceedings, p. 14-22, 1995.

BARGHOUTI, N.S.; KAISER, G.E. Concurrency control in advanced database applications. ACM Computing Surveys, v.23, n.3, p. 269-317, 1991.

BIRMAN, K. The Process-group approach to reliable distributed computing. Comm. $A C M$, v. 36, n. 12, p. 37-53, 1993.

BETZ, M. OMG's CORBA. Dr. Dobb's Special Report, p. 8-23, winter 1994/1995.

BETZ, M. Interoperable objects. Dr. Dobb's Journal, p. 18-38, October 1994.

BETZ, M. Building a CORBA object server. Software Development, p. 53-61, October 1995.

BETZ, M. Networking objects with CORBA. Dr. Dobb's Journal, p. 18-26, November 1995.

BROCKSCHMIDT, K. OLE integration technologies. Dr. Dobb's Special Report, p. $42-49$, winter $1994 / 1995$.

CAMPAGNONI, F. R. IBM's system object model. Dr. Dobb 's Special Report, p. 24-29, winter 1994/1995.

GARCIA-MOLINA, $H$. Using semantic knowledge for transaction processing in a distributed data base. ACM Transactions on Database Systems, v.8, n.2, p. 186$213,1993$.

GENTRY, D. Distributed applications and next's PDO. Dr. Dobb's Special Report, p. 58-61, winter 1994/1995.

NICOL, J. R. et al. Object orientation in heterogeneous distributed computing systems. IEEE Proceedings, p. 57-67, June 1993. 
ORFALI, R.; HARKEY, D. Client/server with distributed objects. Special Report Byte, p. 151-176, April 1995.

VALDÉS, R. Implementing interoperable objects. Dr. Dobb's Special Report, p. 62 72, winter 1994/1995.

WIEDERHOLD, G. Database design. New York : MacGraw-Hill, 1993

\section{Endereços eletrônicos:}

"http://csalpha.unomaha.edu/object-orientation" Object Oriented Databases Homepage

"http://liinwww.ira.uka.de/bibliography/Object/index.html"

Bibliographies on Object-Oriented Programming and Systems

"http://www.acl.lanl.gov/sunrise/DistComp/Objects/corba.html" CORBA

(Common Object Request Broker Architecture) and the OMG

"http://www.informatik.uni-trier.de/ ley/db/index.html" Database Systems \& LogicProgramming

"http://www.dcs.napier.ac.uk/osg/links2.html"Object Systems Group (Links) 
Anexo : Exemplo de uma aplicação 
Exemplo simplificado de uma utilização do aplicativo

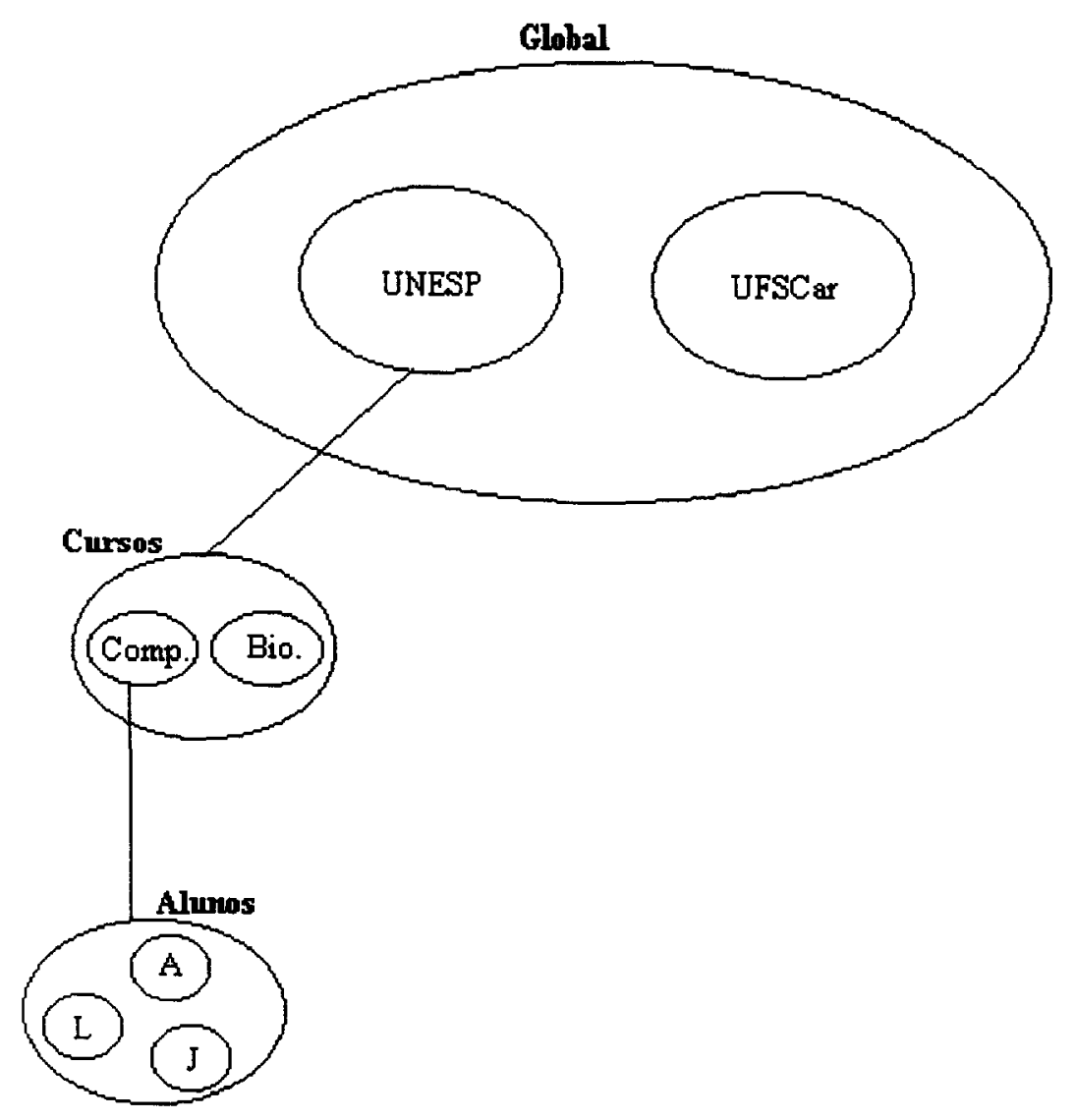

O nosso exemplo irá seguir o esquema apresentado na figura acima. Dentro da colônia Global criamos dois objetos (UNESP e UFSCar) do tipo de objeto t_universidade. $O$ objeto UNESP constringe a colônia cursos que contém dois objetos do tipo de objeto t_curso (computação e biologia). Criamos também a colônia alunos que é constrita pelo objeto computação. Criaremos 3 outros objetos (André, Leonardo, José) que serão do tipo de objeto t_aluno e pertencerão a colônia alunos..

Notação: plural - referente a colônia. singular - referente a objetos. 
1. Criaremos os atributos referentes aos alunos (RG, ingresso, inscricao, endereco, note que o nome do aluno será o nome do nosso objeto, logo nome não constará da lista de atributos).

2. Criaremos os atributos referentes aos cursos (duração e período).

3. Criaremos o atributo referente a universidade (administração).

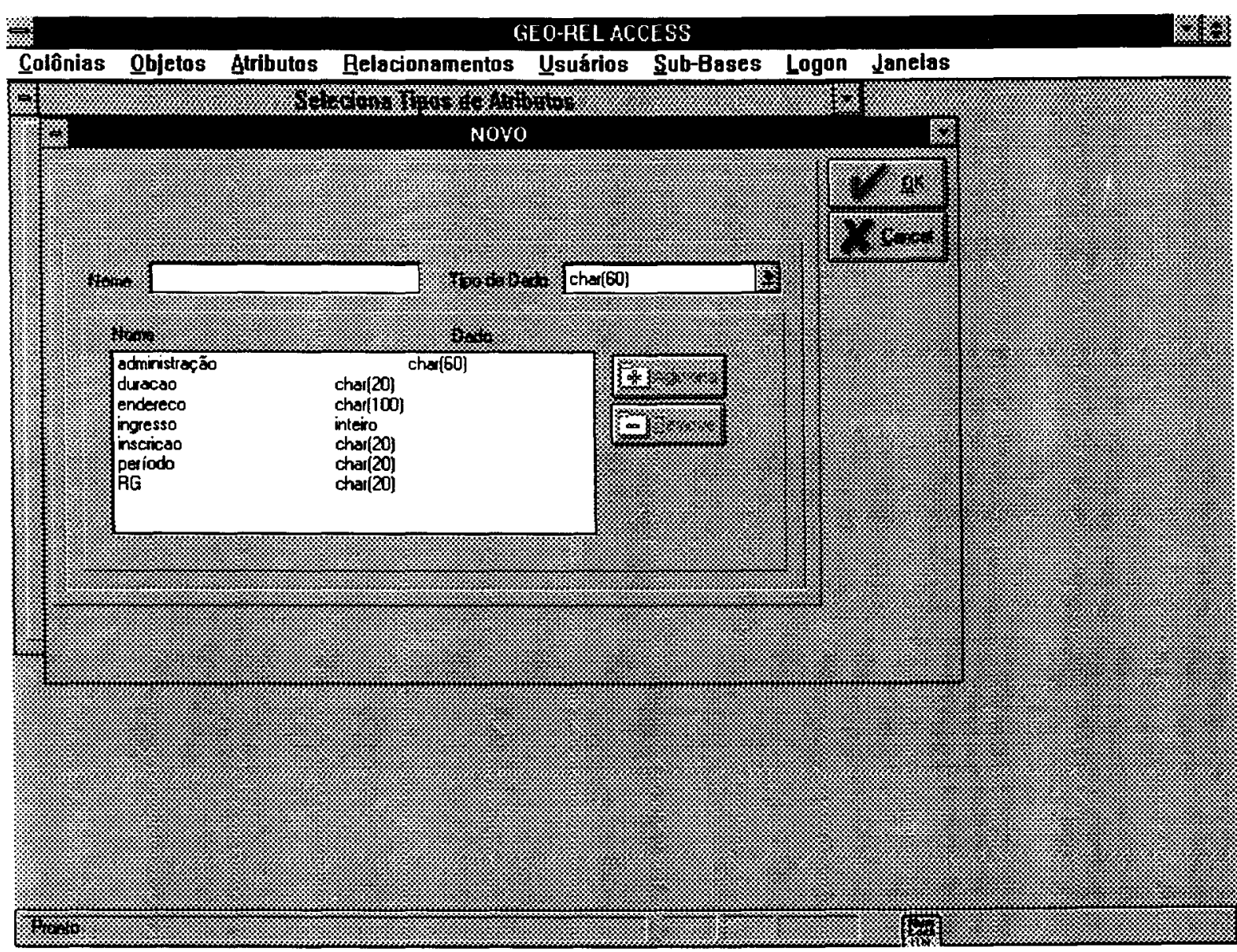


4. Criaremos, agora, o tipo de objeto universidade (habita colônia global).

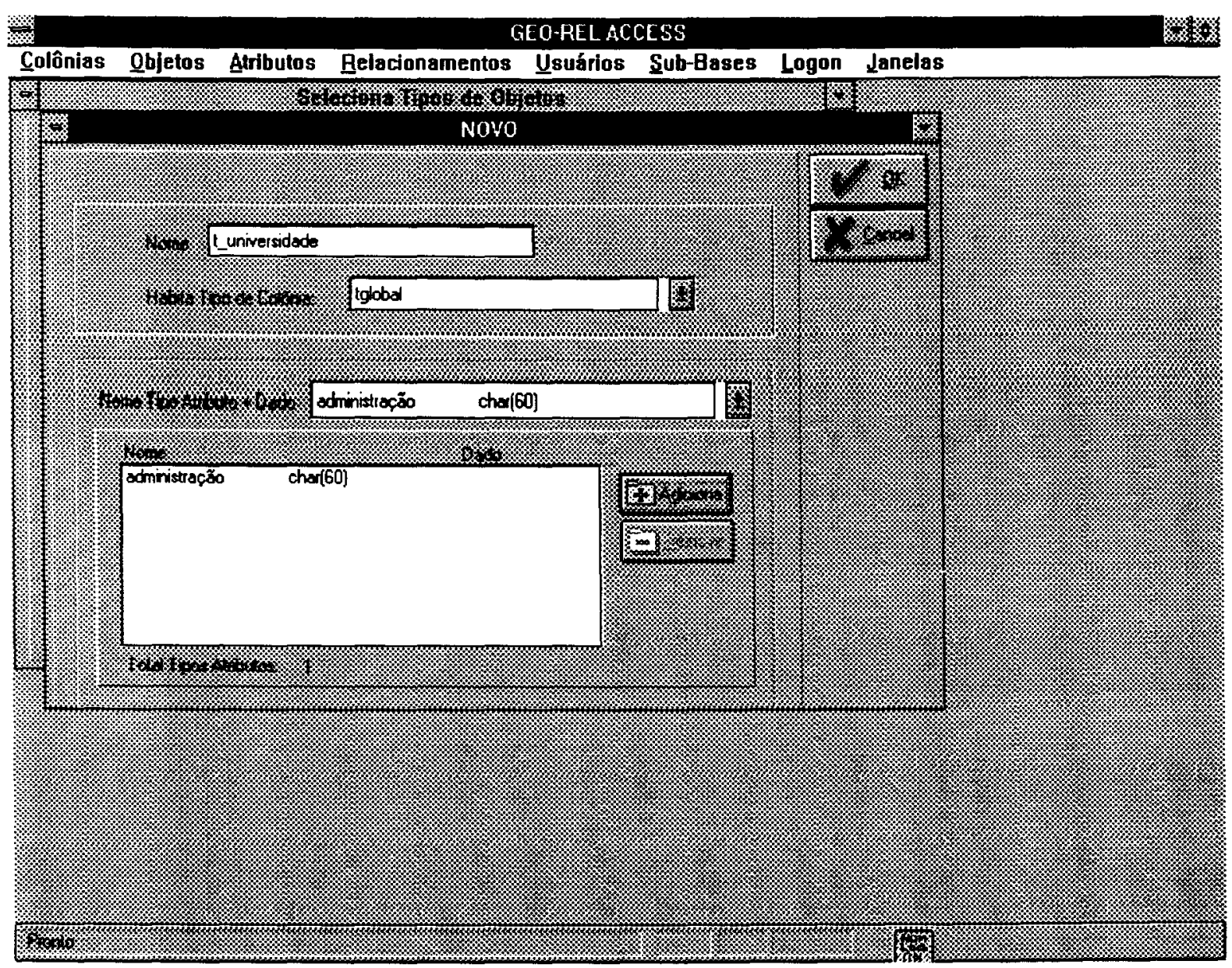


5. Criaremos a seguir os objetos UNESP e UFSCar.

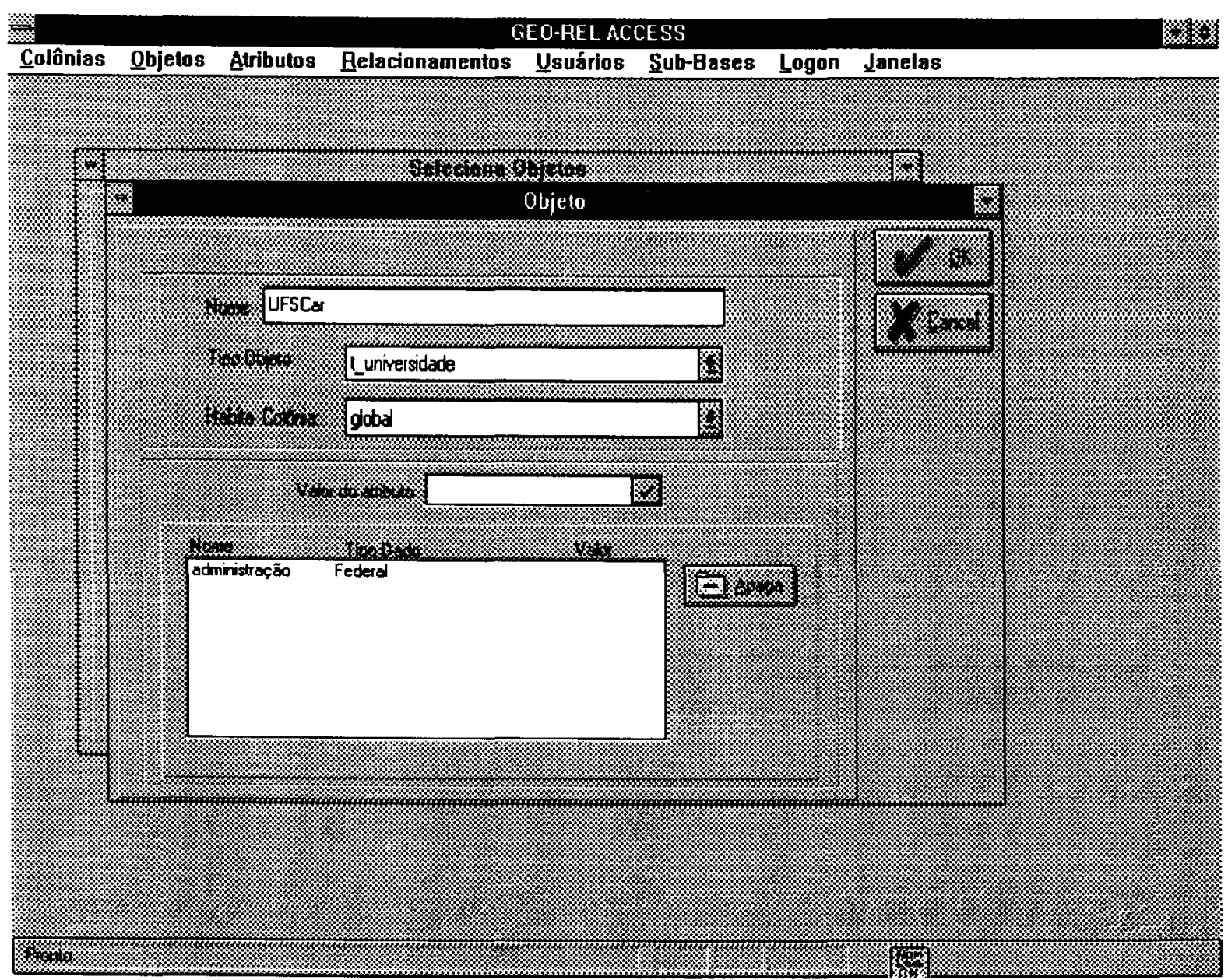


6.Criaremos a colônia t_cursos que é constrita pelo tipo de objeto t_universidade.

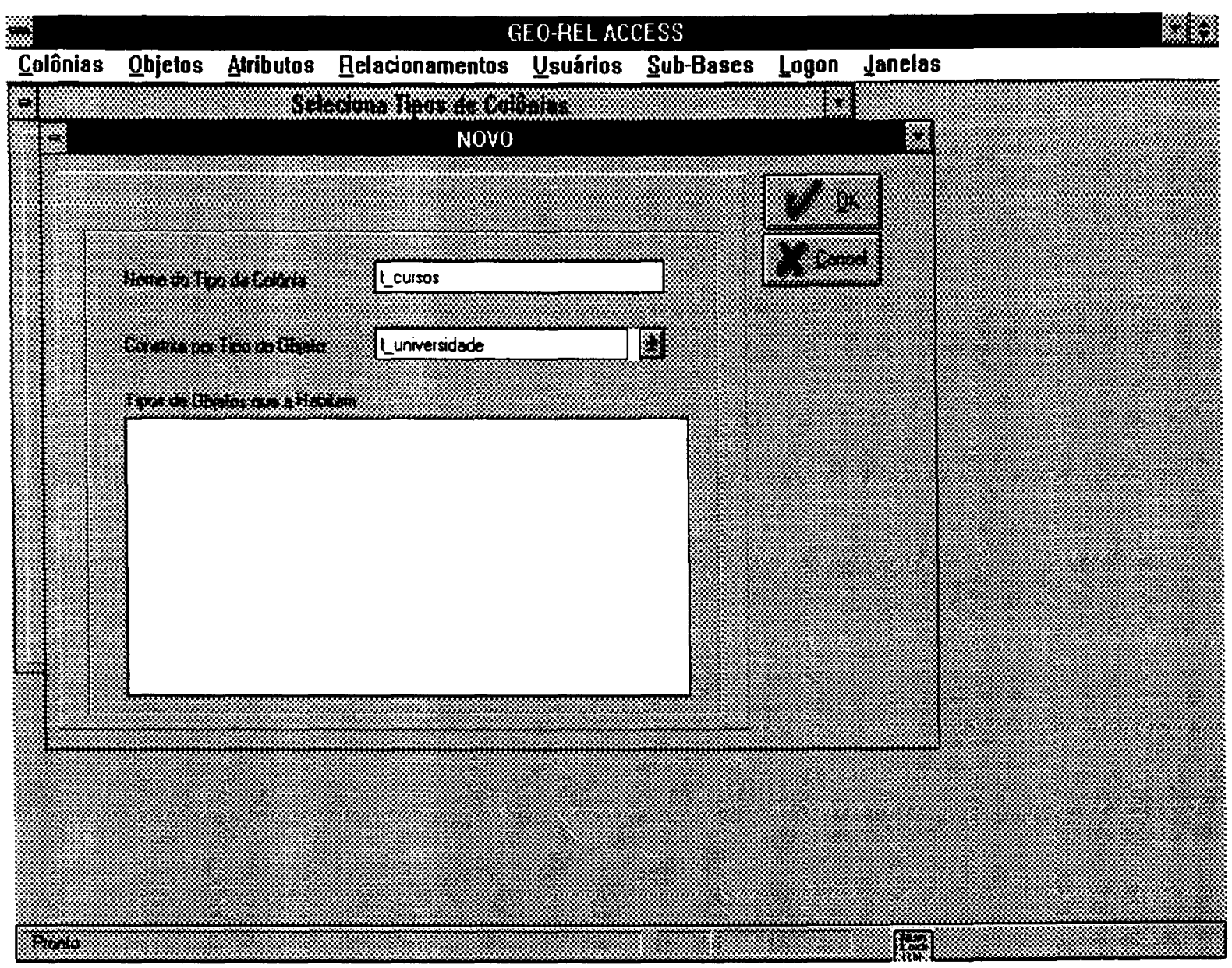


7. Criaremos a colônia cursos que é constrita pelo objeto UNESP. Note que nós deveríamos criar uma outra colônia para o objeto UFSCar, porém isso pode ser feito seguindo os mesmos passos que para o exemplo abaixo.

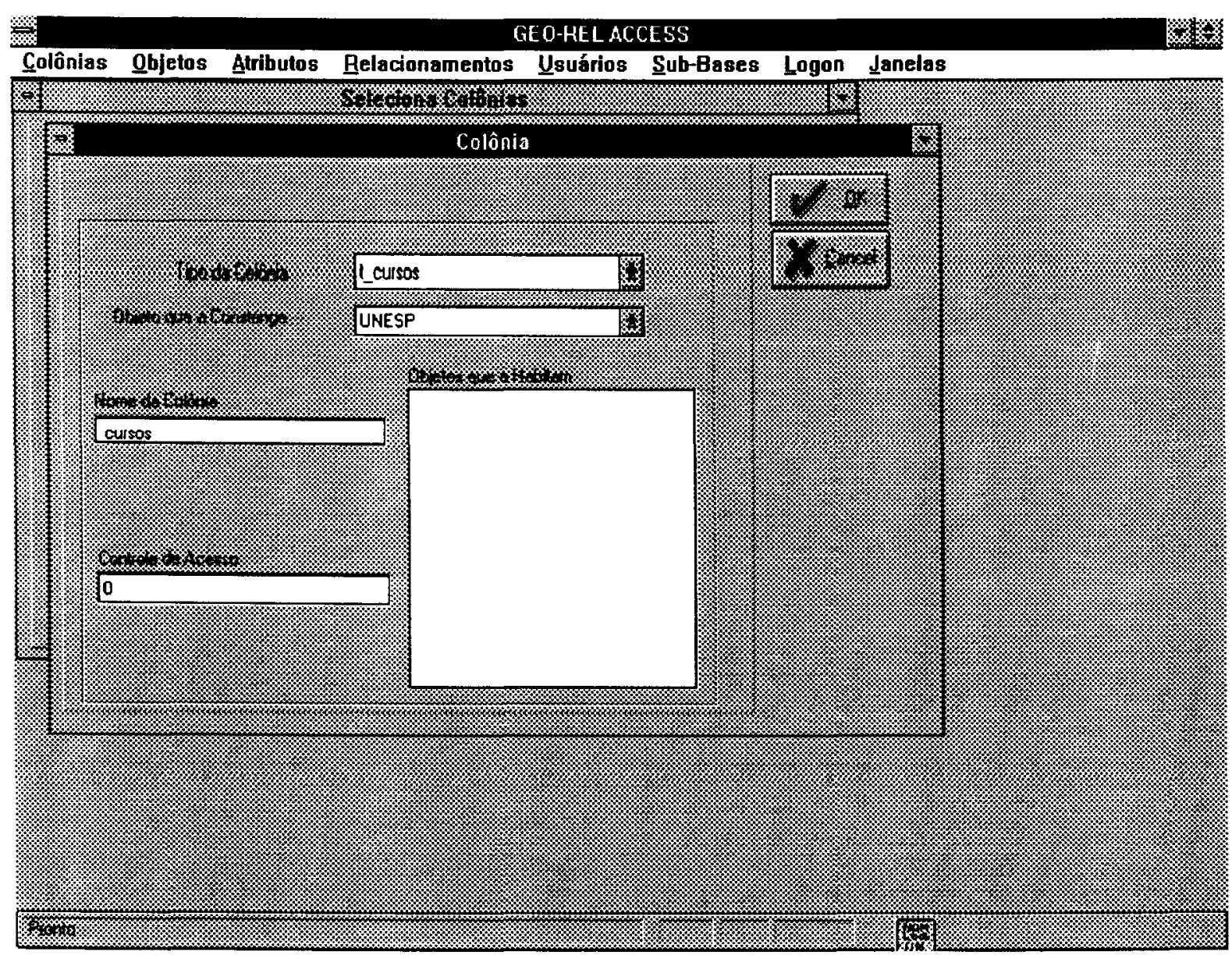


8. Criaremos o tipo de objeto curso.

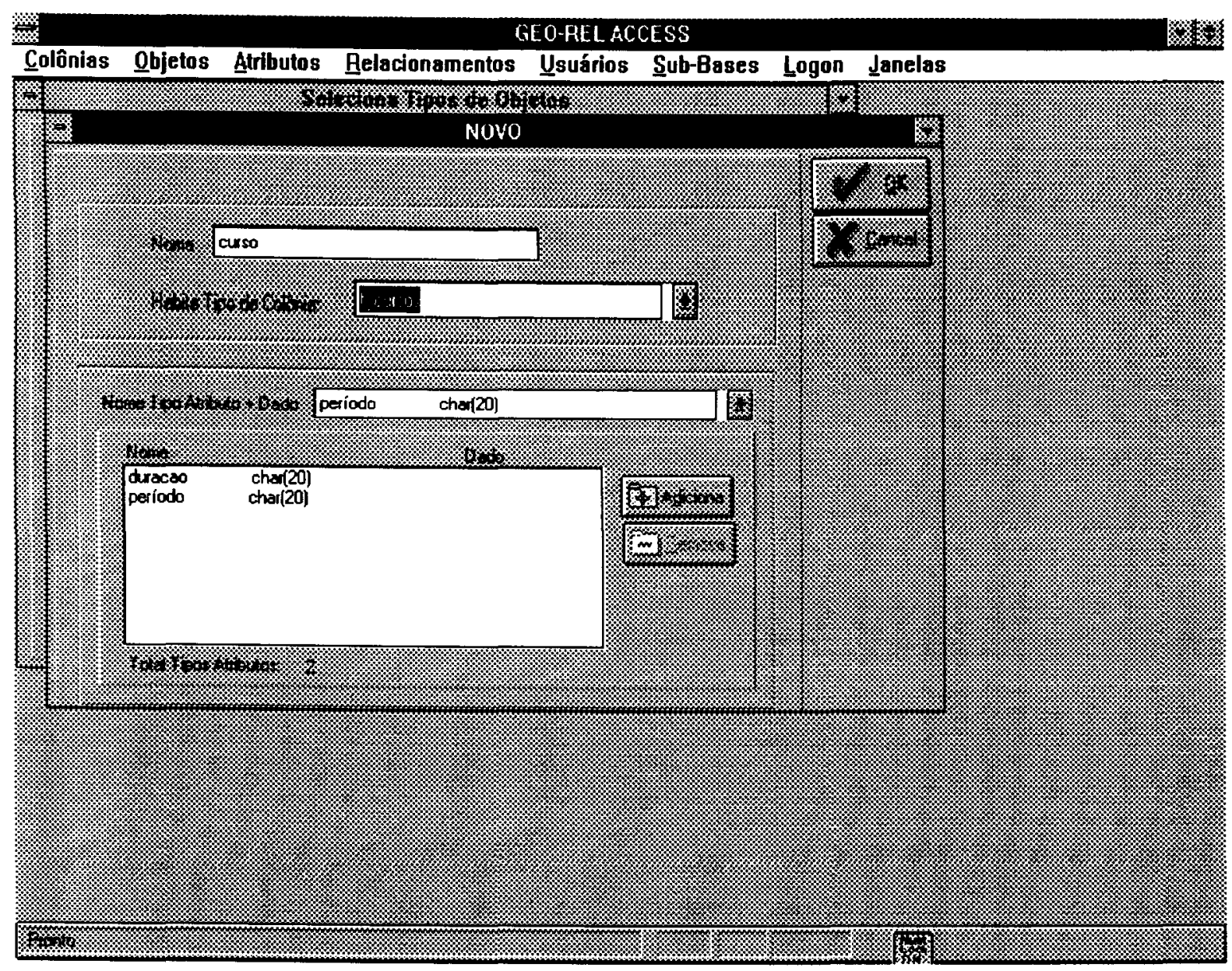


9. Criaremos os objetos Computação e Biologia, ambos habitam colônia cursos.

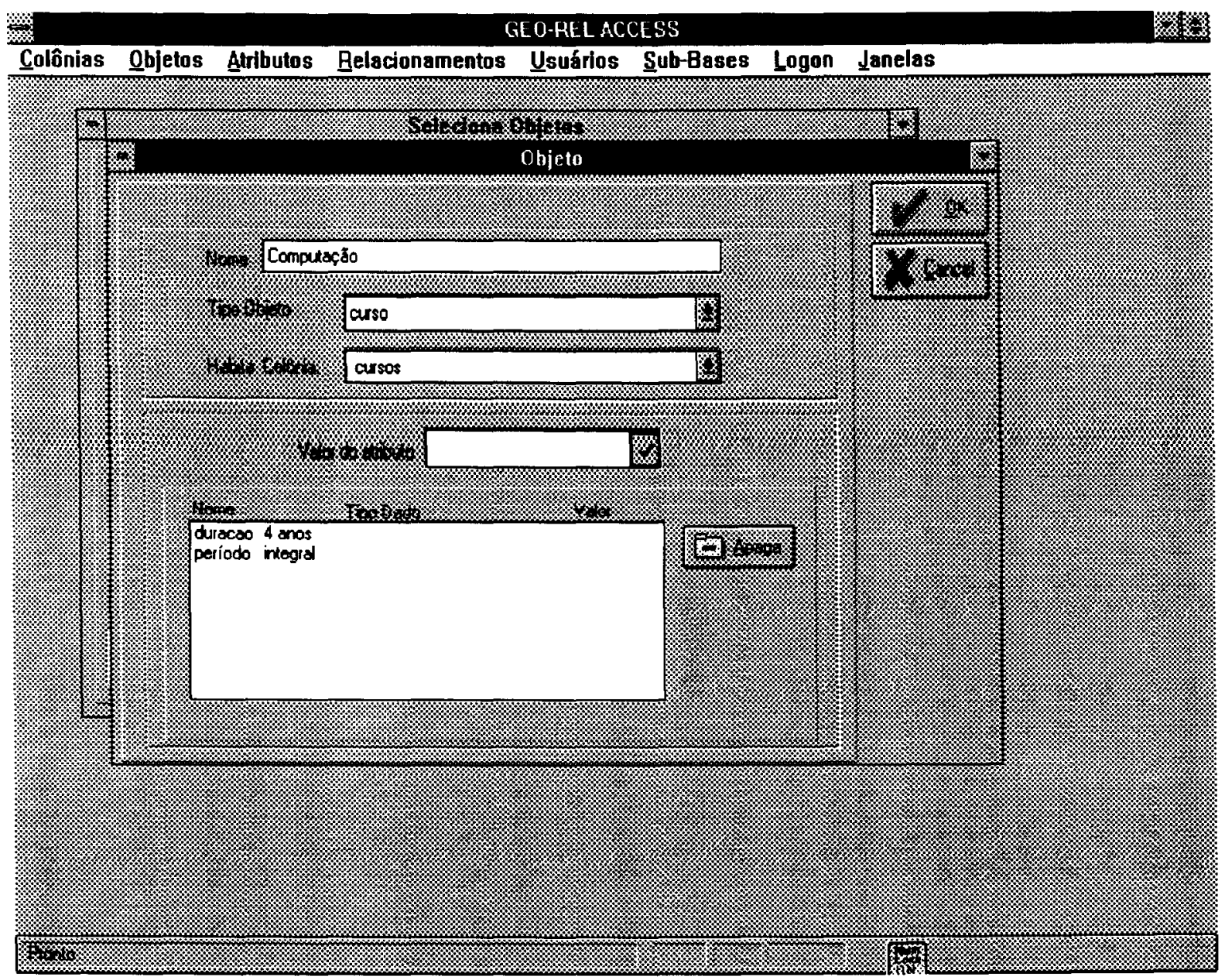


10. Criaremos tipo de colônia t_alunos.

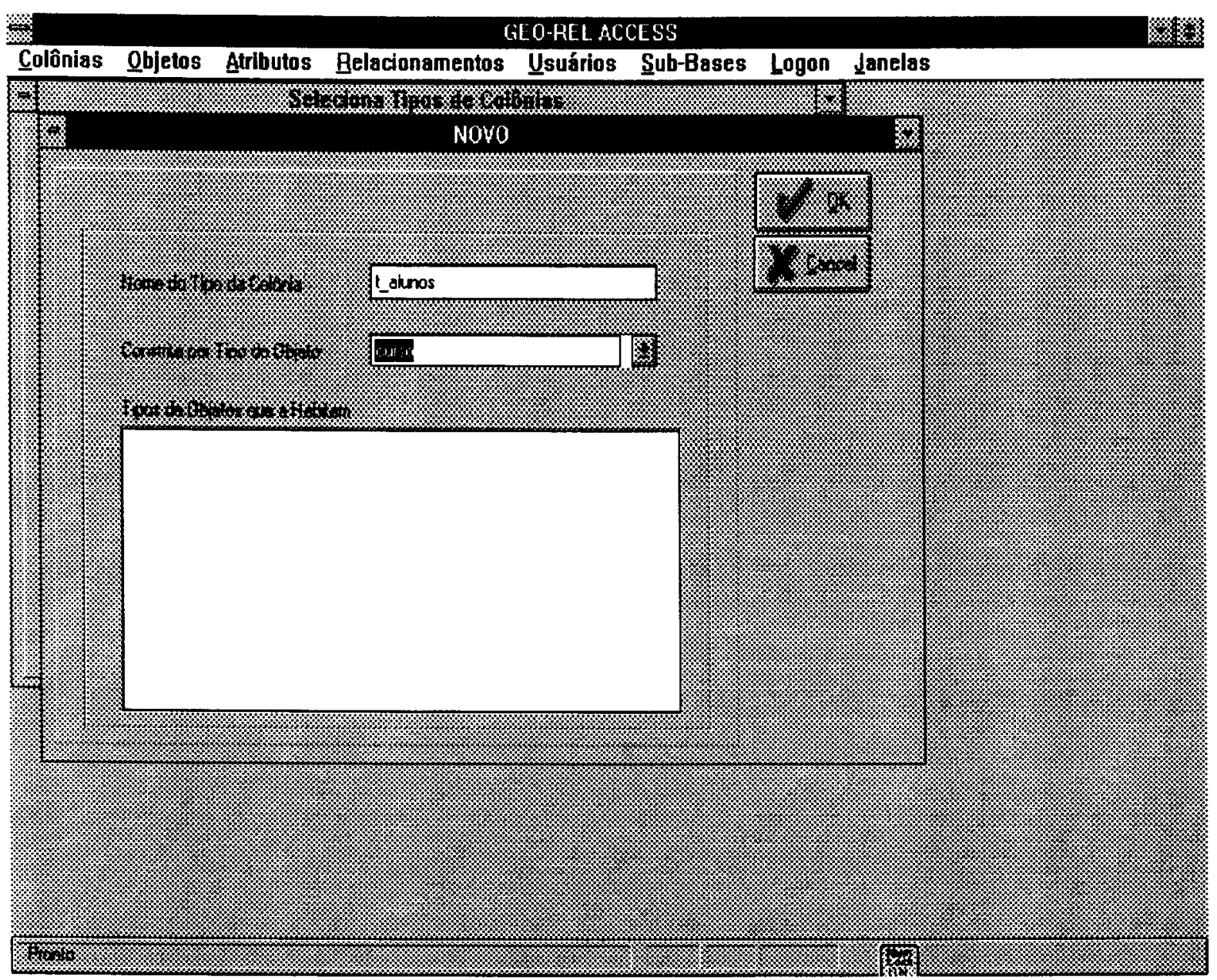


11. Criaremos a colônia alunos.

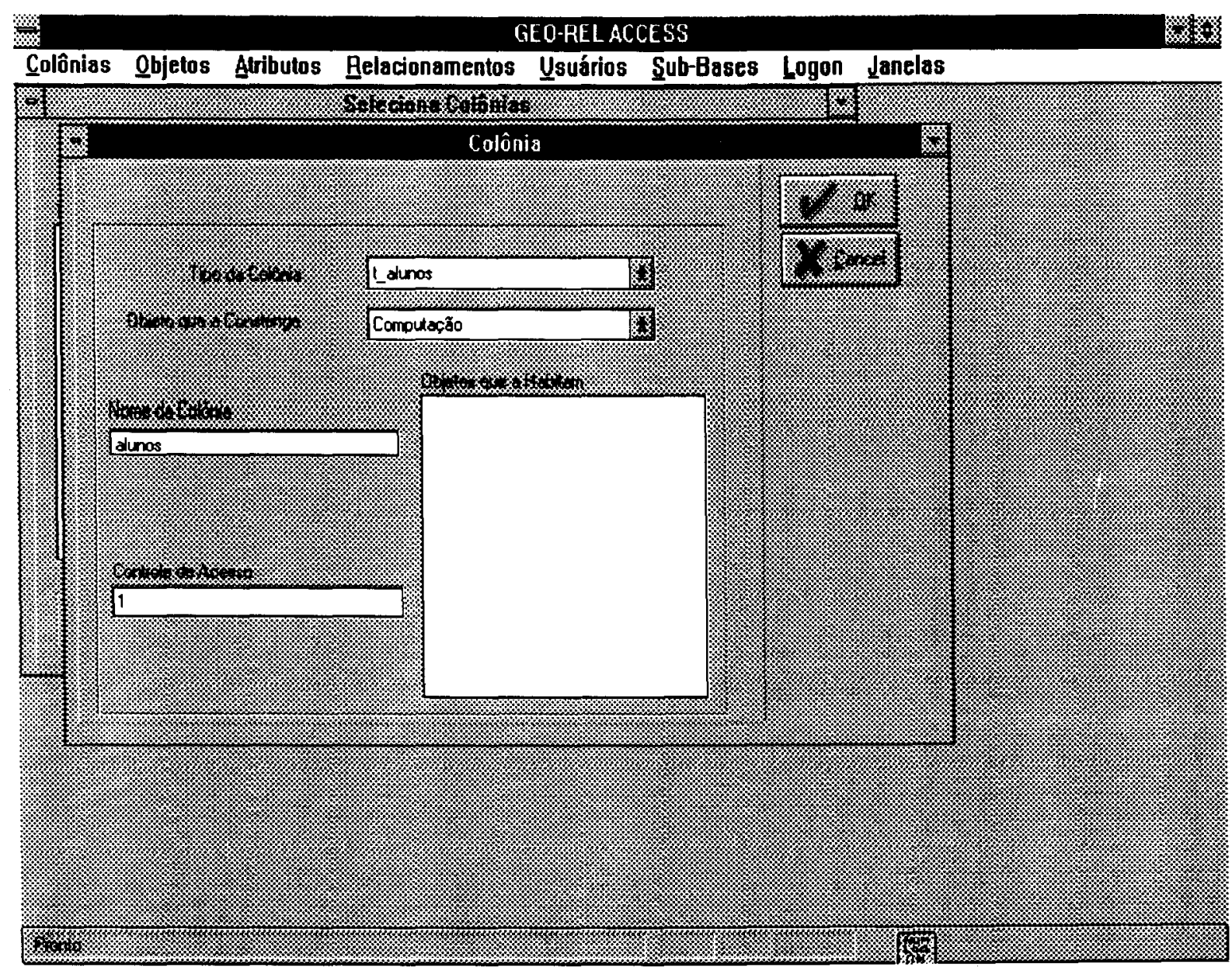


12. Criaremos tipo de objeto $t$ aluno.

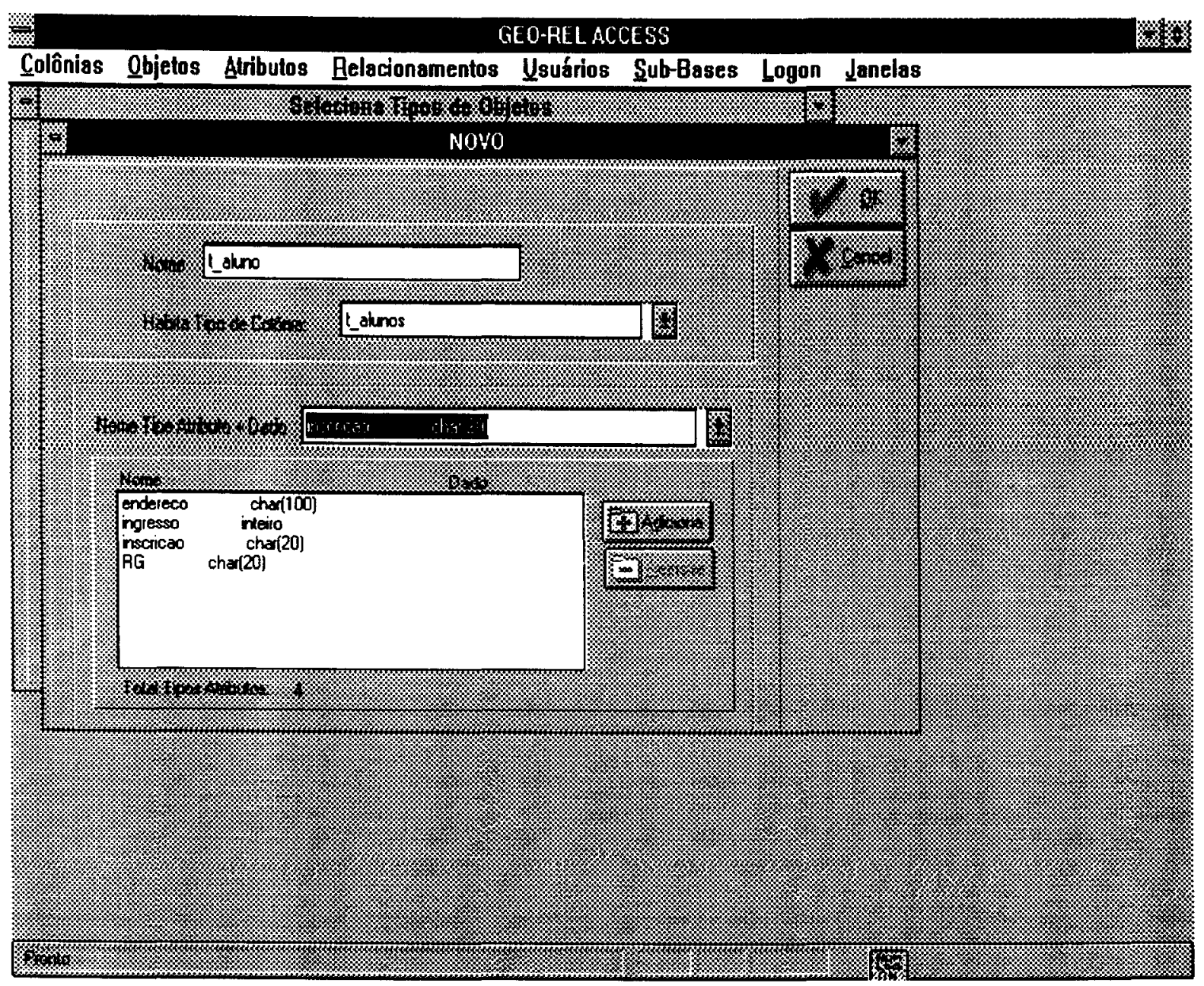


13. Criaremos objetos José, André, Leonardo, todos alunos da Computação da UNESP.

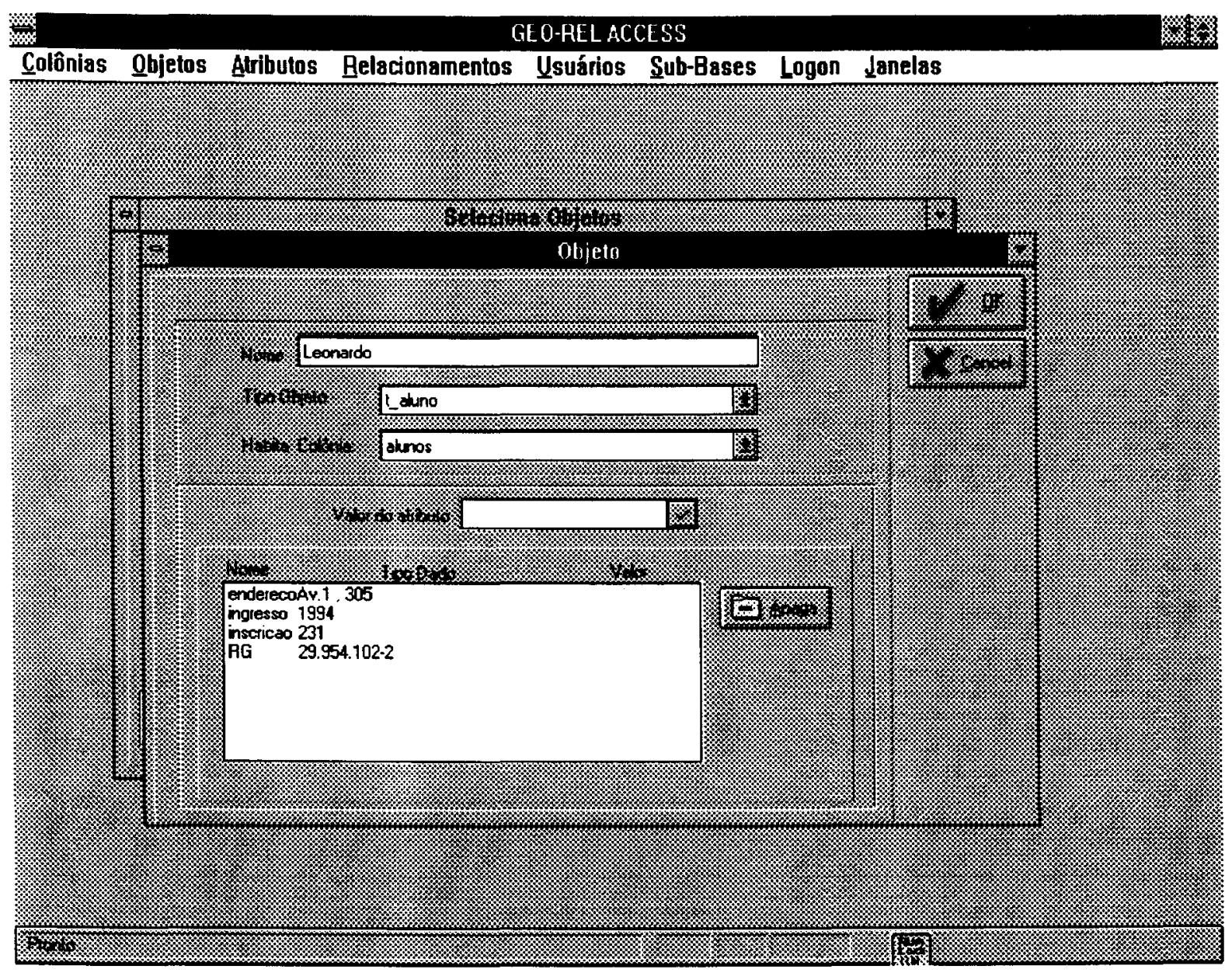


Ao final da inserção de dados teremos as seguintes telas:

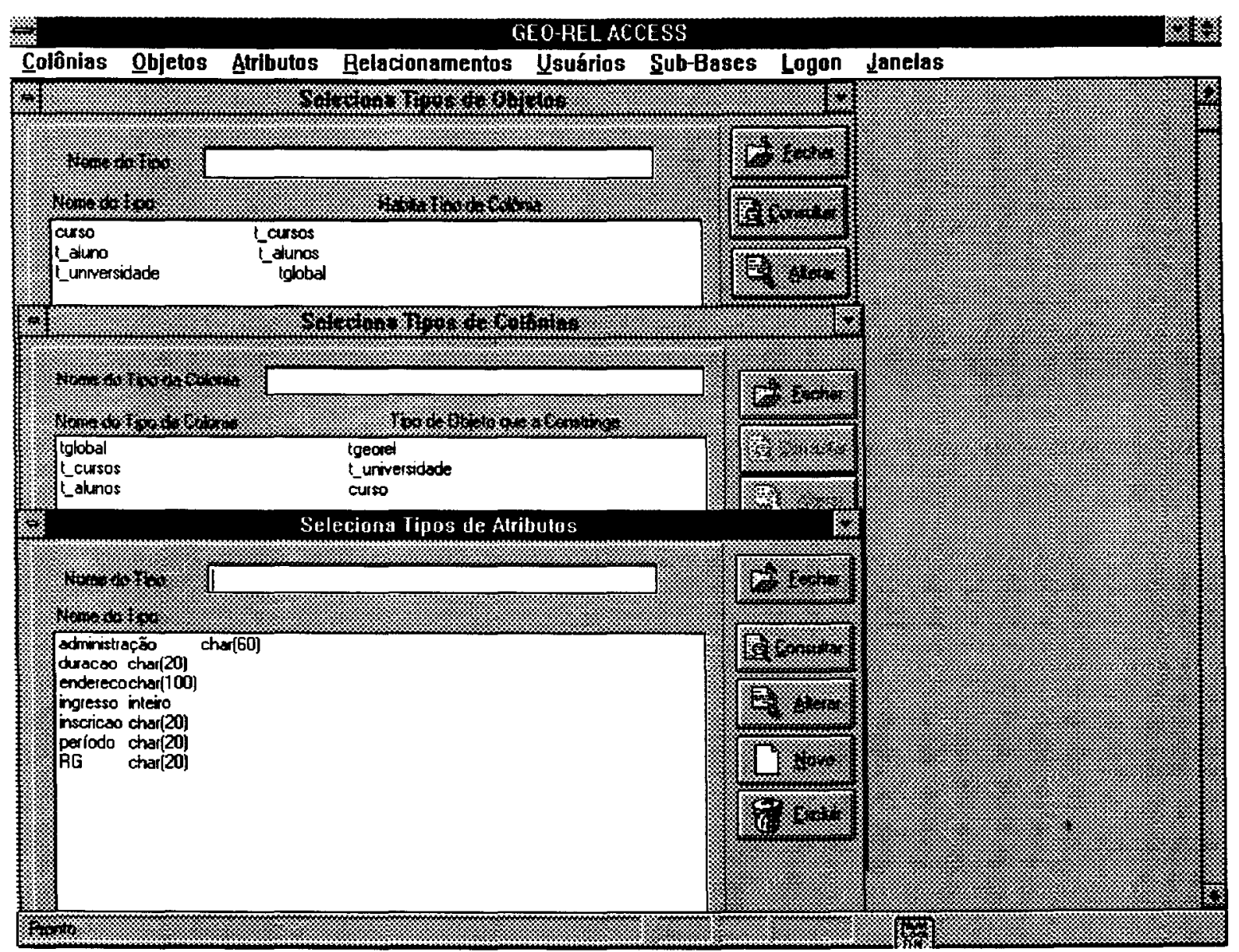



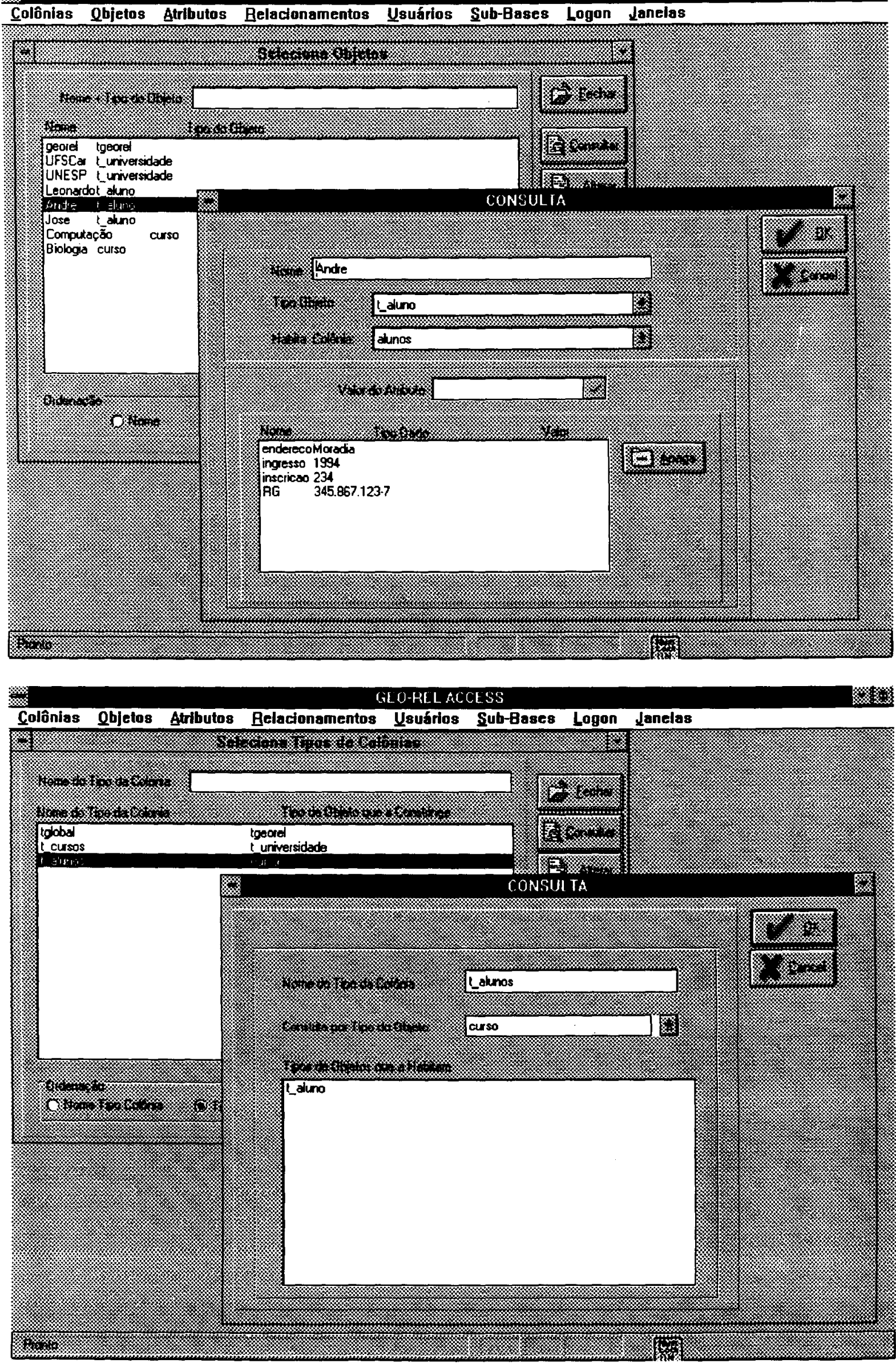